\title{
Wnt signaling and cardiac hypertrophy
}

Citation for published version (APA):

van de Schans, V. A. M. (2009). Wnt signaling and cardiac hypertrophy. [Doctoral Thesis, Maastricht University]. Maastricht University. https://doi.org/10.26481/dis.20090122vs

Document status and date:

Published: 01/01/2009

DOI:

10.26481/dis.20090122vs

Document Version:

Publisher's PDF, also known as Version of record

\section{Please check the document version of this publication:}

- A submitted manuscript is the version of the article upon submission and before peer-review. There can be important differences between the submitted version and the official published version of record.

People interested in the research are advised to contact the author for the final version of the publication, or visit the DOI to the publisher's website.

- The final author version and the galley proof are versions of the publication after peer review.

- The final published version features the final layout of the paper including the volume, issue and page numbers.

Link to publication

\footnotetext{
General rights rights.

- You may freely distribute the URL identifying the publication in the public portal. please follow below link for the End User Agreement:

www.umlib.nl/taverne-license

Take down policy

If you believe that this document breaches copyright please contact us at:

repository@maastrichtuniversity.nl

providing details and we will investigate your claim.
}

Copyright and moral rights for the publications made accessible in the public portal are retained by the authors and/or other copyright owners and it is a condition of accessing publications that users recognise and abide by the legal requirements associated with these

- Users may download and print one copy of any publication from the public portal for the purpose of private study or research.

- You may not further distribute the material or use it for any profit-making activity or commercial gain

If the publication is distributed under the terms of Article $25 \mathrm{fa}$ of the Dutch Copyright Act, indicated by the "Taverne" license above, 
Wnt signaling

and

cardiac hypertrophy 
Wnt Signaling and Cardiac Hypertrophy

Thesis, Universiteit Maastricht, Maastricht, The Netherlands ISBN 9789081370707

(C) copyright, V.A.M. van de Schans, Maastricht 2008

Lay-out: Veerle van de Schans

Cover design: Veerle van de Schans

Printing: Drukkerij Martens 


\title{
Wnt Signaling And Cardiac Hypertrophy
}

\author{
PROEFSCHRIFT \\ Ter verkrijging van de graad van doctor \\ aan de Universiteit van Maastricht \\ op gezag van de Rector Magnificus, \\ Prof. G.P.M.F. Mols \\ volgens besluit van het College van Decanen \\ in het openbaar te verdedigen \\ op donderdag 22 januari 2009 om 16.00 uur \\ door \\ Veerle Anna Maria van de Schans \\ Geboren op 26 mei 1976 te Neerpelt
}




\section{Promotor}

Prof. J.F.M. Smits

\section{Co-Promotor}

Dr. W.M. Blankesteijn

\section{Beoordelingscommissie:}

Prof. Dr. Ir. A.M.W.J. Schols (voorzitter)

Prof. Dr. M.J.A.P. Daemen

Prof. Dr. S. Dimmeler (University of Frankfurt, Germany)

Dr. S. Heymans

Prof. Dr. F.C.S. Ramaekers

Financial support by the Netherlands Heart Fundation for the publication of this thesis is gratefully acknowledged.

Additional support was granted by Merck Sharp \& Dohme B.V., AstraZeneca B.V. and Bristol-Myers Squibb N.V..

Also Lloydspharma is gratefully acknowlegded for the financial support. 
Werk-vecht-huil-zing-lach en BEWONDER 


\section{List of abbreviations}

\begin{tabular}{|c|c|}
\hline $\mathrm{ACE}$ & angiotensin converting enzym \\
\hline ANF & atrial natriuretic factor \\
\hline Ang II & angiotensin II \\
\hline APC & adenomatous polyposis coli \\
\hline $\mathrm{ARB}$ & AT1 receptor blocker \\
\hline ARVC & arrhythmogenic right ventricular cardiomyopathy \\
\hline ASA & acetyl salicylacid \\
\hline BNP & brain natriuretic peptide \\
\hline CaMK & Ca-Calmodulin kinase \\
\hline $\mathrm{Cx} 43$ & connexin 43 \\
\hline DKK & kickkopf \\
\hline Dvl & dishevelled \\
\hline Et-1 & endothelin-1 \\
\hline FAK & focal adhesion kinase \\
\hline FRP & frizzled related protein \\
\hline $\mathrm{Fz}$ & frizzled \\
\hline GPCR & G-protein coupled receptors \\
\hline GSK-3 $\beta$ & glycogen synthase kinase $-3 \beta$ \\
\hline $\mathrm{HF}$ & heart failure \\
\hline HMG & high mobility group \\
\hline JNK & Jun N-terminal Kinase \\
\hline Lef & lymphoid enhancing factor \\
\hline LRP & lipoprotein related-receptor protein \\
\hline MCS & mesenchymal stem cell \\
\hline MI & myocardial infarction \\
\hline MMP & matrix metalloproteinase \\
\hline $\mathrm{NaCl}$ & sodium chloride \\
\hline NFAT & nuclear factor of activated T-cells \\
\hline NSAID & non-steroidal anti-inflammatory drug \\
\hline PKA & protein kinase A \\
\hline PKC & protein kinase $\mathrm{C}$ \\
\hline RAS & renin-angiotensin system \\
\hline ROK & Rho Kinase \\
\hline RT-PCR & real-time Poly Chain Reaction \\
\hline sFRP & soluble Frizzled related protein \\
\hline SHHF & spontaneously hypertensive rats prone to heart failure \\
\hline TAC & thoraric aortic contriction \\
\hline Tcf & T-cell factor \\
\hline TGF & transforming growth factor \\
\hline TNF & tumor necrosis factor \\
\hline TSP & thrombospondin \\
\hline $\mathrm{WiF}$ & wistar Furth \\
\hline WIF & Wnt-inhibitory Factor \\
\hline$\alpha-\mathrm{MHC}$ & $\alpha$-myosin heavy chain \\
\hline$\beta-\mathrm{MHC}$ & $\beta$-myosin heavy chain \\
\hline
\end{tabular}




\section{Contents}

$\begin{array}{llr}\text { Chapter } 1 \text { Introduction } & 9\end{array}$

Chapter 2 Regulation of Wnt signaling in time after 35 aortic banding in rats.

Chapter 3 Interruption of Wnt signaling attenuates the onset of pressure overload-induced cardiac hypertrophy

Chapter 4 Lithium treatment does not augment the hypertrophic response but induces heart failure after aortic banding in rats

Chapter 5 Effect of AT-1 antagonist treatment on Wnt signaling in spontaneously hypertensive heart failure-prone rats

Chapter 6 Anti-Hypertrophic Remodeling of the Heart in Cyp1A1-mRen2 transgenic rats.

Chapter 7 Summary and Conclusions:

Wnt signaling and cardiac hypertrophy

Samenvatting en Conclusies

Dankwoord

List of publications

Curriculum Vitae

Full Colour Images 



\section{Chapter 1}

\section{Introduction}

Adapted from:

- V.A.M. van de Schans; J.F.M. Smits, W.M. Blankesteijn. The Wnt/Frizzled pathway in cardiovascular development and disease: Friend or Foe.

Eur J Pharmacol. 2008 May 13;585(2-3):338-45.

- W.M. Blankesteijn; V.A.M. van de Schans; P. ter Horst; J.F.M Smits. The Wnt/Frizzled/GSK-3 $\beta$ pathway, a novel therapeutic target for cardiac hypertrophy.

Trends Pharmacol Sci. 2008 Apr;29(4):175-80 


\subsection{General Introduction}

\section{Causes of cardiac hypertrophy}

The left ventricle is the main pumping chamber of the heart. Chronic increases in hemodynamic load result in an enlargement of the muscle, the so called "left ventricular hypertrophy". Initially, the hypertrophic response is beneficial by diminishing wall stress and potential hemodynamic compromise but in the long run, left ventricular hypertrophy can be harmful and lead to left ventricular dysfunction, dilated cardiomyopathy, ischemic heart disease, heart failure and sudden death ${ }^{1-3}$.

The etiology of cardiac hypertrophy is multifactorial and can involve mechanical stresses $^{4,5}$ such as volume ${ }^{6}$ or pressure overload ${ }^{7,8}$. It can also involve local factors, such as neurotransmitters ${ }^{9}$ and hormones ${ }^{10}$ directly acting on the cardiomyocytes. This leads to the activation of numerous signaling pathways ${ }^{11-14}$, alterations in calcium homeostasis and an increase in the expression of the embryonic genes and genes encoding extracellular matrix proteins ${ }^{15}$. Moreover, genetic factors also appear to play a role, as some patients are more likely to develop cardiac hypertrophy than others ${ }^{16,17}$.

\section{Hypertrophic remodeling of the heart: physiological and pathological adaptations}

Hypertrophic growth is believed to diminish wall stress and oxygen consumption of the heart $^{18}$. Hypertrophic remodeling leads to a change in geometry, structure, and composition of the heart. This dynamic remodeling works well for the physiological adaptation. However, when this equilibrium goes out of balance, the result can be pathological growth and abnormal physiology ${ }^{19}$. Two different pathological hypertrophy phenotypes can be distinguished ${ }^{20}$ (see figure 1): the first is concentric hypertrophy due to pressure overload in conditions such as aortic stenosis or hypertension, which is characterized by parallel addition of sarcomeres and lateral growth of individual cardiomyocytes (increase in ratio of wall thickness/chamber dimension). A second form of cardiac hypertrophy is eccentric hypertrophy due to volume overload in conditions such as chronic aortic regurgitation, mitral regurgitation 
or prior infarction, characterized by addition of sarcomeres in series and longitudinal cell growth (cavity dilatation with a decrease in ratio of wall thickness/chamber dimension) $)^{10,21}$.

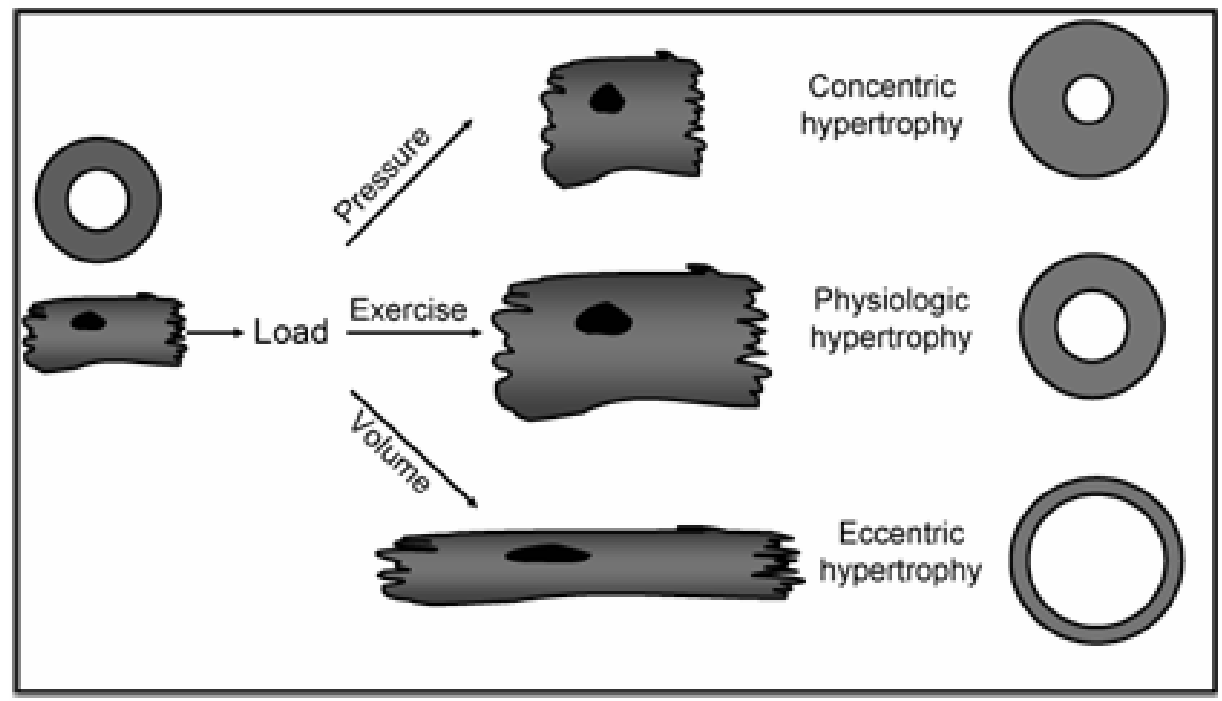

Figure 1: The three major patterns of ventricular remodeling. Increased load leads to phenotypically changes in the morphology of the myocyte. Concentric cardiomyocyte hypertrophy is a result of pressure load and leads to growth in myocyte thickness whereas eccentric cardiomyocyte hypertrophy is the result of volume overload and produces myocyte lengthening. Physiological hypertrophy, induced by exercise or pregnancy, is referred as a combination of concentric and eccentric hypertrophy whereby there is a growth of the myocyte in length and width.

Myocardial hypertrophy is an early milestone in the clinical course of heart failure ${ }^{22}$, a major public health problem which is associated with high morbidity and mortality ${ }^{23}$. Until the early 90s, heart failure was viewed as a hemodynamic disorder in which impaired pump performance increases pulmonary and systemic venous pressures resulting in fluid retention and reduced cardiac output. Nowadays, we know that it is more than a hemodynamic disorder because therapy, initially improving the functional abnormalities such as high venous pressure and low cardiac output, often fail to improve survival ${ }^{24}$. So, the important target of treatment of cardiac hypertrophy is not necessarily the reduction of LV mass itself but more the correction of the molecular 
pathways that account for the cardiac hypertrophy-related complications and/or the enhancement of the activity of cell-mediated cytoprotective mechanisms ${ }^{25}$.

A third form of hypertrophy is the so-called "physiological hypertrophy", caused by chronic exercise training which is not associated with contractile dysfunction and is morphologically and molecularly distinct from overload-induced hypertrophy ${ }^{26-28}$. But also during pregnancy physiological hypertrophy is observed to compensate for the increased cardiac output to match placental blood flow ${ }^{29}$. The physiological hypertrophic growth is characterized by a proportional increase in length and width of cardiac myocytes ${ }^{22}$ (see figure 1). Physiological hypertrophy can simply be considered as cardiac hypertrophy that does not cause or contribute to disease ${ }^{29}$.

\subsection{Signaling pathways in pathological left ventricular hypertrophy}

The identities of signaling pathways that couple the demand for increased contractile force to increased myocyte growth and altered gene expression have been actively investigated for many years ${ }^{11,13,22,30,31}$. None of these signaling pathways operates in isolation, but they participate in a more orchestrated response that generates interdependent and cross-talking networks ${ }^{32}$. Nuclear transcription factors are often the final target of signal transducing cascades, thereby converting membrane and cytoplasmic signaling events into specific changes in gene expression. A cascade of successive transduction steps allows signal enhancement and diversification at branching points and thus permits combinatorial interactions between multiple pathways $^{30,33}$. Pathological hypertrophy is the net result of pro-hypertrophic and antihypertrophic signaling pathways, the latter giving rise to deterioration of cardiac funtion and heart failure.

\section{Pro-hypertrophic signals}

Different forms of pro-hypertrophic stimuli are mediating the response of the cardiomyocytes, such as mechanical stress ${ }^{4}, 34$, neurohumoral activation ${ }^{35,36}$, growth factors and cytokines. Mechanical stress leading to mechano-transduction signaling is 
initiated by integrins and/or associated cytoskeletal/signaling proteins, such as focal adhesion kinase (FAK), melusin, vinculin, zyxin (reviewed by Knöll et al. ${ }^{4}$ and by Brancaccio et al. ${ }^{5}$ ). A second sensor of mechanical stress has been proposed at the level of Z-disc within each sarcomere ${ }^{13}$. These proteins trigger coordinated downstream signaling cascades ${ }^{5}$.

Stimulation of the hypertrophic response activates a number of neurohumoral systems, such as the sympathetic nervous system, the Renin-Angiotension System (RAS) and cytokine release ${ }^{37}$. These systems function to maintain short term haemodynamic stability, but may deteriorate cardiac function in the long term ${ }^{8}$. The majority of these molecules operate through activation of transmembrane G-protein coupled receptors (GPCRs) $)^{37,38}$ whereby the most relevant myocardial GPCRs include adrenergic (comprised of several subtypes of $\alpha^{22,39}$ - and $\beta$-adrenergic receptors ${ }^{40}$ ) and muscarinic receptors ${ }^{11}$, which are coupled to heterotrimeric G-proteins of the $G_{\alpha q / \alpha 11}$ subclass $^{13}$. The best known factors which mediate cardiac hypertrophy are Angiotensin II $(\text { AngII })^{36}$, Endothelin-1 (ET-1) ${ }^{36}$, Norepinephrine ${ }^{40}$, Tumor necrosis factor $(\mathrm{TNF})^{41}$ and Transforming growth factor $\beta$ (TGF- $\beta)^{14}$.

\section{Anti-hypertrophic signals}

A number of endogenous molecules can regulate the hypertrophic response negatively. One such group of molecules counteracting the prohypertrophic response are the natriuretic peptides. Atrial natriuretic peptide (ANP) and brain natriuretic peptide (BNP) negatively regulate cardiac hypertrophy by inhibiting a variety of hypertrophic cellular signals ${ }^{42}$.

Another extensively studied molecule, known to negatively regulate the hypertrophic response, is Glycogen Synthase Kinase- $3 \beta(\mathrm{GSK}-3 \beta)^{43}$. Research over the past years has identified GSK-3 $\beta$ as a "nodal point" in many cellular and physiological functions and deregulation of GSK-3 $\beta$ activity has been implicated in the development of human 
diseases such as Alzheimer's disease ${ }^{44}$, bipolar disorder ${ }^{45}$, many forms of cancer ${ }^{46}$, diabetes mellitus type II ${ }^{47,48}$ and cardiac diseases ${ }^{49-53}$. The interest of our research group in the mode of action of GSK-3 $\beta$ is based on its participation in canonical Wnt signaling. GSK-3 $\beta$ is active in quiescent cells whereas cell stimulation leads to inhibition of GSK-3 $\beta$. Two distinct mechanisms regulate this inhibition ${ }^{53,54}$ : the primary mechanism of regulation involves a variety of stimuli that inhibit GSK-3 $\beta$ by triggering its phosphorylation at an N-terminal $\operatorname{serine}^{9}\left(\operatorname{Ser}^{9}\right) \operatorname{residu}^{55,56}$ by many different kinases, including insulin/insulin-like growth factor signaling, neurotrophic factor signaling ${ }^{57}$, p70 S6 kinase, p90 ${ }^{\text {Rsk }}$ (also called MAPKAP kinase-1), Protein Kinase A (PKA), Akt (Protein Kinase B) ${ }^{51}$ and certain isoforms of Protein Kinase C (reviewed by Doble et al. and by Grimes et al.) ${ }^{49,54}$ (Figure 2).
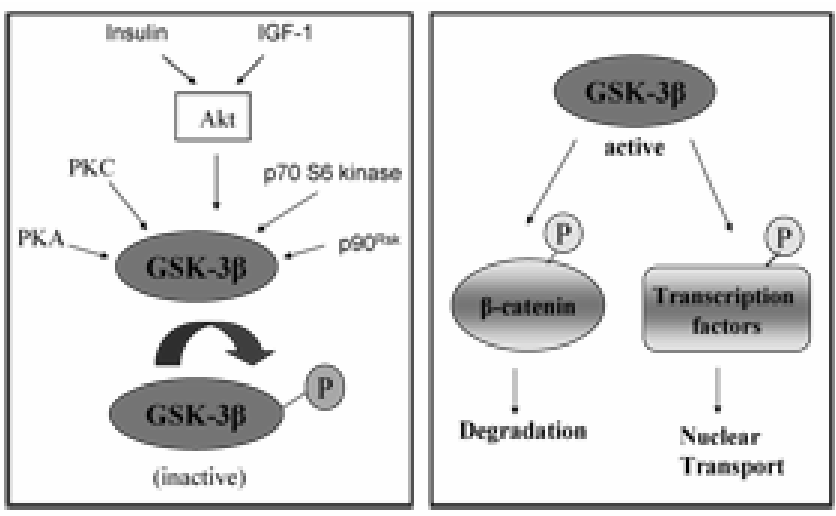

Figure 2. Mechanism of action of GSK-3 $\beta$. The left panel shows the phosphorylation on the Ser9 residu leads to inhibition of GSK-3 $\beta$ activity. Some of protein kinase proposed to phosphorylate this site, are depicted. IGF-1, Insulin-like growth factor-1; PKA, protein kinase A; PKC, protein kinase C. The right panel shows the effects of GSK-3 $\beta$ on its substrates. Phosphorylation of the substrates of GSK- $3 \beta$ leads to enhanced degradation or to nuclear transport of transcription factors.

Another regulatory mechanism of inhibition of GKS-3 $\beta$ is used by the canonical Wnt pathway whereby Wnt activation is thought to involve disruption of a complex containing GKS-3 $\beta$, Axin, adenomatous polypolis coli (APC) and also $\beta$-catenin ${ }^{47,58,59}$.

In opposition to the inhibitory modulation of GSK-3 $\beta$, tyrosine ${ }^{216}\left(\mathrm{Tyr}^{216}\right)$ phosphorylation of GSK-3 $\beta$ increases the enzyme's activity ${ }^{54,60,61}$. It has been reported that there is a role of Dishevelled-1 (Dvl-1), a component of canonical Wnt signaling 
that will be discussed in more detail below, in the dephosphorylation at $\mathrm{Tyr}^{216}$ of GSK$3 \beta^{62}$.

\section{GSK-3 $\beta$ and cardiac hypertrophy}

The role of GSK-3 $\beta$ in cardiac hypertrophy has been extensively investigated and is described in several excellent reviews (Hardt and Sadoshima ${ }^{63}$, Kerkela et al. ${ }^{53}$, Sugden et al. $\left.{ }^{64}\right)$. Pro-hypertrophic stimuli consistently lead to phosphorylation and inhibition of GSK-3 $\beta$. Haq et al. showed that the kinase activity of GSK-3 $\beta$ was inhibited by hypertrophic stimuli both in vitro and in vivo ${ }^{65}$. Cardiac-specific expression of a signalresistant form of GSK-3 $\beta$, containing a Ser9 to Ala mutation, diminishes the hypertrophic growth response to calcineurin activation, adrenergic stimulation, and pressure overload $^{66}$. In transgenic mice, specific overexpression of GSK-3 $\beta$ in the heart resulted in a physiologic concentric hypertrophy (normal growth) of ventricular cardiomyocytes, leading to a smaller heart with depressed contractility ${ }^{67}$.

Phosphorylation of substrates by GSK-3 $\beta$ leads to their enhanced degradation by the ubiquitin-proteasome system. This applies to three central regulators of cell cycle progression and proliferative growth: cyclin D1, c-myc and $\beta$-catenin. On the other hand, inactivation of GSK-3 $\beta$ leads to the release of growth-promoting substances, such as c-myc and $\beta$-catenin, which are not degraded and stimulate hypertrophic growth $^{53}$. The group of Force found that hypertrophic stress disrupted the GSK$3 \beta /$ Frat1 complex, releasing GSK-3 $\beta$ from this inhibitor. The subsequent stabilization of $\beta$-catenin is achieved via $\operatorname{Ser}^{9}$ phosphorylation of GSK-3 $\beta$ via the recruitment of Akt to the Axin complex ${ }^{68}$.

\subsection{Wnt signaling}

Intensive investigation of signal transduction by secreted Wnt proteins over the past two decades has revealed a huge, yet still incomplete, cast of gene and protein characters. The majority of this research concerns the canonical Wnt pathway, which 
signals through the stabilization of $\beta$-catenin ${ }^{69,70}$. An increasing body of research, however, focuses on non-canonical, $\beta$-catenin-independent Wnt pathways ${ }^{71}{ }^{72}$. Wnt signaling controls various cellular and biological processes, ranging from cell adhesion $^{73,74}$, stem cell self renewal ${ }^{75}$, and cancer development ${ }^{76-78}$, to differentiation of multiple cell lineages ${ }^{79}$, cell polarity, cell migration, cell proliferation and development of various tissues ${ }^{80,81}$.

The Wnts comprise a large class of secreted proteins and as many as 19 mammalian Wnt family members are known. Expression of different Wnt proteins can lead to vastly different outcomes of signaling ${ }^{82}$. A more detailed description of the complexities of Wnt regulatory activity can be obtained from excellent reviews and essays (Cadigan and $\mathrm{Liu}^{83}$, Nelson and Nusse ${ }^{84}$ ). Another useful resource is 'The Wnt Homepage' (http://www.stanford.edu/ rnusse/wntwindow.html).

\section{Canonical Wnt signaling: a brief overview}

The canonical Wnt (also referred as Wnt/ $\beta$-catenin) pathway is the best understood and has been characterized by a combination of genetics and biochemistry. A core set of proteins and an ever-growing list of proteins that modify their function have been identified in this way, as extensively reviewed elsewere ${ }^{84-86}$.

When Wnt receptors are not engaged, two scaffolding proteins in the destruction complex, the tumor suppressors $\mathrm{APC}^{87}$ and $\operatorname{axin}^{88}$, bind newly synthesized $\beta$-catenin ${ }^{89}$. GSK-3 $\beta$ phosphorylates serine/threonine residues 41,37 and 33 at the amino terminus of $\beta$-catenin ${ }^{90}$ and the resulting phosphorylated footprints recruit a $\beta$-TrCP-containing E3 ubiquitin ligase, which targets $\beta$-catenin for proteasomal degradation ${ }^{80,91}$. As a result, the levels of free $\beta$-catenin in the cells remain low and nuclear TCF/ $\beta$-catenin complex formation is prevented ${ }^{92,93}$ (Figure 3). So, in the 'off state', GSK-3 $\beta$ is constitutively active and cells maintain low cytoplasmic and nuclear levels of $\beta$ - 
catenin. A detailed description of the $\beta$-catenin destruction complex is provided by Kimelman and $\mathrm{Xu}^{91}$.

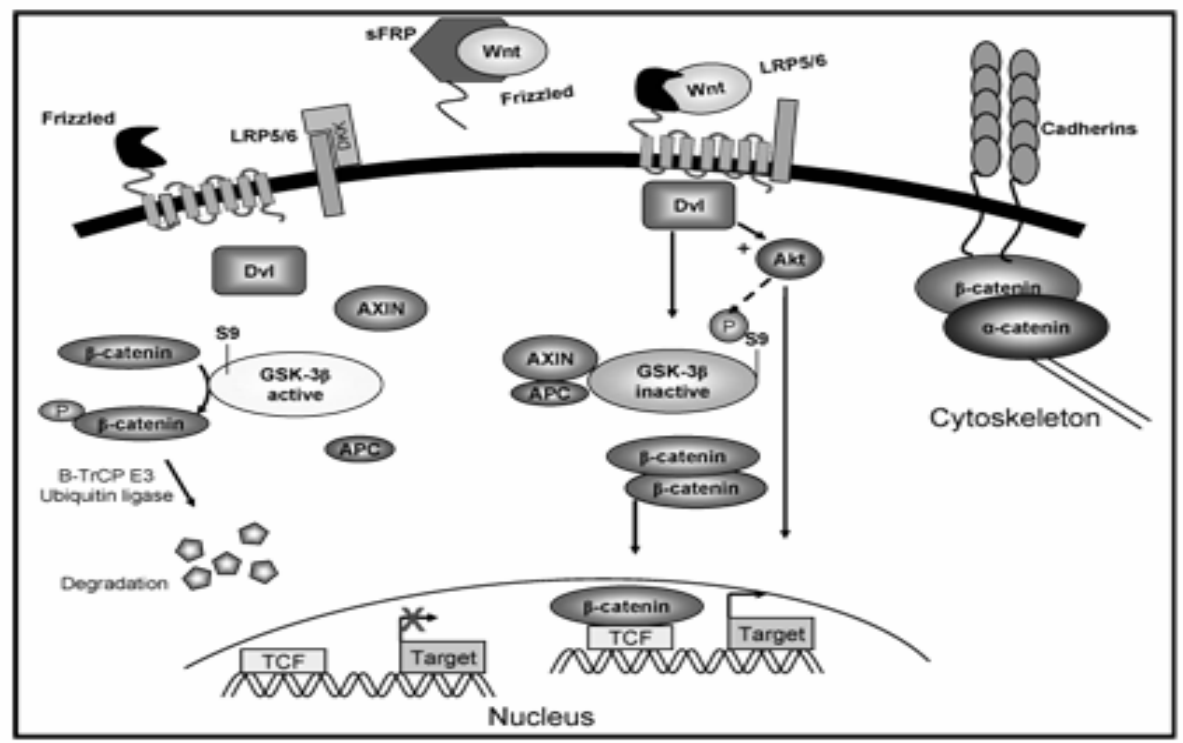

Figure 3: The canonical Wnt signalling pathway. The effects of inactive (left part) and activated (middle part) Wnt signaling are depicted. In the absence of Wnt stimulation, the level of free cytosolic $\beta$-catenin is kept low by GSK-3 $\beta$ phosphorylating $\beta$-catenin on serine and threonine residues at the amino-terminal region, thereby targeting it for ubiquitination and degradation in proteasomes. The phosphorylation of $\beta$-catenin by GSK-3 $\beta$ occurs in a complex with Axin and adenomatous polyposis coli (APC) protein as well as many other components (not shown for clarity). In the middle of the cartoon, the effect of activation of a Frizzled (Fz) 7 transmembrane receptor by a Wnt ligand is shown. In a complex with Lipoprotein related-receptor protein (LRP)-5 or -6 , this leads to the activation of Dishevelled (Dvl). The activated Dvl protein inhibits the GSK-3 $\beta$ activity by two distinct mechanisms: first it

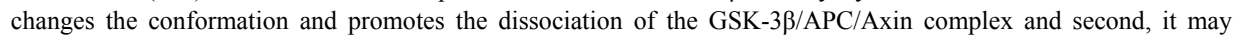
increase Akt activity, resulting in phosphorylation of the Ser9 residue of GSK-3 $\beta$. The inhibition of GSK-3 $\beta$ leads to stabilization and accumulation of $\beta$-catenin in the cytoplasm. $\beta$-Catenin can shuttle to the nucleus were it interacts with a transcription factor complex of the $\mathrm{T}$ cell factor (TCF) family. This can induce the transcription of genes involved in the hypertrophic response. Moreover, activated Akt by itself can also induce hypertrophic gene transcription. The right part of the scheme shows that $\beta$-catenin also regulates cell adhesion in a complex with $\alpha$ catenin and cadherins.

Wnt signaling is initiated when Wnt ligands engage their cognate receptor complex, consisting of a serpentine receptor of the Frizzled (Fz) family (10 family members in the human genome $)^{94,95}$ together with LRP-5 and LRP-6 coreceptors, members of the low density lipoprotein related-receptor protein family ${ }^{96-98}$. Receptor occupancy inhibits the kinase activity of the destruction complex by an incompletely understood 
mechanism involving the direct interaction of $\operatorname{axin}^{85}$ and the actions of an axin-binding molecule, $\mathrm{Dvl}^{99,100}$.

Three homologs of Dvl have been described which exhibit overlapping patterns of expression and highly conserved domain structure ${ }^{101,102}$. Hyperphosphorylation of Dvl results in a relocalization to the plasma membrane ${ }^{103,104}$ and activated Dvl leads to inactivation of GSK-3 $\beta$ resulting in a slower cytoplasmatic turnover of $\beta$-catenin ${ }^{105}$. As a consequence, $\beta$-catenin accumulates in the cytoplasm and travels into the nucleus where it engages the N-terminus of DNA-binding proteins of the Tcf/Lef family of high mobility group (HMG)-box proteins ${ }^{75,106,107}$. These proteins bind DNA and require $\beta$-catenin to activate transcription of target genes including cyclin $\mathrm{D} 1^{108}$, cmyc $^{109,110}$, E-cadherin ${ }^{111}, \mathrm{uPA}^{110}$ and matrix metalloproteinases MMPs, like MMP7 $7^{112}$ and MMP26 ${ }^{113}$ (Figure 3).

\section{The non-canonical Wnt pathways}

Wnt signaling pathways that do not make use of $\beta$-catenin are referred to as noncanonical Wnt signaling pathways. Several signaling branches were described so far (Figure 4). The vertebrate Wnt/JNK pathway involves activation of small GTPases like rac, rho and cdc42 and more downstream Rho-kinase (ROK) or Jun-N-terminal kinase $(\mathrm{JNK})$ and affects planar polarity ${ }^{114}$.

Another Wnt-mediated signaling pathway stimulates the intracellular increase in $\mathrm{Ca}^{2+}$, possibly mediated by G-proteins ${ }^{115}$. This pathway activates several downstream targets including protein kinase $\mathrm{C}$ (PKC), Ca-calmodulin kinase II (CaMKII $)^{116}$. The elevated levels of $\mathrm{Ca}^{2+}$ can activate the phosphatase Calcineurin, which leads to dephosphorylation of the transcription factor: nuclear factor of activated T-cells (NFAT) resulting in an accumulation of NF-AT in the nucleus and an activation of target genes $^{92}$. 
Which pathway is activated is dictated by the particular Wnt/Fz combination (with or without certain coreceptors), and is subsequently controlled by cytoplasmic diversification via protein-protein interactions ${ }^{92}$.

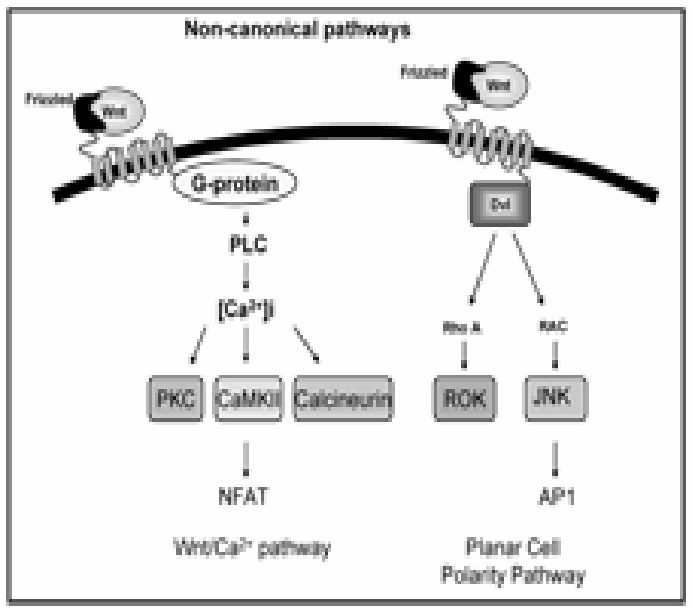

Figure 4. The non-canonical Wnt pathways. In the left part of the scheme, the $\mathrm{Wnt} / \mathrm{Ca} 2+$ pathway is shown, and in the right part the Planar Cell Polarity pathway (PCP) is depicted. The $\mathrm{Wnt} / \mathrm{Ca} 2+$ signalling pathway involves G-proteins, phospholipas C (PLC), protein kinase C (PKC) and $\mathrm{Ca} 2+/$ calmodulin - dependent protein kinase II (CaMKII) and Calcium senstive phosphatase, Calcineurin. This leads to activation of NFAT, a family of transcription factors. The PCP pathway acts via dishevelled (Dvl) and involves Rac, RhoA, wich stimulates c-jun kinase (JNK) and Rho kinase (ROK). JNK activates AP1, a complex of smaller proteins, which can form homo- or heterodimers whereby the composition of the AP1 complex is a decisive factor for target gene activation.

\section{Antagonists of Wnt signaling}

Wnt-mediated signals can be modulated extracellulary by secreted proteins. There are two major classes of Wnt antagonists that function in quite different ways. The two classes are the Frizzled Related Protein (FRP) class and the Dickkopf (DKK) class ${ }^{117}$. The interaction between Wnt and Fz receptors is inhibited by members of the FRP class, which includes the FRPs, the WIF (Wnt-inhibitory factor)-1 and Cerberus ${ }^{118}$. The DKK class inhibits the LRP5/6 coreceptor activity. The subsequent interaction of DKK/LRP complex with Kremen internalizes the complex followed by its degradation, thus diminishing the number of Wnt coreceptors available for signaling ${ }^{118}$.

\section{A closer view on $\beta$-catenin, a downstream protein of the canonical Wnt pathway}

$\beta$-Catenin has historically been recognized as both a second messenger molecule in the canconical Wnt signaling pathway and as a component of adherens junctions ${ }^{119,}{ }^{120}$. The adherens junctions can be found in the intercalated disks, specialized structures that functionally and structurally connect adjacent cardiomyocytes ${ }^{73,}$ 121, 122 . It remains 
unclear how such an odd dual function evolved in one protein ${ }^{87}$. The interactions of $\beta$ catenin with adhesion, transcription and destruction complexes raise many questions. How does $\beta$-catenin choose among its possible partners? Do different complexes compete for a limiting pool of $\beta$-catenin? And can it move from one complex to another ${ }^{78,123-125}$ ?

Structurally, $\beta$-catenin has a large central region composed of 12 repeats of three helices each, a rigid scaffold for the binding of many factors. The N- and C-terminal regions are much smaller, and appear to form mostly flexible regions that primarily interact with transcriptional activating factors ${ }^{91}$. Selective targeting of distinct molecular forms of $\beta$-catenin provides a mechanism by which cells could potentially separate the adhesion and signaling functions of $\beta$-catenin ${ }^{126}$. Through its central armadillo repeat region, $\beta$-catenin forms mutually exclusive complexes with cadherin adhesion molecules ${ }^{127}$, TCF/Lef family of transcription factors and $\mathrm{APC}^{128}$, whereas $\alpha-$ catenin binds to the $\mathrm{N}$-terminal $\alpha$-helix ${ }^{123}$. Wnt signaling generates a closed $\beta$-catenin conformation that selectively binds TCF. In contrast, the cadherin preferentially binds a $\beta$-catenin- $\alpha$-catenin dimer ${ }^{123}$. The N-terminal cluster of serine and threonine residues of $\beta$-catenin are putative GSK-3 $\beta$ sites of phosphorylation, which target $\beta$-catenin as signals for ubiquitin-mediated degradation ${ }^{105,129}$.

Gottardi and Gumbiner propose that segregation of these functions of $\beta$-catenin may be necessary for two reasons. First, selective targeting of $\beta$-catenin to transcriptional complexes would prevent the cadherin from competing with Wnt signaling activity, which may be important during low or transient Wnt activation where signaling may need to be especially efficient. Second, such a mechanism would ensure that cell-cell adhesion is maintained during Wnt induction throughout development. Thus, generation and targeting of distinct molecular forms of $\beta$-catenin could ensure that adhesion and signaling are not always coupled, and when necessary, can be regulated independently of one another ${ }^{126}$. 


\subsection{Wnt signaling and the diseased heart}

\section{Wnt signaling and cardiac hypertrophy}

\section{Cardiac hypertrophy: Wnt signaling}

The first indication of the re-expression of Wnt signaling components during the hypertrophic response in the heart came from a subtractive hybridization experiment performed by our group. In this experiment, it was shown that fz-2 expression was upregulated during the hypertrophic development in the rat heart ${ }^{130}$. Recently, these results were confirmed and expanded by Cerutti et al. ${ }^{131}$, showing a positive correlation between left ventricular (LV) mass and fz-2 expression in the rat and a negative correlation between LV mass and expression of DKK-3, an antagonist of Wnt signaling. Downstream of $\mathrm{fz}, \beta$-catenin mRNA was expressed in fetal and adult heart and lower levels were observed in hypertrophic heart compared to adult heart, as shown by Rezvani et al. ${ }^{132}$, whereas higher levels of $\beta$-catenin protein expression was detected in the hypertrophic heart ${ }^{132}$. The findings indicate the involvement of the $\mathrm{Wnt} / \mathrm{Fz}$ signaling pathway in cardiac hypertrophy.

\section{Cardiac hypertrophy: $\beta$-catenin as a transcription factor.}

The role of $\beta$-catenin in cardiac hypertrophy has been addressed in several studies. Stabilization of $\beta$-catenin is sufficient for the hypertrophic response in cardiomyocytes, as shown by Haq et $a l^{68}$. The stabilization of $\beta$-catenin was achieved via $\mathrm{Ser}^{9}$ phosphorylation of GSK-3 $\beta$, through a Wnt-independent mechanism. By using a mouse with cardiac-specific deletion of the $\beta$-catenin gene, Chen et al. ${ }^{133}$ demonstrated that deletion of $\beta$-catenin/TCF/Lef signaling led to a blunted hypertrophic response both in physiologic growth and in pathological growth of the heart. Qu et al. ${ }^{134}$ showed that heterozygous $\beta$-catenin deleted mice had no structural and functional abnormality in normal physiological condition. Importantly, loss of one copy of the $\beta$-catenin gene significantly inhibited cardiac hypertrophy in response to pressure overload. However, Baurand et al. ${ }^{135}$ observed discrepant results concerning the same molecule by showing 
that downregulation of $\beta$-catenin initiates adaptive cardiomyocyte hypertrophy in adult heart whereas expression of a nondegradable mutant results in a phenotype of smaller cardiomyocytes. The hypertrophic response was induced by angiotensin II infusion in this study and this suggests that the effect of $\beta$-catenin on cardiac hypertrophy may be dependent on the hypertrophic stimulus that is used.

Another role of $\beta$-catenin as a transcriptional activator in cardiac remodeling is by the regulation of Connexin 43 (Cx43) expression. Wnt-1 is a specific inducer of $\mathrm{Cx} 43$ expression in the cardiomyocytes. This effect is mediated through Wnt-dependent accumulation of $\beta$-catenin. $\mathrm{Cx} 43$ is by far the most abundant cardiovascular gap junction protein. After stress-induced cardiac hypertrophy, deletion of $\beta$-catenin resulted in a $33 \%$ reduction in expression of $\mathrm{Cx} 43^{136}$, which suggests a role for $\beta$ catenin as a transcription factor in cardiac remodeling.

\section{Cardiac hypertrophy: $\beta$-catenin and the adherens junctions}

Besides being a transcription factor, $\beta$-catenin is also found in adherens junctions. The strength of adherens junctions is enhanced by the binding of a cadherin cytoplasmatic domain to $\beta$-catenin, which in turn links to the actin cytoskeleton via $\alpha$-catenin ${ }^{137}$. The role of $\beta$-catenin signaling in myocyte shape regulation during cardiac hypertrophy and failure is not clearly defined, but some observations suggest a link. In hypertrophic cardiomyopathic cardiomyocytes, increased $\beta$-catenin was detected in the intercalated disks ${ }^{138}$ whereas specific deletion of $\beta$-catenin in cardiomyocytes results in a significant increase in $\gamma$-catenin to compensate for the absence of $\beta$-catenin ${ }^{121}$. Even though the heart endures higher mechanical stress than any other organ, $\gamma$-catenin can compensate for the absence of $\beta$-catenin and maintains the normal structure and function of the intercalated disk in the adult heart. $\beta$-Catenin and $\gamma$-catenin are highly homologous proteins so they may share certain common functions ${ }^{121}$. 


\section{Wnt signaling in Heart Failure}

The transition from compensated cardiac hypertrophy to decompensated heart failure is far from fully understood. Therefore, it is of interest to study the alterations in Wnt signaling in this respect. Schumann et al. ${ }^{139}$ have investigated the expression of sFRPs in the failing human heart. They showed that mRNA levels of pro-apoptotic sFRP 3 and 4 were elevated in the failing ventricles compared to donor hearts, which was not the case for sFRP 1 and 2. Moreover, they observed a reduced canonical Wnt signaling in the failing heart.

\section{Wnt signaling and other heart diseases}

\section{Myocardial infarction}

Myocardial infarction (MI) is one of the leading causes of morbidity and mortality in the world. It is caused by an acute occlusion of a coronary artery, which results in cardiac ischemia which leads to cardiomyocyte death. Infarct healing is a dynamic, well-controlled process, which includes the migration and proliferation of fibroblastlike cells into the infarct area ${ }^{140,141}$.

After experimental MI in rats and mice, Fz-2 mRNA expression was upregulated ${ }^{142,143}$ and was localized at the interface between viable myocardium and infarct area as detected by in situ hybridization ${ }^{142}$. Analysis of the expression of multiple members of the Wnt and frizzled families by real-time Poly Chain Reaction (RT-PCR) showed an upregulation of Wnt-10b and Fz-1,-2,-5 and -10 and a downregulation of Wnt-7b in the infarct area 1 week after infarction in the mouse ${ }^{143}$. Blocking the Wnt pathway by overexpressing FrzA (sFRP1), an antagonist of Wnt signaling, interacted with different phases of infarct healing and reduced infarct size with improved cardiac function due to reduced apoptosis thereby limiting the scar area ${ }^{143}$. Dvl, directly downstream of Fz, showed high levels of expression 4 days after MI and remained upregulated during the first week after MI ${ }^{144}$. Dvl-1 positive stained cells were not confined to the border zone 
but also observed in the centre of the infarcted area, suggesting that this gene is also expressed by myofibroblasts ${ }^{144}$.

Myocardial ischemia plays a critical role in the cardiomyocyte death by mechanism of necrosis and apoptosis ${ }^{145}$ and the damaged heart is limited in its ability to regenerate and replace dead myocardium ${ }^{146}$. Ischemic preconditioning (PC) after MI has been shown to significantly reduce infarct size, arrhythmias, and postischemic contractile dysfunction ${ }^{145,147}$. The group of Duplàa demonstrated that blocking the Wnt pathway by FrzA (sFRP1) reverses the cardioprotection afforded by PC and does this by decreasing the phosphorylation of GSK- $3 \beta^{148}$. This demonstrates an important role of Wnt signaling after MI in the cardioprotection by PC. $\beta$-Catenin has also an important role in the healing process after MI and PC. The group of Kaga et $a l^{155}$ showed that cytosolic and nuclear accumulations of $\beta$-catenin are involved in the angiogenic and anti-apoptotic effects of PC by increased TCF/Lef transcriptional activity ${ }^{145}$. In vivo, $\beta$ catenin overexpression via gene transfer reduced the infarcted area and preserved systolic function in a rat MI model through modulating survival, hypertrophy and angiogenesis $^{149}$.

Another novel therapeutic option to prevent ischemic heart failure as a result of MI, is cell therapy with adult stem cells ${ }^{150}$ to improve the cardiac function. Intracardiac implantation of Akt-overexpressing mesenchymal stem cell (MSC) showed a dramatic diminution of infarct size ${ }^{146}$ and sFRP2 plays a major role in mediating the survival signal of Akt-MSCs on the ischemic myocardium ${ }^{151}$. The study of Mirotsou demonstrated in vitro that SFRP2 increases total as well as nuclear $\beta$-catenin within the hypoxic cardiomyocyte in a dose-dependent manner. The mechanism by which sFRP2 increases $\beta$-catenin within the cardiomyocytes is not entirely clear ${ }^{151}$. In conclusion, $\beta$ catenin can protect against apoptosis, can regulate growth of cardiomyocytes, and therefore canonical Wnt signaling may play an important role in the healing process after MI. 


\section{Arrhythmogenic right ventricular cardiomyopathy (ARVC)}

Another cardiac disease, Arrhythmogenic Right Ventricular Cardiomyopathy (ARVC) is a fibro-adipocytic replacement of cardiac myocytes that typically occurs in conjunction with myocyte apoptosis and cardiac dysfunction ${ }^{152,}{ }^{153}$. Suppression of desmoplakin expression leads to nuclear localization of the desmosomal protein $\gamma$ catenin and a 2 -fold reduction in canonical Wnt signaling. The resulting phenotype is increased expression of adipogenic and fibrogenic genes and accumulation of fat droplets. So canonical Wnt signaling is important to prevent the switch from myogenis to adipogenesis ${ }^{152}$.

In conclusion, activation of Wnt signaling is observed in different adaptations of the cardiovascular system under pathological conditions.

\subsection{Therapeutic interventions in Wnt signaling}

Compounds that can inhibit Wnt signaling are under development or investigation, initially for the treatment of cancer. Candidate approaches include agents that have no obvious link to canonical Wnt signaling such as non-steroidal anti-inflammatory drugs (NSAIDs), tyrosine-kinase inhibitor Imatinib ${ }^{154}$, but also small molecule inhibitors or antibodies against Wnts have been proposed. A brief overview of some agents targeting Wnt signaling is given below (for an excellent review, we refer to Barker and Clevers ${ }^{155}$ ).

The NSAIDs, including selective cyclooxygenase (COX)-2 inhibitors, exert their action through multifaceted effects on Wnt signaling. Indomethacin and suldinac has a dual impact on Wnt signaling: repression of $\beta$-catenin transcription and induction of $\beta$ catenin protein degradation ${ }^{156,157}$. Aspirin (Acetyl salicylacid) does not affect $\beta$-catenin protein level but stabilizes $\beta$-catenin in its inactive phosphorylated form, thereby preventing its function as a co-transcriptional factor ${ }^{157,}{ }^{158}$. Imatinib mesylate (a.k.a. Gleevec or Glivec) is a small molecule antagonist with activity against tyrosine kinases, thereby targeting tyrosine phosphorylation via growth factor receptors in the regulation of $\beta$-catenin ${ }^{157,159-161}$. Tyrosine phosphorylation of $\beta$-catenin decreases its 
binding to E-cadherin and stimulates association of $\beta$-catenin with the basal transcription machinery ${ }^{160}$.

The drugs developed to block aberrant Tcf $/ \beta$-catenin signaling have great potential as effective cancer therapeutics ${ }^{155}$. But in the hypertrophic response, no mutations in APC, Axin or $\beta$-catenin have been described so far. Therefore, intervention at the level of Tcf $/ \beta$-catenin signaling does not seem the method of choice for treatment of cardiac hypertrophy. Furthermore, both canonical and non-canonical Wnt signaling are involved in cardiovascular remodeling, so there is a need for antagonists that intervene more upstream in the Wnt pathway. This presents an opportunity to develop small molecule ligands or antibodies that inhibit more upstream components in the Wnt signaling pathway, such as blocking Fz activation or inhibiting the interaction of Dvl with Fz receptors. Antibody-based therapy using a Wnt1 monoclonal antibody is effective in a head and neck cancer cell line over-expressing Wnt1. This Wnt1 monoclonal antibody suppressed Wnt signaling, blocked proliferation and induced apoptosis ${ }^{155}$. Also an anti-Wnt2 monoclonal antibody induced apoptosis in human cancer cells ${ }^{162}$. These are still in vitro results, but to know the therapeutical potential, in vivo efficacy as antitumour agents will have to be evaluated in rodent cancer models ${ }^{155}$.

\subsection{Aim of the thesis}

Chronic cardiac hypertrophy is clinically associated with increased morbidity and mortality and often a precursor of heart failure. Thus, pathological cardiac hypertrophy appears detrimental for the heart, at least in a chronic state. The molecular signals underlying the genesis of hypertrophy have been studied over the past decades and the hypertrophic response is the net result of activation of pro-hypertrophic and antihypertrophic pathways.

The overall aim of the studies described in this thesis was to obtain more insight in the role of the Wnt signaling pathway in the development of cardiac hypertrophy. Furthermore, we investigated the role of $\beta$-catenin, a pro-hypertrophic protein and 
GSK-3 $\beta$, an anti-hypertrophic protein, and other components of the Wnt signaling pathway in hypertension induced cardiac hypertrophy.

In Chapter 2 of this thesis, Wnt signal transduction during the development of cardiac hypertrophy in rats is described. In Chapter 3, intervention in the canonical Wnt pathway by the deletion of the Dvl-1 gene in mice was studied after induction of pressure overload. The cardiac mass index, mRNA of hypertrophic biomarkers as well as $\beta$-catenin and GSK-3 $\beta$ protein levels were determined. In Chapter 4 , the effects of treatment with Lithium, an inhibitor of GSK-3 $\beta$ activity, and Acetylic Salicyl Acid (ASA), blocking $\beta$-catenin/TCF transcription, were studied in the hypertrophic response in the heart of mice.

The second part of this thesis will focus on the Renin Angiotensin system and Wnt signaling in left ventricular hypertrophy due to hypertension. Given the importance of preventing cardiac remodeling next to blood pressure lowering in antihypertensive therapy, the study described in Chapter 5 was designed to investigate the effects of AT-1 receptor antagonists on early stage cardiac remodeling and we determined the effect of the drugs on blood pressure, markers of hypertrophy and components of Wnt signaling. A transgenic rat [TGR(Cypla1-Ren2)], studied in Chapter 6, allowed the induction of Ang II-dependent malignant hypertension. The hypertension can be toggled off by withdrawal of the special diet, so the onset and the level of hypertension can be controlled and studied as well as the withdrawal of the malignant hypertension. We examined the Wnt downstream components $\beta$-catenin and GSK-3 $\beta$ in the malignant hypertensive state as well as in the state of reversibility of this malignant hypertension.

Finally, Chapter 7 contains the discussion of the findings of the experimental chapters in relation to the current literature to give direction to future research. 


\section{Reference}

1. Gardin JM, Lauer MS. Left ventricular hypertrophy: the next treatable, silent killer? Jama.2004;292(19):2396-2398.

2. Kahan T, Bergfeldt L. Left ventricular hypertrophy in hypertension: its arrhythmogenic potential. Heart.2005;91(2):250-256.

3. Peterson KL. Pressure overload hypertrophy and congestive heart failure. Where is the "Achilles' heel"? $J$ Am Coll Cardiol.2002;39(4):672-675.

4. Knoll R, Hoshijima M, Chien K. Cardiac mechanotransduction and implications for heart disease. J Mol Med.2003;81(12):750-756.

5. Brancaccio M, Hirsch E, Notte A, et al. Integrin signalling: The tug-of-war in heart hypertrophy. Cardiovasc Res.2006;70(3):422-433.

6. Holmes JW. Candidate mechanical stimuli for hypertrophy during volume overload. J Appl Physiol.2004;97(4):1453-1460.

7. Miyamoto T, Takeishi Y, Takahashi H, et al. Activation of distinct signal transduction pathways in hypertrophied hearts by pressure and volume overload. Basic Res Cardiol.2004;99(5):328-337.

8. Liew CC, Dzau VJ. Molecular genetics and genomics of heart failure. Nat Rev Genet.2004;5(11):811825 .

9. Omura T, Yoshiyama M, Yoshida K, et al. Dominant negative mutant of c-Jun inhibits cardiomyocyte hypertrophy induced by endothelin 1 and phenylephrine. Hypertension.2002;39(1):81-86.

10. Lorell BH, Carabello BA. Left ventricular hypertrophy: pathogenesis, detection, and prognosis. Circulation.2000;102(4):470-479.

11. Frey N, Olson EN. Cardiac hypertrophy: the good, the bad, and the ugly. Annu Rev Physiol.2003;65:4579.

12. Haq S, Choukroun G, Lim H, et al. Differential activation of signal transduction pathways in human hearts with hypertrophy versus advanced heart failure. Circulation.2001;103(5):670-677.

13. Heineke J, Molkentin JD. Regulation of cardiac hypertrophy by intracellular signalling pathways. Nat Rev Mol Cell Biol.2006;7(8):589-600.

14. Yamazaki T, Komuro I, Yazaki Y. Signalling pathways for cardiac hypertrophy. Cell Signal.1998;10(10):693-698.

15. Braunwald E, Bristow MR. Congestive heart failure: fifty years of progress. Circulation.2000;102(20 Suppl 4):IV14-23.

16. van den Hoff MJ, Postma AV, Michel MC. Candidate genes for the hereditary component of cardiac hypertrophy. J Hypertens.2006;24(2):273-277.

17. Schunkert H, Hense HW, Holmer SR, et al. Association between a deletion polymorphism of the angiotensin-converting-enzyme gene and left ventricular hypertrophy. $N$ Engl $J$ Med.1994;330(23):1634-1638.

18. Berenji K, Drazner MH, Rothermel BA, et al. Does load-induced ventricular hypertrophy progress to systolic heart failure? Am J Physiol Heart Circ Physiol.2005;289(1):H8-H16.

19. Sussman MA, McCulloch A, Borg TK. Dance band on the Titanic: biomechanical signaling in cardiac hypertrophy. Circ Res.2002;91(10):888-898.

20. Calderone A, Takahashi N, Izzo NJ, Jr., et al. Pressure- and volume-induced left ventricular hypertrophies are associated with distinct myocyte phenotypes and differential induction of peptide growth factor mRNAs. Circulation. 1995;92(9):2385-2390.

21. Frey N, Katus HA, Olson EN, et al. Hypertrophy of the heart: a new therapeutic target? Circulation.2004;109(13):1580-1589.

22. Hunter JJ, Chien KR. Signaling pathways for cardiac hypertrophy and failure. $N$ Engl $J$ Med.1999;341(17):1276-1283.

23. Jortani SA, Prabhu SD, Valdes R, Jr. Strategies for developing biomarkers of heart failure. Clin Chem.2004;50(2):265-278.

24. Katz AM. Proliferative signaling and disease progression in heart failure. Circ J.2002;66(3):225-231. 
25. Morisco C, Sadoshima J, Trimarco B, et al. Is treating cardiac hypertrophy salutary or detrimental: the two faces of Janus. Am J Physiol Heart Circ Physiol.2003;284(4):H1043-1047.

26. Shiojima I, Sato K, Izumiya Y, et al. Disruption of coordinated cardiac hypertrophy and angiogenesis contributes to the transition to heart failure. J Clin Invest.2005;115(8):2108-2118.

27. Iemitsu M, Maeda S, Miyauchi T, et al. Gene expression profiling of exercise-induced cardiac hypertrophy in rats. Acta Physiol Scand.2005;185(4):259-270.

28. Iemitsu M, Miyauchi T, Maeda S, et al. Physiological and pathological cardiac hypertrophy induce different molecular phenotypes in the rat. Am J Physiol Regul Integr Comp Physiol.2001;281(6):R20292036.

29. Dorn GW, 2nd. The fuzzy logic of physiological cardiac hypertrophy. Hypertension.2007;49(5):962970.

30. Schaub MC, Hefti MA, Harder BA, et al. Various hypertrophic stimuli induce distinct phenotypes in cardiomyocytes. J Mol Med.1997;75(11-12):901-920.

31. Molkentin JD, Dorn IG, 2nd. Cytoplasmic signaling pathways that regulate cardiac hypertrophy. Annu Rev Physiol.2001;63:391-426.

32. Selvetella G, Hirsch E, Notte A, et al. Adaptive and maladaptive hypertrophic pathways: points of convergence and divergence. Cardiovasc Res.2004;63(3):373-380.

33. Akazawa H, Komuro I. Roles of cardiac transcription factors in cardiac hypertrophy. Circ Res.2003;92(10):1079-1088.

34. Ross RS, Borg TK. Integrins and the myocardium. Circ Res.2001;88(11):1112-1119.

35. Wollert KC, Drexler H. The renin-angiotensin system and experimental heart failure. Cardiovasc Res. 1999;43(4):838-849.

36. Sugden PH. Signaling pathways activated by vasoactive peptides in the cardiac myocyte and their role in myocardial pathologies. J Card Fail.2002;8(6 Suppl):S359-369.

37. Wang QD, Bohlooly YM, Sjoquist PO. Murine models for the study of congestive heart failure: Implications for understanding molecular mechanisms and for drug discovery. J Pharmacol Toxicol Methods.2004;50(3):163-174.

38. Fernandez-Patron C. Therapeutic potential of the epidermal growth factor receptor transactivation in hypertension: a convergent signaling pathway of vascular tone, oxidative stress, and hypertrophic growth downstream of vasoactive G-protein-coupled receptors? Can J Physiol Pharmacol.2007;85(1):97-104.

39. Akhter SA, Milano CA, Shotwell KF, et al. Transgenic mice with cardiac overexpression of alpha1Badrenergic receptors. In vivo alpha1-adrenergic receptor-mediated regulation of beta-adrenergic signaling. J Biol Chem.1997;272(34):21253-21259.

40. Naga Prasad SV, Nienaber J, Rockman HA. Beta-adrenergic axis and heart disease. Trends Genet.2001;17(10):S44-49.

41. Sekiguchi $\mathrm{K}, \mathrm{Li} \mathrm{X}$, Coker $\mathrm{M}$, et al. Cross-regulation between the renin-angiotensin system and inflammatory mediators in cardiac hypertrophy and failure. Cardiovasc Res.2004;63(3):433-442.

42. Nishikimi T, Maeda N, Matsuoka $\mathrm{H}$. The role of natriuretic peptides in cardioprotection. Cardiovasc Res.2006;69(2):318-328.

43. Dorn GW, 2nd, Force T. Protein kinase cascades in the regulation of cardiac hypertrophy. $J$ Clin Invest.2005;115(3):527-537.

44. Balaraman Y, Limaye AR, Levey AI, et al. Glycogen synthase kinase 3beta and Alzheimer's disease: pathophysiological and therapeutic significance. Cell Mol Life Sci.2006;63(11):1226-1235.

45. Kaladchibachi SA, Doble B, Anthopoulos N, et al. Glycogen synthase kinase 3, circadian rhythms, and bipolar disorder: a molecular link in the therapeutic action of lithium. J Circadian Rhythms.2007;5:3.

46. Kim L, Kimmel AR. GSK3, a master switch regulating cell-fate specification and tumorigenesis. Curr Opin Genet Dev.2000;10(5):508-514.

47. Patel S, Doble B, Woodgett JR. Glycogen synthase kinase-3 in insulin and Wnt signalling: a doubleedged sword? Biochem Soc Trans.2004;32(Pt 5):803-808.

48. Eldar-Finkelman H, Schreyer SA, Shinohara MM, et al. Increased glycogen synthase kinase-3 activity in diabetes- and obesity-prone C57BL/6J mice. Diabetes. 1999;48(8):1662-1666. 
49. Doble BW, Woodgett JR. GSK-3: tricks of the trade for a multi-tasking kinase. J Cell Sci.2003;116(Pt 7):1175-1186.

50. Cohen P, Goedert M. GSK3 inhibitors: development and therapeutic potential. Nat Rev Drug Discov.2004;3(6):479-487.

51. Hardt SE, Sadoshima J. Glycogen synthase kinase-3beta: a novel regulator of cardiac hypertrophy and development. Circ Res.2002;90(10):1055-1063.

52. Meijer L, Flajolet M, Greengard P. Pharmacological inhibitors of glycogen synthase kinase 3. Trends Pharmacol Sci.2004;25(9):471-480.

53. Kerkela R, Woulfe K, Force T. Glycogen synthase kinase-3beta-actively inhibiting hypertrophy. Trends Cardiovasc Med.2007;17(3):91-96.

54. Grimes CA, Jope RS. The multifaceted roles of glycogen synthase kinase 3 beta in cellular signaling. Prog Neurobiol.2001;65(4):391-426.

55. Cohen P, Frame S. The renaissance of GSK3. Nat Rev Mol Cell Biol.2001;2(10):769-776.

56. Cole A, Frame $\mathrm{S}$, Cohen P. Further evidence that the tyrosine phosphorylation of glycogen synthase kinase-3 (GSK3) in mammalian cells is an autophosphorylation event. Biochem J.2004;377(Pt 1):249255.

57. Gould TD, Chen G, Manji HK. In vivo evidence in the brain for lithium inhibition of glycogen synthase kinase-3. Neuropsychopharmacology.2004;29(1):32-38.

58. Dominguez I, Green JB. Missing links in GSK3 regulation. Dev Biol.2001;235(2):303-313.

59. Hedgepeth CM, Deardorff MA, Rankin K, et al. Regulation of glycogen synthase kinase 3beta and downstream Wnt signaling by axin. Mol Cell Biol.1999;19(10):7147-7157.

60. Hughes K, Nikolakaki E, Plyte SE, et al. Modulation of the glycogen synthase kinase-3 family by tyrosine phosphorylation. Embo J.1993;12(2):803-808.

61. Bax B, Carter PS, Lewis C, et al. The structure of phosphorylated GSK-3beta complexed with a peptide, FRATtide, that inhibits beta-catenin phosphorylation. Structure.2001;9(12):1143-1152.

62. Kim S, Lee J, Park J, et al. BP75, bromodomain-containing M(r) 75,000 protein, binds dishevelled-1 and enhances Wnt signaling by inactivating glycogen synthase kinase-3 beta. Cancer Res.2003;63(16):47924795.

63. Hardt SE, Sadoshima J. Negative regulators of cardiac hypertrophy. Cardiovasc Res.2004;63(3):500509.

64. Sugden PH, Fuller SJ, Weiss SC, et al. Glycogen synthase kinase 3 (GSK3) in the heart: a point of integration in hypertrophic signalling and a therapeutic target? A critical analysis. $\mathrm{Br} J$ Pharmacol.2008;153 Suppl 1:S137-153.

65. Haq S, Choukroun G, Kang ZB, et al. Glycogen synthase kinase-3beta is a negative regulator of cardiomyocyte hypertrophy. J Cell Biol.2000;151(1):117-130.

66. Antos CL, McKinsey TA, Frey N, et al. Activated glycogen synthase- 3 beta suppresses cardiac hypertrophy in vivo. Proc Natl Acad Sci U S A.2002;99(2):907-912.

67. Michael A, Haq S, Chen $X$, et al. Glycogen synthase kinase-3beta regulates growth, calcium homeostasis, and diastolic function in the heart. J Biol Chem.2004;279(20):21383-21393.

68. Haq S, Michael A, Andreucci M, et al. Stabilization of beta-catenin by a Wnt-independent mechanism regulates cardiomyocyte growth. Proc Natl Acad Sci U S A.2003;100(8):4610-4615.

69. Moon RT, Bowerman B, Boutros M, et al. The promise and perils of Wnt signaling through betacatenin. Science. 2002;296(5573):1644-1646.

70. Seto ES, Bellen HJ. The ins and outs of Wingless signaling. Trends Cell Biol.2004;14(1):45-53.

71. Veeman MT, Axelrod JD, Moon RT. A second canon. Functions and mechanisms of beta-cateninindependent Wnt signaling. Dev Cell.2003;5(3):367-377.

72. Sheldahl LC, Slusarski DC, Pandur P, et al. Dishevelled activates Ca2+ flux, PKC, and CamKII in vertebrate embryos. J Cell Biol.2003;161(4):769-777.

73. Lilien J, Balsamo J. The regulation of cadherin-mediated adhesion by tyrosine phosphorylation/dephosphorylation of beta-catenin. Curr Opin Cell Biol.2005;17(5):459-465.

74. Venkiteswaran K, Xiao K, Summers S, et al. Regulation of endothelial barrier function and growth by VE-cadherin, plakoglobin, and beta-catenin. Am J Physiol Cell Physiol.2002;283(3):C811-821. 
75. Reya T, Clevers H. Wnt signalling in stem cells and cancer. Nature.2005;434(7035):843-850.

76. Doucas H, Garcea G, Neal CP, et al. Changes in the Wnt signalling pathway in gastrointestinal cancers and their prognostic significance. Eur J Cancer.2005;41(3):365-379.

77. Gregorieff A, Clevers H. Wnt signaling in the intestinal epithelium: from endoderm to cancer. Genes Dev.2005;19(8):877-890.

78. Behrens J. Control of beta-catenin signaling in tumor development. Ann N Y Acad Sci.2000;910:21-33; discussion 33-25.

79. Wang J, Wynshaw-Boris A. The canonical Wnt pathway in early mammalian embryogenesis and stem cell maintenance/differentiation. Curr Opin Genet Dev.2004;14(5):533-539.

80. Peifer M, Polakis P. Wnt signaling in oncogenesis and embryogenesis--a look outside the nucleus. Science. 2000;287(5458):1606-1609.

81. Eisenberg LM, Eisenberg CA. Wnt signal transduction and the formation of the myocardium. Dev Biol.2006;293(2):305-315.

82. Mikels AJ, Nusse R. Purified Wnt5a protein activates or inhibits beta-catenin-TCF signaling depending on receptor context. PLoS Biol.2006;4(4):e115.

83. Cadigan KM, Liu YI. Wnt signaling: complexity at the surface. J Cell Sci.2006;119(Pt 3):395-402.

84. Nelson WJ, Nusse R. Convergence of Wnt, beta-catenin, and cadherin pathways. Science.2004;303(5663):1483-1487.

85. Tolwinski NS, Wieschaus E. Rethinking WNT signaling. Trends Genet.2004;20(4):177-181.

86. Kikuchi A, Kishida S, Yamamoto H. Regulation of Wnt signaling by protein-protein interaction and post-translational modifications. Exp Mol Med.2006;38(1):1-10.

87. Xiong Y, Kotake Y. No exit strategy? No problem: APC inhibits beta-catenin inside the nucleus. Genes Dev.2006;20(6):637-642.

88. Cong F, Varmus H. Nuclear-cytoplasmic shuttling of Axin regulates subcellular localization of betacatenin. Proc Natl Acad Sci U S A.2004;101(9):2882-2887.

89. Hinoi $\mathrm{T}$, Yamamoto $\mathrm{H}$, Kishida $\mathrm{M}$, et al. Complex formation of adenomatous polyposis coli gene product and axin facilitates glycogen synthase kinase-3 beta-dependent phosphorylation of beta-catenin and down-regulates beta-catenin. J Biol Chem.2000;275(44):34399-34406.

90. Huelsken J, Behrens J. The Wnt signalling pathway. J Cell Sci.2002;115(Pt 21):3977-3978.

91. Kimelman $\mathrm{D}, \mathrm{Xu}$ W. beta-catenin destruction complex: insights and questions from a structural perspective. Oncogene.2006;25(57):7482-7491.

92. van Es JH, Barker N, Clevers H. You Wnt some, you lose some: oncogenes in the Wnt signaling pathway. Curr Opin Genet Dev.2003;13(1):28-33.

93. Oving IM, Clevers HC. Molecular causes of colon cancer. Eur J Clin Invest.2002;32(6):448-457.

94. Boutros M, Mihaly J, Bouwmeester T, et al. Signaling specificity by Frizzled receptors in Drosophila. Science.2000;288(5472):1825-1828.

95. Huang HC, Klein PS. The Frizzled family: receptors for multiple signal transduction pathways. Genome Biol.2004;5(7):234.

96. Cong F, Schweizer L, Varmus H. Wnt signals across the plasma membrane to activate the beta-catenin pathway by forming oligomers containing its receptors, Frizzled and LRP. Development.2004;131(20):5103-5115.

97. Huelsken J, Birchmeier W. New aspects of Wnt signaling pathways in higher vertebrates. Curr Opin Genet Dev.2001;11(5):547-553.

98. Pinson KI, Brennan J, Monkley S, et al. An LDL-receptor-related protein mediates Wnt signalling in mice. Nature. 2000;407(6803):535-538.

99. Wharton KA, Jr. Runnin' with the Dvl: proteins that associate with Dsh/Dvl and their significance to Wnt signal transduction. Dev Biol.2003;253(1):1-17.

100. Li L, Yuan H, Xie W, et al. Dishevelled proteins lead to two signaling pathways. Regulation of LEF-1 and c-Jun N-terminal kinase in mammalian cells. J Biol Chem.1999;274(1):129-134.

101. Sussman DJ, Klingensmith J, Salinas $P$, et al. Isolation and characterization of a mouse homolog of the Drosophila segment polarity gene dishevelled. Dev Biol.1994;166(1):73-86. 
102. Klingensmith J, Yang Y, Axelrod JD, et al. Conservation of dishevelled structure and function between flies and mice: isolation and characterization of Dvl2. Mech Dev.1996;58(1-2):15-26.

103. Tian Q, Jin H, Cui Y, et al. Regulation of Wnt gene expression. Dev Growth Differ.2005;47(5):273-281.

104. Cliffe A, Hamada F, Bienz M. A role of Dishevelled in relocating Axin to the plasma membrane during wingless signaling. Curr Biol.2003;13(11):960-966.

105. Chen RH, Ding WV, McCormick F. Wnt signaling to beta-catenin involves two interactive components. Glycogen synthase kinase-3beta inhibition and activation of protein kinase C. $J$ Biol Chem.2000;275(23):17894-17899.

106. Behrens J, von Kries JP, Kuhl M, et al. Functional interaction of beta-catenin with the transcription factor LEF-1. Nature. 1996;382(6592):638-642.

107. Korinek V, Barker N, Morin PJ, et al. Constitutive transcriptional activation by a beta-catenin-Tcf complex in APC-/- colon carcinoma. Science.1997;275(5307):1784-1787.

108. Tetsu O, McCormick F. Beta-catenin regulates expression of cyclin D1 in colon carcinoma cells. Nature. 1999;398(6726):422-426.

109. He TC, Sparks AB, Rago C, et al. Identification of c-MYC as a target of the APC pathway. Science. 1998;281(5382):1509-1512.

110. Brabletz T, Herrmann K, Jung A, et al. Expression of nuclear beta-catenin and c-myc is correlated with tumor size but not with proliferative activity of colorectal adenomas. Am J Pathol.2000;156(3):865-870.

111. Anna CH, Iida M, Sills RC, et al. Expression of potential beta-catenin targets, cyclin D1, c-Jun, c-Myc, E-cadherin, and EGFR in chemically induced hepatocellular neoplasms from $\mathrm{B} 6 \mathrm{C} 3 \mathrm{~F} 1$ mice. Toxicol Appl Pharmacol.2003;190(2):135-145.

112. Brabletz T, Jung A, Dag S, et al. beta-catenin regulates the expression of the matrix metalloproteinase-7 in human colorectal cancer. Am J Pathol.1999;155(4):1033-1038.

113. Marchenko ND, Marchenko GN, Weinreb RN, et al. Beta-catenin regulates the gene of MMP-26, a novel metalloproteinase expressed both in carcinomas and normal epithelial cells. Int J Biochem Cell Biol.2004;36(5):942-956.

114. Quaiser $T$, Anton R, Kuhl M. Kinases and $G$ proteins join the Wnt receptor complex. Bioessays.2006;28(4):339-343.

115. Pandur $\mathrm{P}$, Maurus $\mathrm{D}$, Kuhl $\mathrm{M}$. Increasingly complex: new players enter the Wnt signaling network. Bioessays.2002;24(10):881-884.

116. Pongracz JE, Stockley RA. Wnt signalling in lung development and diseases. Respir Res.2006;7:15.

117. Kawano Y, Kypta R. Secreted antagonists of the Wnt signalling pathway. J Cell Sci.2003;116(Pt 13):2627-2634.

118. Krishnan V, Bryant HU, Macdougald OA. Regulation of bone mass by Wnt signaling. $J$ Clin Invest.2006;116(5):1202-1209.

119. Bowley E, O'Gorman DB, Gan BS. Beta-catenin signaling in fibroproliferative disease. J Surg Res.2007;138(1):141-150.

120. Ben-Ze'ev A, Shtutman M, Zhurinsky J. The integration of cell adhesion with gene expression: the role of beta-catenin. Exp Cell Res.2000;261(1):75-82.

121. Zhou J, Qu J, Yi XP, et al. Upregulation of gamma-catenin compensates for the loss of beta-catenin in adult cardiomyocytes. Am J Physiol Heart Circ Physiol.2007;292(1):H270-276.

122. Gooding JM, Yap KL, Ikura M. The cadherin-catenin complex as a focal point of cell adhesion and signalling: new insights from three-dimensional structures. Bioessays. 2004;26(5):497-511.

123. Harris TJ, Peifer M. Decisions, decisions: beta-catenin chooses between adhesion and transcription. Trends Cell Biol.2005;15(5):234-237.

124. Miller JR, Moon RT. Signal transduction through beta-catenin and specification of cell fate during embryogenesis. Genes Dev.1996;10(20):2527-2539.

125. Bienz M, Clevers H. Armadillo/beta-catenin signals in the nucleus--proof beyond a reasonable doubt? Nat Cell Biol.2003;5(3):179-182.

126. Gottardi CJ, Gumbiner BM. Distinct molecular forms of beta-catenin are targeted to adhesive or transcriptional complexes. J Cell Biol.2004;167(2):339-349. 
127. Piedra J, Martinez D, Castano J, et al. Regulation of beta-catenin structure and activity by tyrosine phosphorylation. J Biol Chem.2001;276(23):20436-20443.

128. Gottardi CJ, Gumbiner BM. Adhesion signaling: how beta-catenin interacts with its partners. Curr Biol.2001;11(19):R792-794.

129. Liu C, Kato Y, Zhang Z, et al. beta-Trcp couples beta-catenin phosphorylation-degradation and regulates Xenopus axis formation. Proc Natl Acad Sci U S A.1999;96(11):6273-6278.

130. Blankesteijn WM, Essers-Janssen YP, Ulrich MM, et al. Increased expression of a homologue of drosophila tissue polarity gene "frizzled" in left ventricular hypertrophy in the rat, as identified by subtractive hybridization. J Mol Cell Cardiol.1996;28(5):1187-1191.

131. Cerutti C, Kurdi M, Bricca G, et al. Transcriptional alterations in the left ventricle of three hypertensive rat models. Physiol Genomics. 2006;27(3):295-308.

132. Rezvani M, Liew CC. Role of the adenomatous polyposis coli gene product in human cardiac development and disease. J Biol Chem.2000;275(24):18470-18475.

133. Chen X, Shevtsov SP, Hsich E, et al. The beta-catenin/T-cell factor/lymphocyte enhancer factor signaling pathway is required for normal and stress-induced cardiac hypertrophy. Mol Cell Biol.2006;26(12):4462-4473.

134. Qu J, Zhou J, Ping Yi X, et al. Cardiac-specific haploinsufficiency of beta-catenin attenuates cardiac hypertrophy but enhances fetal gene expression in response to aortic constriction. $J$ Mol Cell Cardiol.2007;43(3):319-326.

135. Baurand A, Zelarayan L, Betney R, et al. Beta-catenin downregulation is required for adaptive cardiac remodeling. Circ Res.2007;100(9):1353-1362.

136. Ai Z, Fischer A, Spray DC, et al. Wnt-1 regulation of connexin43 in cardiac myocytes. $J$ Clin Invest.2000;105(2):161-171.

137. Marrs JA, Nelson WJ. Cadherin cell adhesion molecules in differentiation and embryogenesis. Int Rev Cytol.1996;165:159-205.

138. Masuelli L, Bei R, Sacchetti $P$, et al. Beta-catenin accumulates in intercalated disks of hypertrophic cardiomyopathic hearts. Cardiovasc Res.2003;60(2):376-387.

139. Schumann H, Holtz J, Zerkowski HR, et al. Expression of secreted frizzled related proteins 3 and 4 in human ventricular myocardium correlates with apoptosis related gene expression. Cardiovasc Res.2000;45(3):720-728.

140. Blankesteijn WM, Creemers E, Lutgens E, et al. Dynamics of cardiac wound healing following myocardial infarction: observations in genetically altered mice. Acta Physiol Scand.2001;173(1):75-82.

141. Lutgens E, Daemen MJ, de Muinck ED, et al. Chronic myocardial infarction in the mouse: cardiac structural and functional changes. Cardiovasc Res.1999;41(3):586-593.

142. Blankesteijn WM, Essers-Janssen YP, Verluyten MJ, et al. A homologue of Drosophila tissue polarity gene frizzled is expressed in migrating myofibroblasts in the infarcted rat heart. Nat Med.1997;3(5):541544.

143. Barandon L, Couffinhal T, Ezan J, et al. Reduction of infarct size and prevention of cardiac rupture in transgenic mice overexpressing FrzA. Circulation.2003;108(18):2282-2289.

144. Chen L, Wu Q, Guo F, et al. Expression of Dishevelled-1 in wound healing after acute myocardial infarction: possible involvement in myofibroblast proliferation and migration. $J$ Cell Mol Med.2004;8(2):257-264.

145. Kaga S, Zhan L, Altaf E, et al. Glycogen synthase kinase-3beta/beta-catenin promotes angiogenic and anti-apoptotic signaling through the induction of VEGF, Bcl-2 and survivin expression in rat ischemic preconditioned myocardium. J Mol Cell Cardiol.2006;40(1):138-147.

146. Mangi AA, Noiseux N, Kong D, et al. Mesenchymal stem cells modified with Akt prevent remodeling and restore performance of infarcted hearts. Nat Med.2003;9(9):1195-1201.

147. Downey JM, Davis AM, Cohen MV. Signaling pathways in ischemic preconditioning. Heart Fail Rev. 2007.

148. Barandon L, Dufourcq $P$, Costet $P$, et al. Involvement of FrzA/sFRP-1 and the Wnt/frizzled pathway in ischemic preconditioning. Circ Res.2005;96(12):1299-1306. 
149. Hahn JY, Cho HJ, Bae JW, et al. Beta-catenin overexpression reduces myocardial infarct size through differential effects on cardiomyocytes and cardiac fibroblasts. J Biol Chem.2006;281(41):30979-30989.

150. Dimmeler S. Viewpoint: stem cells in cardiology. Circulation.2006;113(18):f69-70.

151. Mirotsou M, Zhang Z, Deb A, et al. Secreted frizzled related protein 2 (Sfrp2) is the key Aktmesenchymal stem cell-released paracrine factor mediating myocardial survival and repair. Proc Natl Acad Sci U S A.2007;104(5):1643-1648.

152. Garcia-Gras E, Lombardi R, Giocondo MJ, et al. Suppression of canonical Wnt/beta-catenin signaling by nuclear plakoglobin recapitulates phenotype of arrhythmogenic right ventricular cardiomyopathy. $J$ Clin Invest.2006;116(7):2012-2021.

153. MacRae CA, Birchmeier W, Thierfelder L. Arrhythmogenic right ventricular cardiomyopathy: moving toward mechanism. J Clin Invest.2006;116(7):1825-1828.

154. Moon RT, Kohn AD, De Ferrari GV, et al. WNT and beta-catenin signalling: diseases and therapies. Nat Rev Genet.2004;5(9):691-701.

155. Barker N, Clevers H. Mining the Wnt pathway for cancer therapeutics. Nat Rev Drug Discov.2006;5(12):997-1014.

156. Clapper ML, Coudry J, Chang WC. beta-catenin-mediated signaling: a molecular target for early chemopreventive intervention. Mutat Res.2004;555(1-2):97-105.

157. Dihlmann S, von Knebel Doeberitz M. Wnt/beta-catenin-pathway as a molecular target for future anticancer therapeutics. Int J Cancer.2005;113(4):515-524.

158. Dihlmann S, Klein S, Doeberitz Mv MK. Reduction of beta-catenin/T-cell transcription factor signaling by aspirin and indomethacin is caused by an increased stabilization of phosphorylated beta-catenin. Mol Cancer Ther.2003;2(6):509-516.

159. Daniel JM, Reynolds AB. Tyrosine phosphorylation and cadherin/catenin function. Bioessays. 1997;19(10):883-891.

160. Zhou L, An N, Haydon RC, et al. Tyrosine kinase inhibitor STI-571/Gleevec down-regulates the betacatenin signaling activity. Cancer Lett.2003;193(2):161-170.

161. Takahashi-Yanaga F, Sasaguri $T$. The Wnt/beta-catenin signaling pathway as a target in drug discovery. J Pharmacol Sci.2007;104(4):293-302.

162. You L, He B, Xu Z, et al. An anti-Wnt-2 monoclonal antibody induces apoptosis in malignant melanoma cells and inhibits tumor growth. Cancer Res.2004;64(15):5385-5389. 


\section{Chapter 2}

\section{Regulation of Wnt signaling in time after aortic banding in rats.}

V.A.M. van de Schans; H.T.M. Vervoort; M.E. van Gijn; G. Maes; J.F.M. Smits; W.

M. Blankesteijn 


\begin{abstract}
The development of cardiac hypertrophy is a primary event in the pathogenesis of heart failure. The canonical Wnt pathway (also referred to as the Wnt/ $\beta$-catenin pathway) plays various roles in embryonic, postnatal and oncogenic growth of many tissues. Wnt stimulation acts to stabilize $\beta$-catenin levels, by binding of a Wnt to a complex of a serpentine receptor of the Frizzled family and a LRP-5 or LRP-6 coreceptor. Receptor occupancy activates the Dvl protein and this Dvl protein inhibits the action of GSK-3 $\beta$, a potent suppressor of the hypertrophic response. Stabilized $\beta$-catenin translocates to the nucleus where it can activate Tcf/Lef signaling and upregulate the expression of $\beta$ catenin target genes.

In the present study, we examined the regulation of the expression of components of the canonical Wnt pathway in the first 10 days after induction of pressure overloadinduced cardiac hypertrophy. Rats were subjected to aortic constriction for 1,4,7 and 10 days or to sham surgery. The expression of components of the canonical Wnt pathway in the left ventricle was determined by Real-Time PCR and Western Blotting. Our results demonstrate that during the development of cardiac hypertrophy there is a reexpression of the canonical Wnt pathway with an upregulation of $\beta$-catenin protein levels, and mRNA transcripts of Fz-2 and Dvl-1.
\end{abstract}




\section{Introduction}

In order to maintain sufficient cardiac output, the heart can respond to a myriad of physiologic and pathological stimuli ${ }^{1}$. The heart reacts to hemodynamic overload by undergoing left ventricular hypertrophy, an adaptive response involving many alterations in myocardial structure and function. In the long term, left ventricular hypertrophy can progress to heart failure ${ }^{2}$. In the adult heart, the hypertrophic response is accompanied by re-expression of many fetal genes. Understanding the molecular signaling pathways accompanying these changes in the heart is important to design novel therapeutic interventions to interrupt or reverse the hypertrophic growth before the heart is going into failure.

One of the first organs to function in the growing embryo is the heart. The Wnt signaling pathway is indispensible for the normal development of the heart ${ }^{3,4}$. Canonical Wnt signaling is initiated when Wnt ligands engage their cognate receptor complex, consisting of a serpentine receptor of the Frizzled (Fz) family and a member of the low density Lipoprotein Receptor-related Protein (LRP) family, LRP-5 or LRP6. This complex activates the downstream component Dishevelled (Dvl). Activated Dvl

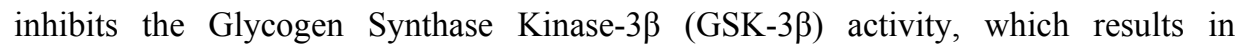
stabilization and accumulation of $\beta$-catenin in the cell ${ }^{5}$. Stabilized $\beta$-catenin translocates to the nucleus where it interacts with transcription factor of the $\mathrm{T}$ cell factor/lymphoid enhancer factor (Tcf/Lef) family, thereby inducing the transcription of target genes ${ }^{6,7}$. In the absence of Wnt stimulation, the N-terminal cluster of serine and threonine residues of $\beta$-catenin are putative GSK-3 $\beta$ phosphorlyation sites, which serve as signals for ubiquitin-mediated degradation ${ }^{8}$. GSK-3 $\beta$, an ubiquitous serine/threonine protein kinase $\mathrm{e}^{9,10}$, by itself has anti-hypertrophic effects but pro-hypertrophic stimuli can inactivate GSK-3 $\beta$ by phosphorylation of the serine 9 site ${ }^{9,11,12}$. Also canonical Wnt signaling results in the inactivation of GSK-3 $\beta$ via destabilization of the $\beta$-catenin destruction complex rather than via ser $^{9}$ phosphorylation $^{13}$. Previously, our group reported that Fz-2 mRNA expression was upregulated at 10 days after aortic banding in the rat heart ${ }^{14}$. Cerutti et al. ${ }^{15}$ confirmed and extented these results by showing that 
there was a positive correlation between left ventricular mass and Fz-2 expression in rat.

This raises the question what the time frame is in which components of the canonical Wnt pathway would be upregulated during the hypertrophic response in the left ventricle. The goal of the present study was to examine different components of the canonical Wnt signaling pathway during the development of cardiac hypertrophy. This was determined by Real-Time PCR and Western blotting.

\section{Materials and methods}

\section{Animals and Surgery.}

Adult male Wistar rats (Winkelmann, Borchen, Germany) of an age of 10 weeks (approximately 300g) were used. They were housed under a 12-h light/dark cycle and had free access to food and water. Left ventricular hypertrophy was induced by aortic banding as described by Willems et al.16 with minor modifications. The rats were aneasthetized with pentobarbital $(60 \mathrm{mg} / \mathrm{kg}$ i.p.). Through a ventromedial incision the aorta was ligated between the renal arteries to a diameter of $0.1 \mathrm{~mm}$. This was achieved by inserting a 30 -gauge needle between the ligature and the aorta, which was removed after completing the ligation. Sham surgery was identical with the exception of the actual ligation of the aorta. The experiments were performed according to the guidelines of the Maastricht University and were approved by the institutional animal ethics committee.

\section{Real time PCR.}

The animals were anesthetized with ether, killed by cervical dislocation. The hearts were removed, rinsed in ice-cold phosphate-buffered saline. The atria were removed, the heart was divided into left ventricular free wall, septum and right ventricle, immediately snap-frozen in liquid nitrogen and stored at $-80^{\circ} \mathrm{C}$. Left ventricular tissue was homogenized with a PRO200 tissue homogenizer (PRO Scientific, Monroe, CT, USA) and isolated by using UltraspecTM-II RNA isolation system (BioTecx 
Laboratories, Houston TX, USA) according to the manufacturer's recommendations. RNA was further purified by DNase digestion using the DNA-Free RNA kitTM (Zymo Research, Orange, CA, USA) to remove genomic DNA. First strand cDNA was synthesized by adding $100 \mathrm{ng}$ of DNase-treated total RNA to Ready-To-Go You Prime First-Strand Beads (Amersham Biosciences Europe, Freiburg, Germany). Random hexamers were used as primers. The reactions were incubated at $37^{\circ} \mathrm{C}$ for 1 hour and at $95^{\circ} \mathrm{C}$ for 2 minutes. The resulting cDNA was either immediately used as template for real-time PCR or stored at $-20^{\circ} \mathrm{C}$. Real-time PCR primers were chosen with the assistance of the computer program Primer Express (version 1.5; Applied Biosystems, Foster City, CA, USA). These primers were used to quantify the mRNA levels of atrial natriuretic factor (ANF), brain natriuretic peptide (BNP), $\alpha$-Myosin heavy chain $(\alpha-$ MHC), $\beta$-Myosin heavy chain ( $\beta$-MHC), Frizzled 1 (Fz-1), Fz-2, Wnt-5a, Dishevelled1 (Dvl-1), $\beta$-catenin. Real-time PCR was started with 10 minutes at $95^{\circ} \mathrm{C}$, than cycled between $95^{\circ} \mathrm{C} / 10 \mathrm{~s}$ and $57^{\circ} \mathrm{C}-60^{\circ} \mathrm{C} / 15 \mathrm{sec}$ for 40 cycles in the MyIQ system of Biorad (Biorad, Hercules, CA, USA). The expression was determined by measuring the binding of the fluorescent dye SYBR Green I, using SYBRGreen PCR Master Mix kit (Eurogentec, Seraing, Belgium). Gene expression was normalized to the housekeeping gene Cyclophilin. All samples were run in duplicate. Data analyses were performed using the MyIQ System software (Biorad, USA).

\section{Western immunoblot analyses.}

Total protein extracts were prepared as follows: left ventricular tissue was added to 1 $\mathrm{ml}$ ice-cold Laemmli buffer (6.6\% Glycerol; 1.5\%SDS; $41.5 \mathrm{mM}$ Tris/HCl $\mathrm{pH}=8.0)$ and homogenized with a PRO200 tissue homogenizer (PRO Scientific, USA). After sonification and centrifugation, the supernatant was collected and stored at $-80^{\circ} \mathrm{C}$. The protein content of supernatant was measured by using the BCA protein Assay (Pierce biotechnology Inc., Rockford IL, USA). For Western blotting, $20 \mu \mathrm{g}$ of total protein was denatured by boiling in Laemmli sample buffer and separated on a $10 \%$ SDSPAGE gel, and transferred onto a HybondC nitrocellulose membrane (Amersham 
Biosciences, Europe). After blocking in 5\% nonfat dry milk (Biorad, USA), 0.1\% Tween 20 in Tris-buffered Saline for 1 hour, membranes were incubated overnight with the following primary antibodies at $4^{\circ} \mathrm{C}$ : $\beta$-catenin, GSK-3 $\beta$ (BD Transduction Laboratories, Lexington, KY, USA), $\alpha$-tubulin (Santa Cruz Biotechnology, CA, USA), and Phospho-Ser9 GSK-3 $\beta$ (Cell Signaling Technology, Beverly MA, USA). Antirabbit IgG and anti-mouse IgG Horseradish Peroxidase-conjugated antibodies (DAKO, Glostrup, Denmark) were used as the secondary antibodies as appropriate. The membranes were developed by Supersignal West Pico chemiluminescence kit (Pierce biotechnology Inc.,USA).

\section{Statistical Analysis.}

All data are presented as means \pm SEM. One-way ANOVA with Dunnett's Multiple Comparison test was used to compare the means. P-values $<0.05$ were considered to indicate statistical significance.

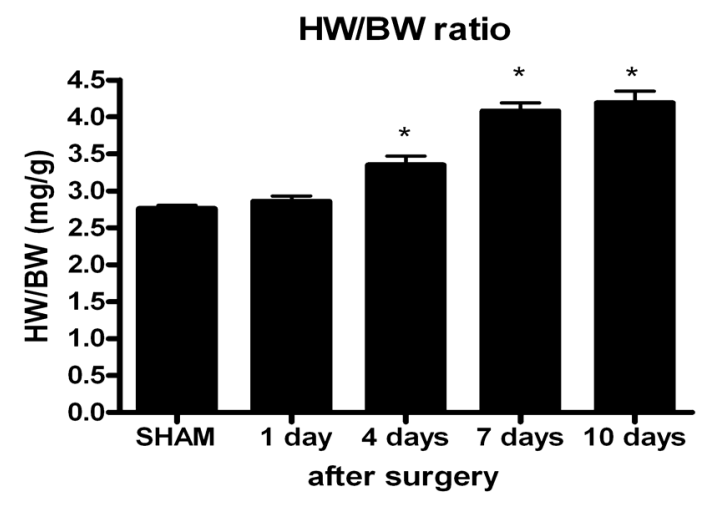

Figure 1

The heart weigth/body weigth ratio in sham operated and aortic banding operated wistar rats. Values are expressed as means \pm S.E.M. and * $\mathrm{P}<0.05$ vs. Sham. All $\mathrm{n}=5-6$

\section{Results}

\section{Induction of hypertrophic markers in time}

Aortic banding induced a significant increase in the HW/BW ratio starting at 4 days after surgery (Fig 1). Cardiac hypertrophy was accompanied by re-expression of the fetal gene program. The mRNA expression of natriuretic peptides (both ANF and BNP) 
was measured by Real-Time PCR (Fig 2A and 2B). In fig 2A, a significant upregulation of ANF mRNA transcripts is shown 7 and 10 days after induction of cardiac hypertrophy. BNP mRNA expression (fig 2B) was significantly upregulated at all time points; at day 1 the highest level of BNP mRNA expression was reached. The cytoskeletal proteins $\beta$-MHC (the fetal type) and $\alpha$-MHC (the adult type) were also determined by real-time PCR (Fig $2 \mathrm{C}$ and 2D). As shown in fig. $2 \mathrm{C}$, the rats exhibited significant increases in mRNA expression of $\beta$-MHC at days 1 and 4 after induction of cardiac hypertrophy, compared to sham. The number of $\alpha-\mathrm{MHC}$ mRNA transcripts (fig. 2D) was also significantly upregulated 1 day after induction of hypertrophy.

A

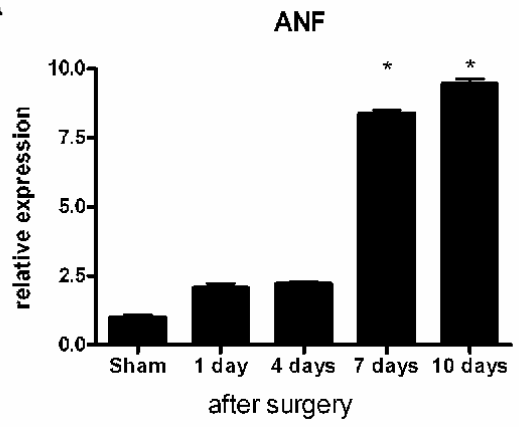

C

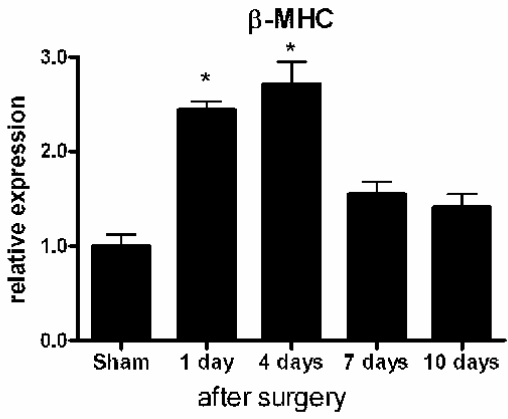

B

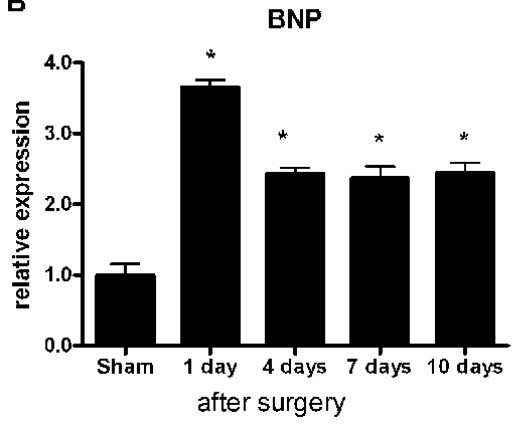

D

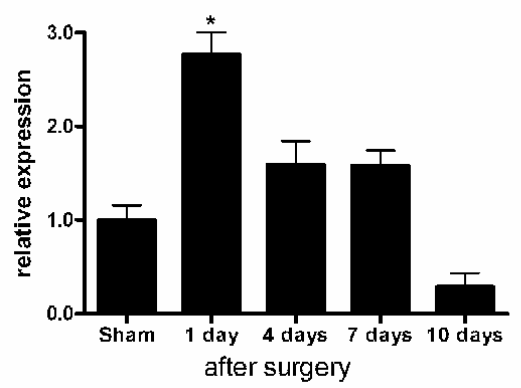

Figure 2

Characterization of different markers of cardiac hypertrophy 1,4,7 and 10 days after aortic banding. A: Expression of ANF, B: Expression of BNP, C: Expression of $\beta$-MHC, D: Expression of $\alpha-\mathrm{MHC}$, all normalized to the housekeeping gene Cyclophilin. Values are expressed as means \pm S.E.M. and * $\mathrm{P}<0.05$ vs. Sham. All $\mathrm{n}=5-6$. 


\section{Expression of components of the canonical Wnt pathway in time}

During the development of hypertrophy, we observed 4-fold reduction in mRNA levels of Wnt-5a starting at day 1 after aortic banding; this level of mRNA transcripts remained significantly reduced at other time points (Fig 3A.). No mRNA of Wnt-3a could be detected at any time point (not shown). We did not see a difference in Fz-1 mRNA expression (Fig. 3B) in time whereas the Fz-2 mRNA expression (Fig. 3C) gradually increased in time reaching statistical significance at 10 days after pressure overload induction. When Wnt activates a $\mathrm{Fz}$ receptor, Dvl is the first known intracellular component of the Wnt signal transduction pathway. In fig. 3D, the mRNA expression of Dvl-1 is shown in time. There was a significant upregulation at day 10 compared to sham and day 1 after induction of hypertrophy.
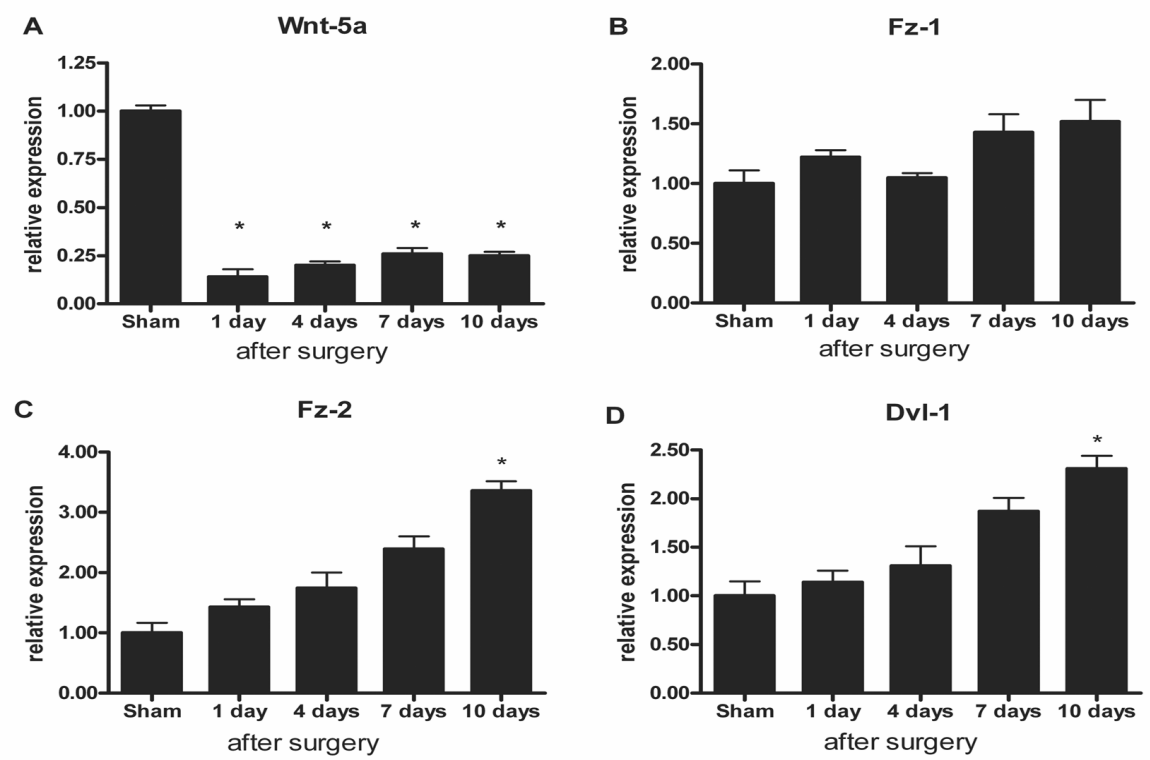

Figure 3

Expression of mRNA transcripts of components of the Wnt pathway. Expression of mRNA transcripts is determined by Real-Time PCR for Wnt-5a (A), Fz-1 (B), Fz-2 (C), Dvl-1 (D) and after 1,4,7 and 10 days of aortic banding or after sham surgery, normalized to the housekeeping gene Cyclophilin. Values are expressed as means \pm S.E.M. and * $\mathrm{P}<0.05$ vs. Sham. All $\mathrm{n}=5-6$ 
Regulation of GSK-3ß phosphorylation during the development of cardiac hypertrophy

$\beta$-Catenin protein levels are regulated by targeted degradation after GSK-3 $\beta$-mediated phosphorylation. To determine the role of GSK-3 $\beta$ in $\beta$-catenin activation, we analyzed the amounts of total GSK-3 $\beta$, as well as its inactive (Ser ${ }^{9}$-phosphorylated) and active (Tyr ${ }^{216}$ - phosphorylated) form by Western Blotting. As shown in Fig. 4A, at days 4 and 10 after induction of hypertrophy, the pSer $^{9}-$ GSK-3 $\beta /$ total GSK-3 $\beta$ ratio tended to increase in both groups, statistical significance was reached at day 4. At day 7, there was a dip in $\mathrm{pSer}^{9}-\mathrm{GSK}-3 \beta /$ total GSK-3 $\beta$ ratio. In contrast, aortic banding induced a gradual decrease in the $\mathrm{pTyr}^{216}$-GSK-3 $\beta /$ total GSK-3 $\beta$ ratio which reached statistical significance at 10 days after induction of hypertrophy (Fig. 4B).
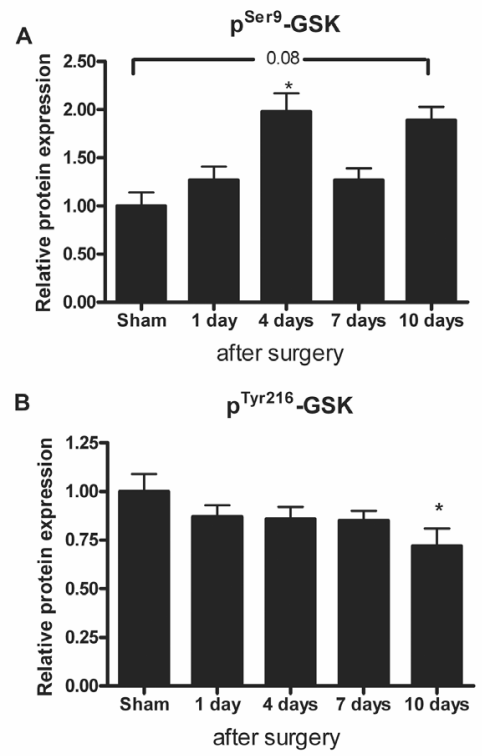

\section{Figure 4}

GSK-3 $\beta$ activity as determined by Western Blotting. A and $\mathrm{B}$ : Western blots of $\mathrm{pSer}{ }^{9}-\mathrm{GSK}-3 \beta$ (inactive form), $\mathrm{pTyr}^{216}$ GSK-3 $\beta$ (active form) and total GSK-3 $\beta$ protein expression. Densitometric analysis of the pSer-GSK-3 $\beta$ (A) and $\mathrm{pTyr}^{216}$-GSK-3 $\beta$ protein (B), expressed relative to total $(\mathrm{t})$ GSK-3 $\beta$ protein. Values are expressed as means \pm S.E.M. and $* \mathrm{P}<0.05$ vs. Sham. All $\mathrm{n}=3-4$.

\section{$\beta$-catenin and the hypertrophic response}

Finally, we examined the expression of $\beta$-catenin, the second messenger molecule of the canonical Wnt pathway, by Real-Time PCR (Fig. 5A) and Western Blotting (Fig. 5B). The number of $\beta$-catenin transcripts was significantly increased 1 day after 
induction of cardiac hypertrophy compared to the other groups and then returned to the levels observed in the sham groups (Fig. 5A). In Fig. 5B, a quantitative analysis of the amounts of $\beta$-catenin protein is shown. There is a significant increase in the amount of $\beta$-catenin protein 1, 4 and 10 days after induction of aortic banding.
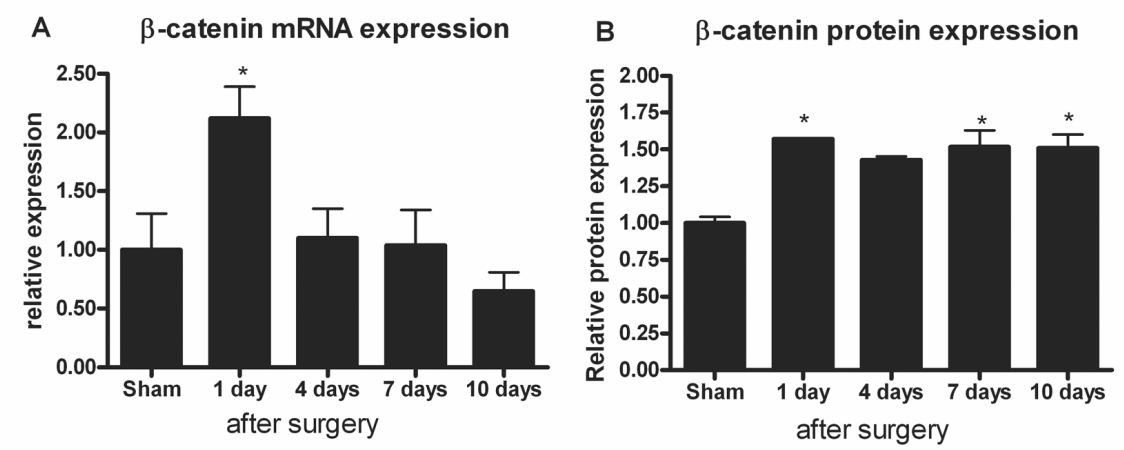

\section{Figure 5}

Expression of $\beta$-catenin. mRNA transcripts of $\beta$-catenin (A) and protein content (B) after 1,4,7 and 10 days of aortic banding or after sham surgery. A: mRNA levels are normalized to the housekeeping gene Cyclophilin. All $n=5-6$ and B: Quantification of the Western Blot signals, expressed as $\beta$-catenin/ $\alpha$-tubulin ratios. All $n=3-4$. Values are expressed as means \pm S.E.M. and $* \mathrm{P}<0.05$ vs. Sham.

\section{Discussion}

The present study demonstrates that during the development of cardiac hypertrophy, components of the canonical Wnt signaling are upregulated such as mRNA transcripts of Fz-2 and Dvl-1. Also an increased GSK-3 $\beta$ phosphorylation and an increase in $\beta$ catenin protein levels are observed.

Wnt signaling has been implicated in a vast number of human diseases including cancer $^{17}$, osteoporosis ${ }^{18}$ and cardiovascular diseases ${ }^{19}$. Althought Wnts can signal through different pathways, the canonical Wnt pathway or the Wnt/ $\beta$-catenin pathway is the best studied of all the pathways. Wnts are secreted proteins and have been classified into separate groups. The Wnt-1 group, to which Wnt-3a belongs, appears to signal exclusively via the canonical Wnt pathway whereas the Wnt-5a group posses 
more complex signaling properties: it has been reported to activate non- $\beta$-catenin mediated Wnt signaling but it can also act as an inhibitor of canonical Wnt signaling ${ }^{20-}$ 23. Hypertrophy induced by aortic banding resulted in a significant downregulation of Wnt-5a mRNA transcripts whereas Wnt-3a mRNA was not detectable in left ventricular heart tissue. Futher investigations of the effects of different Wnts in the development of cardiac hypertrophy would provide better understanding of the role of Wnts in the hypertrophic response.

During cardiac morphogenesis, moderate myocardial expression of Fz-2 was observed in the ventricular septum at 12 and 14 days after conception ${ }^{24}$, as well as during cardiac hypertrophic development in rats ${ }^{14}$, where re-expression of Fz-2 mRNA was showed in the left ventricular tissue. The present study confirmed these observation and those published by Cerutti et al., showing a positive correlation between Fz-2 expression and left ventricular mass. Fz-1 mRNA expression showed no upregulation after induction of cardiac hypertrophy. When Wnt is engaged with Fz, the Dvl protein is the most upstream component of intracellular signal transduction. Dvl is known to antagonize the action of GSK-3 $\beta$ on the $\beta$-catenin phosphorylation ${ }^{25}$. Aortic banding in rats results in a significant upregulation of Dvl-1 mRNA expression 10 days after induction of cardiac hypertrophy.

Dvl leads to inhibition of GSK-3 $\beta$, one of the most powerful antihypertrophic entities described so far $^{12,26}$, but also involved in cardiogenesis ${ }^{27}$. The loss of GSK-3 $\alpha$ or GSK-3 $\beta$ results in the abnormal development of the heart where GSK-3 $\beta$ has an important role in modulating the left-right asymmetry and affecting the heart positioning, modulated through the $\mathrm{Wnt} / \beta$-catenin signaling pathway. GSK-3 $\beta$ is active in quiescent cells and cell stimulation leads to inhibition of GSK-3 $\beta$ by two distinct mechanisms ${ }^{13}$, 28 . One mechanism involves the inhibition of GSK-3 $\beta$ by its phosphorylation of the N-terminal $\mathrm{Ser}^{9}$, catalysed by several different protein kinases. Another mechanism is Wnt activation where GSK-3 $\beta$ inhibition does not involve 
phosphorylation but a rather poorly understood mechanism. In our study, after aortic banding, Ser ${ }^{9}$ phosphorylation of GSK-3 $\beta$ was significantly increased at day 4 (and a trend day 10) whereas at day 7, a decrease in $\operatorname{Ser}^{9}$ phosphorylation of GSK-3 $\beta$ was noticed. Haq. et $\mathrm{al}^{29}$ showed that $\operatorname{Ser}^{9}$ phosphorylation of GSK-3 $\beta$ reached a peak 3 days after TAC but returned to baseline levels 7 days after TAC in the rat, they did not study later time points. GSK-3 $\beta$ activity is also regulated by $\operatorname{Tyr}^{216}$ kinases and $\operatorname{Tyr}^{216}$ phosphorylation is a good indication of the GSK-3 $\beta$ activity ${ }^{30}$. In this study, there was a decrease in $\mathrm{Tyr}^{216}$ phosphorylation after 10 days of constriction. It will be important to further identify the different effectors regulating the activity of GSK-3 $\beta$ in the hypertrophic response.

GSK-3 $\beta$ phosphorylates serine and threonine residues of $\beta$-catenin, which serve as signals for ubiquitin-mediated degradation ${ }^{8}$. Wnt inhibition of GSK-3 $\beta$ is essential for the stabilization of $\beta$-catenin, resulting in transcriptional activation. Haq. et al. showed that $\beta$-catenin was stabilized by hypertrophic stimuli and overexpression of $\beta$-catenin could induce hypertrophic growth of cardiomyocytes ${ }^{29}$. Loss of one copy of the $\beta$ catenin gene significantly inhibits cardiac hypertrophy in response to aortic constriction but had no major effect on physiological cardiac hypertrophy during postnatal development ${ }^{31}$. But also targeted deletion of $\beta$-catenin in the heart attenuates the hypertrophic response in both physiological and pathological condition ${ }^{32}$. In this paper, determination of the $\beta$-catenin proteins levels showed a significant increase 1,4 and 10 days after aortic banding, which appears to support the role of $\beta$-catenin in cardiac hypertrophy development described in the other studies ${ }^{29,30,32}$.

In summary, components of the canonicial Wnt pathway are upregulated in the pathological hypertrophic growth of cardiomyocytes. Wnt-induced upregulation of $\beta$ catenin protein was assiociated with an increased Fz-2, Dvl-1 mRNA expression and a decrease in GSK-3 $\beta$ activity. Therefore, intervention in the canonical Wnt signaling pathway could serve as a novel therapeutic strategy to prevent cardiac hypertrophy. 


\section{Reference}

1. Tardiff JC. Cardiac hypertrophy: stressing out the heart. J Clin Invest.2006;116(6):1467-1470.

2. Selvetella G, Hirsch E, Notte A, et al. Adaptive and maladaptive hypertrophic pathways: points of convergence and divergence. Cardiovasc Res.2004;63(3):373-380.

3. Brade $\mathrm{T}$, Manner J, Kuhl M. The role of Wnt signalling in cardiac development and tissue remodelling in the mature heart. Cardiovasc Res.2006;72(2):198-209.

4. Tzahor E. Wnt/beta-catenin signaling and cardiogenesis: timing does matter. Dev Cell.2007;13(1):10-13.

5. Wong NA, Pignatelli M. Beta-catenin--a linchpin in colorectal carcinogenesis? Am J Pathol.2002;160(2):389-401.

6. Mann B, Gelos M, Siedow A, et al. Target genes of beta-catenin-T cell-factor/lymphoidenhancer-factor signaling in human colorectal carcinomas. Proc Natl Acad Sci $U S$ A.1999;96(4):1603-1608.

7. Ben-Ze'ev A, Shtutman M, Zhurinsky J. The integration of cell adhesion with gene expression: the role of beta-catenin. Exp Cell Res.2000;261(1):75-82.

8. Chen RH, Ding WV, McCormick F. Wnt signaling to beta-catenin involves two interactive components. Glycogen synthase kinase-3beta inhibition and activation of protein kinase C. J Biol Chem.2000;275(23):17894-17899.

9. Hardt SE, Sadoshima J. Negative regulators of cardiac hypertrophy. Cardiovasc Res.2004;63(3):500-509.

10. Hardt SE, Sadoshima J. Glycogen synthase kinase-3beta: a novel regulator of cardiac hypertrophy and development. Circ Res.2002;90(10):1055-1063.

11. Frey N, Olson EN. Cardiac hypertrophy: the good, the bad, and the ugly. Annu Rev Physiol.2003;65:45-79.

12. Haq S, Choukroun G, Kang ZB, et al. Glycogen synthase kinase-3beta is a negative regulator of cardiomyocyte hypertrophy. J Cell Biol.2000;151(1):117-130.

13. Kerkela R, Woulfe K, Force T. Glycogen synthase kinase-3beta-actively inhibiting hypertrophy. Trends Cardiovasc Med.2007;17(3):91-96.

14. Blankesteijn WM, Essers-Janssen YP, Ulrich MM, et al. Increased expression of a homologue of drosophila tissue polarity gene "frizzled" in left ventricular hypertrophy in the rat, as identified by subtractive hybridization. J Mol Cell Cardiol.1996;28(5):1187-1191.

15. Cerutti C, Kurdi M, Bricca G, et al. Transcriptional alterations in the left ventricle of three hypertensive rat models. Physiol Genomics.2006;27(3):295-308.

16. Willems IE, Havenith MG, Smits JF, et al. Structural alterations in heart valves during left ventricular pressure overload in the rat. Lab Invest.1994;71(1):127-133.

17. Reya T, Clevers H. Wnt signalling in stem cells and cancer. Nature.2005;434(7035):843-850.

18. Krishnan V, Bryant $\mathrm{HU}$, Macdougald OA. Regulation of bone mass by Wnt signaling. J Clin Invest.2006;116(5):1202-1209.

19. van Gijn ME, Daemen MJ, Smits JF, et al. The wnt-frizzled cascade in cardiovascular disease. Cardiovasc Res.2002;55(1):16-24.

20. Pongracz JE, Stockley RA. Wnt signalling in lung development and diseases. Respir Res.2006;7:15.

21. Quaiser $T$, Anton $R$, Kuhl M. Kinases and $G$ proteins join the Wnt receptor complex. Bioessays.2006;28(4):339-343.

22. Kremenevskaja N, von Wasielewski R, Rao AS, et al. Wnt-5a has tumor suppressor activity in thyroid carcinoma. Oncogene.2005;24(13):2144-2154.

23. Topol L, Jiang $X$, Choi $H$, et al. Wnt-5a inhibits the canonical Wnt pathway by promoting GSK3-independent beta-catenin degradation. J Cell Biol.2003;162(5):899-908. 
24. van Gijn ME, Blankesteijn WM, Smits JF, et al. Frizzled 2 is transiently expressed in neural crest-containing areas during development of the heart and great arteries in the mouse. Anat Embryol (Berl).2001;203(3):185-192.

25. Wharton KA, Jr. Runnin' with the Dvl: proteins that associate with Dsh/Dvl and their significance to Wnt signal transduction. Dev Biol.2003;253(1):1-17.

26. Antos CL, McKinsey TA, Frey N, et al. Activated glycogen synthase-3 beta suppresses cardiac hypertrophy in vivo. Proc Natl Acad Sci U S A.2002;99(2):907-912.

27. Lee HC, Tsai JN, Liao PY, et al. Glycogen synthase kinase 3 alpha and 3 beta have distinct functions during cardiogenesis of zebrafish embryo. BMC Dev Biol.2007;7:93.

28. Grimes CA, Jope RS. The multifaceted roles of glycogen synthase kinase 3beta in cellular signaling. Prog Neurobiol.2001;65(4):391-426.

29. Haq S, Michael A, Andreucci M, et al. Stabilization of beta-catenin by a Wnt-independent mechanism regulates cardiomyocyte growth. Proc Natl Acad Sci U S A.2003;100(8):46104615.

30. van de Schans VA, van den Borne SW, Strzelecka AE, et al. Interruption of Wnt signaling attenuates the onset of pressure overload-induced cardiac hypertrophy. Hypertension.2007;49(3):473-480.

31. Qu J, Zhou J, Ping Yi X, et al. Cardiac-specific haploinsufficiency of beta-catenin attenuates cardiac hypertrophy but enhances fetal gene expression in response to aortic constriction. $J$ Mol Cell Cardiol.2007;43(3):319-326.

32. Chen X, Shevtsov SP, Hsich E, et al. The beta-catenin/T-cell factor/lymphocyte enhancer factor signaling pathway is required for normal and stress-induced cardiac hypertrophy. $\mathrm{Mol}$ Cell Biol.2006;26(12):4462-4473. 


\section{Chapter 3}

\section{Interruption of Wnt signaling attenuates} the onset of pressure overload-induced cardiac hypertrophy

V.A.M. van de Schans; S.W.M. van den Borne; A.E. Strzelecka; B.J.A. Janssen; J.L.J. van der Velden; R.C.J. Langen; A. Wynshaw-Boris; J.F.M. Smits; W.M. Blankesteijn 


\begin{abstract}
The hypertrophic response of the heart has recently been recognized as the net result of activation of pro- and anti-hypertrophic pathways. Here we report the involvement of the Wnt/Frizzled pathway in the onset of cardiac hypertrophy development. Stimulation of the Wnt/Frizzled pathway activates the dishevelled (Dvl) protein. Dishevelled subsequently can inhibit glycogen synthase kinase-3 $\beta$, a protein with potent anti-hypertrophic actions through diverse molecular mechanisms. In the Wnt/Frizzled pathway, inhibition of Glycogen Synthase Kinase-3 $\beta$ leads to an increased amount of $\beta$-catenin, which can act as a transcription factor for several hypertrophy-associated target genes. In this study we subjected mice lacking the Dvl-1 gene $\left(D v l-1^{-/}\right)$and their wildtype littermates to thoracic aortic constriction for 7, 14 and 35 days. In $D v l-1^{-/}$mice, 7 days of pressure overload-induced increases in left ventricular posterior wall thickness and expression of ANF and BNP were attenuated compared to their wildtype littermates. $\beta$-Catenin protein amount was reduced in the $D v l-1^{-/}$group, and an increased glycogen synthase kinase-3 $\beta$ activity was observed. Moreover, the increase in the amount of $\mathrm{Ser}^{473}$-phosphorylated Akt, a stimulator of cardiac hypertrophy, was lower in the $D v l-1^{-/}$group. In conclusion, we have demonstrated that interruption of Wnt signaling in the $D v l-1^{-/}$mice attenuates the onset of pressure overload-induced cardiac hypertrophy through mechanisms involving glycogen synthase kinase-3 $\beta$ and Akt. Therefore, the Wnt/Frizzled pathway may provide novel therapeutic targets for anti-hypertrophic therapy.
\end{abstract}




\section{Introduction}

Cardiac hypertrophy is an adaptive response of the heart to an increased workload, caused by a variety of pathological stimuli including hypertension, myocardial infarction and valvular disease. Because cardiomyocytes are terminally differentiated, these cells can only respond by hypertrophic growth ${ }^{1}$. This growth is initially beneficial but a sustained hypertrophic response often leads to heart failure ${ }^{2}$. In this hypertrophic response, extracellular stimulation is translated into a cellular response, leading to changes in the contractile apparatus and to an activation of many signaling pathways ${ }^{3}$. Several of these signaling pathways transduce prohypertrophic signals, but it has been shown that a number of endogenous molecules can regulate the hypertrophic response negatively ${ }^{4}$.

One of the most powerful negative regulators that can antagonize the hypertrophic

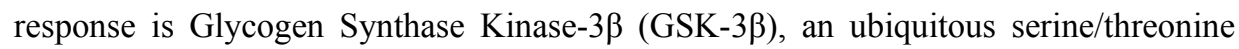
protein kinase $\mathrm{e}^{4,5}$. GSK-3 $\beta$ is a downstream regulatory switch of multiple signaling pathways which regulates a wide range of cellular functions ${ }^{6}$. Dysregulation of GSK$3 \beta$ plays a role in many human diseases including diabetes, Alzheimer's disease, bipolar disorder, cancer ${ }^{7}$ and heart failure ${ }^{8}$. In cardiomyocytes, inhibition of GSK-3 $\beta$ augmented the hypertrophic response ${ }^{9,}{ }^{10}$, whereas overexpression of GSK-3 $\beta$ had an inhibitory effect on the development of cardiac hypertrophy ${ }^{11}$.

The activity of GSK-3 $\beta$ can be modulated by several signaling pathways, including the insulin-like growth factor pathway ${ }^{12}, \beta$-adrenergic signaling ${ }^{13,14}$ and Wnt signaling ${ }^{15}$. In this study we focussed on the role of the Wnt/Frizzled $(\mathrm{Fz})$ pathway in the development of cardiac hypertrophy. In this pathway, a Wnt ligand binds to a membrane-bound complex consisting of a member of the Fz receptor family and a lipoprotein-related protein (LRP) ${ }^{16}$. This results in the activation of a member of the dishevelled (Dvl) protein family, which in its turn inhibits GSK-3 $\beta^{17}$. The mechanism by which Wnt actually regulates GSK-3 $\beta$ is poorly understood ${ }^{18}$. The inhibition of GSK-3 $\beta$ results in a decreased phosphorylation and subsequent accumulation of $\beta$ catenin, a second messenger of Wnt signaling, in the cytoplasm. 
To study the effect of interruption of Wnt signaling on the onset of cardiac hypertrophy

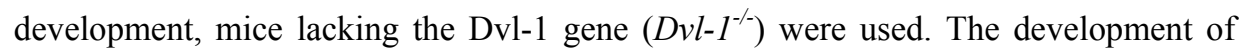
pressure overload-induced cardiac hypertrophy was studied in these mice and their wildtype littermates $\left(D v l-1^{+++}\right)$by subjecting the mice to thoracic aortic constriction (TAC). The effects of pressure overload were monitored by echocardiography and histological techniques. Moreover, the amounts of Akt, GSK-3 $\beta$ and $\beta$-catenin were determined, GSK-3 $\beta$ activity was measured and the expression of the hypertrophyassociated genes atrial natriuretic factor (ANF), brain natriuretic protein (BNP) and proto-oncogenes, was analyzed.

\section{Methods}

An expanded Methods section detailing the techniques and procedures mentioned here is available in an online supplement at http://hyper.ahajournals.org.

\section{Animals}

Dvl-1 knockout $\left(D v l-1^{-/}\right)$mice, generated as previously described ${ }^{19}$, were inbred $(>10$ generations) into a 129/S6 background. $D v l-l^{-/-}$mice of both sexes and wildtype ( $D v l-$ $1^{+/+}$) littermates were used. All experimental procedures were approved by the Committee for Animal Research of Maastricht University and were in accordance with the guide for care and use of laboratory animals, published by the National Institutes of Health (NIH) Guide for the Care and Use of Laboratory Animals.

\section{Thoracic aortic constriction (TAC) model}

$D v l-\mathrm{I}^{-/}$and littermate $\mathrm{Dvl}-\mathrm{I}^{+/+}$mice were randomly distributed over the TAC-group and sham-operated control group. Animals were anesthetized by intramuscular injection with ketamine (100 mg/kg body weight) and subcutaneous injection with xylazine (10 $\mathrm{mg} / \mathrm{kg}$ body weight), and TAC was induced as described previously $\mathrm{y}^{20}$. 


\section{Two-dimensional guided M-mode echocardiography.}

Animals were anaesthetized and two-dimensional (2D) guided M-mode echocardiography on the mouse was performed using a $20-\mathrm{MHz}$ probe connected to an AU4 Idea device (Esaote Biomedica, Firenze, Italy).

\section{Histological analysis.}

Hearts from $D v l-1^{-/-}$and $D v l-1^{+/+}$mice were arrested in diastole, one half was embedded in paraffin and cut in four $\mu \mathrm{m}$ sections and stained with hematoxylin and eosin (H\&E). Myocyte cross-sectional areas were measured using a computerized morphometric system (version Leica Qwin3.1; Leica, Cambridge, England). All sections were measured in 5 different areas of the left ventricle of the heart. Myocyte cross-sectional area was measured per nucleus; the outline of 100-200 myocytes was traced in each section. An examiner blinded to the genotype of the animals performed all measurements.

\section{Real-Time PCR.}

Total RNA was isolated from left ventricular (LV) tissue, purified by DNAse digestion and transcribed into cDNA using random hexamer primers. The amount of transcripts of ANF, BNP, $\beta$-catenin, Dvl-1, -2, and -3, Fzd2, c-fos, c-myc, c-jun and cyclin D1 was determined on an ABI Prism 7700 Sequence Detection System (Applied Biosystems Foster City CA, USA), using the SYBRGreen PCR Master Mix kit (Eurogentec, Seraing, Belgium). Cardiac gene expression was normalized to the housekeeping gene $\beta$-actin. All samples were run in duplicate. Data analyses were performed using the Sequence Detection System software (Applied Biosystems).

\section{Western immunoblot analyses.}

Total protein extracts $(20 \mu \mathrm{g})$ were separated on a 10\% SDS-PAGE gel and transferred to HybondC nitrocellulose membrane (Amersham Biosciences, Little Chalfond, UK). The membranes were incubated overnight at $4^{\circ} \mathrm{C}$ with the following primary 
antibodies: $\beta$-catenin and GSK-3 $\beta$, (BD Transduction Laboratories, Lexington KY, USA); $\operatorname{pSer}^{9}$ GSK-3 $\beta$, pTyr ${ }^{216}$-GSK-3 $\beta$, Akt and $\mathrm{pSer}^{473}$ Akt (Cell Signaling Technology, Beverly MA, USA); $\alpha$-tubulin (Santa Cruz Biotechnology, Santa Cruz CA, USA). Anti-rabbit IgG and anti-mouse IgG Horseradish Peroxidase-conjugated antibodies (DAKO, Glostrup, Denmark) were used as secondary antibodies as appropriate.

\section{GSK-3ß kinase activity assay.}

Total GSK-3 $\beta$ was immunoprecipated from $200 \mu$ g protein extracts of the heart in lysis buffer. The samples were precleared with protein G-Sepharose beads (Amersham Biosciences) and subjected to immunoprecipitation with anti-mouse GSK-3 $\beta$ antibody (BD Transduction Laboratories) overnight at $4{ }^{\circ} \mathrm{C}$ with gentle agitation, than incubated with protein G-Sepharose for 1 hour at $4{ }^{\circ} \mathrm{C}$ with gentle agitation. Kinase activity was assayed in $40 \mu \mathrm{l}$ of total reaction buffer containing GSK-3 Peptide Substrate (Biomol P-151, Exeter, UK) and $10 \mu \mathrm{Ci}\left[\gamma_{-}{ }^{32} \mathrm{P}\right]$ ATP (Amersham Biosciences). After $30 \mathrm{~min}$ of incubation at $30^{\circ} \mathrm{C}, 25 \mu \mathrm{l}$ aliquots were spotted onto $1.5 \mathrm{~cm} \mathrm{X} 1.5 \mathrm{~cm}$ pieces of Whatman P81 Phosphocellulose paper (Whatman Nederland B.V., 's Hertogenbosch, The Netherlands). Quantification of kinase assay was achieved by counting the amount of ${ }^{32} \mathrm{P}$ incorporated into the substrate in the scintillation counter.

\section{Statistical Analysis.}

All data are presented as means $\pm \mathrm{SE}$. Either Unpaired Student's t-test or two-way ANOVA was used as appropriate. P-values $<0.05$ were considered to indicate statistical significance. 
Table 1. Postmortem and Echocardiografic Analysis of Aortic Banded $D v l-1^{-/}$and $D v l-1^{+/+}$Mice

\begin{tabular}{|c|c|c|c|c|c|c|}
\hline \multirow[b]{3}{*}{ Parameters } & \multirow{3}{*}{$\begin{array}{l}\text { SHAM } \\
D V l-1^{+/+}(\mathrm{n}=8)\end{array}$} & \multirow[b]{3}{*}{$D v l-1^{-\alpha}(\mathrm{n}=9)$} & \multicolumn{4}{|l|}{ TAC } \\
\hline & & & \multicolumn{2}{|l|}{7 days } & \multicolumn{2}{|l|}{14 days } \\
\hline & & & $D v l-1^{+/+}(\mathrm{n}=7)$ & $D v l-1^{-/-}(\mathrm{n}=10)$ & $D v l-1^{+/+}(\mathrm{n}=8)$ & $D v l-1^{-1-}(\mathrm{n}=8)$ \\
\hline BW (g) & $20.5 \pm 0.75$ & $20.8 \pm 0.72$ & $20.4 \pm 1.275$ & $20.3 \pm 0.97$ & $20.5 \pm 0.87$ & $20.5 \pm 0.68$ \\
\hline $\mathrm{HW} / \mathrm{TL}(\mathrm{mg} / \mathrm{mm})$ & $6.7 \pm 0.30$ & $6.7 \pm 0.21$ & $8.1 \pm 0.39^{*}$ & $7.3 \pm 0.45$ & $8.8 \pm 0.59^{*}$ & $8.0 \pm 0.54$ \\
\hline $\mathrm{LVW} / \mathrm{TL}(\mathrm{mg} / \mathrm{mm})$ & $3.04 \pm 0.21$ & $2.90 \pm 0.09$ & $3.98 \pm 0.25^{*}$ & $3.43 \pm 0.23^{\dagger}$ & $4.08 \pm 0.28^{*}$ & $3.55 \pm 0.33$ \\
\hline LuW/TL (mg/mm) & $8.6 \pm 0.43$ & $8.6 \pm 0.31$ & $8.9 \pm 0.39$ & $8.8 \pm 0.68$ & $10.2 \pm 0.91$ & $9.00 \pm 0.47$ \\
\hline Pwts (mm) & $1.040 \pm 0.014$ & $1.029 \pm 0.009$ & $1.258 \pm 0.064^{*}$ & $1.106 \pm 0.049^{\ddagger}$ & $1.294 \pm 0.097^{\star}$ & $1.189 \pm 0.045^{\dagger}$ \\
\hline Pwtd (mm) & $0.832 \pm 0.027$ & $0.816 \pm 0.013$ & $1.014 \pm 0.056^{*}$ & $0.887 \pm 0.034^{\dagger \ddagger}$ & $0.982 \pm 0.086$ & $0.911 \pm 0.027^{\dagger}$ \\
\hline
\end{tabular}

\section{Results}

Attenuated development of cardiac hypertrophy in Dvl-1 ${ }^{-/-}$mice in response to pressure overload.

In Table 1, the post-mortem and echocardioagraphic data from $D v l-1^{-/}$mice and $D v l$ $1^{+/+}$littermates, sacrificed at 7 and 14 days after TAC or after sham surgery are shown. No significant differences were observed in heart weight/tibia length (HW/TL) ratio between sham-operated $D v l-1^{-/}$and $D v l-1^{+/+}$mice. Two-way ANOVA analysis showed a significant effect of both time after TAC $(p<0.001)$ and genotype $(p<0.05)$ on HW/TL ratio (Figure I, available online). In $D v l-1^{+/+}$mice the $\mathrm{HW} / \mathrm{TL}$ ratio was significantly increased at all three time points after TAC $(21 \%, 31 \%$ and $72 \%$ increase compared to sham, respectively), whereas this ratio was only significantly increased at 35 days after TAC in the $D v l-1^{-/}$mice. Similar differences in hypertrophic response were observed when the left ventricular (LV) weights were compared. The lung weight/tibia length ratio showed a tendency towards increase at 35 days after TAC in the both groups, but no statistical significance was reached. 
Interstitial fibrosis, assessed by Sirius Red staining, was increased in both groups after TAC, with no significant differences between the genotypes (Figure II, available online).

To determine posterior wall thickness, 2D-directed M-mode echocardiography was performed (Table 1). Seven days after TAC, a statistically significant increase was observed in both end-systolic and end-diastolic posterior wall thickness in the $\mathrm{Dvl}-\mathrm{I}^{+/+}$ group ( $21 \%$ and $22 \%$, respectively), which was sustained at 14 days after TAC. In contrast, end systolic and end diastolic posterior wall thickness did not increase significantly in $\mathrm{Dvl}-\mathrm{I}^{-/}$mice at 7 days after TAC (7\% and $9 \%$ increase, respectively) and were mildly increased at 14 days after TAC (16\% and $12 \%$, respectively). Conclusively, these findings indicate that the lack of the Dvl-1 gene attenuated the onset of pressure overload-induced hypertrophy.

A Myocyte Cross-sectional area

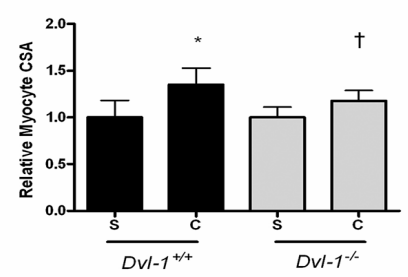

B
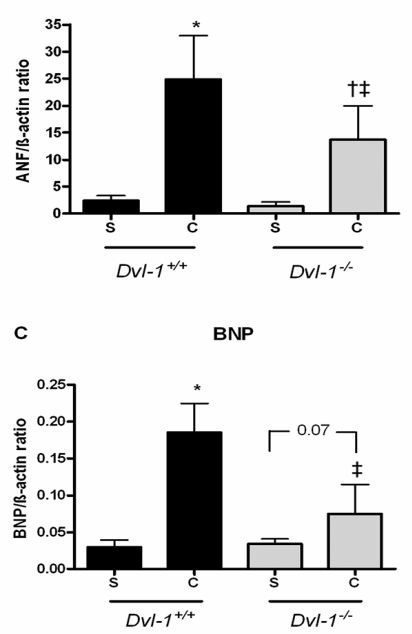

Figure 1. Characterization of different markers of cardiac hypertrophy, induced by 7 days of thoracic aortic banding (TAC). A: Quantification of the cross-sectional area (CSA) of left ventricular cardiomyocytes. B: Expression of ANF, normalized to $\beta$-actin expression. $\mathbf{C}$ : Expression of BNP, normalized to $\beta$-actin expression. $\mathrm{S}=$ Sham, $\mathrm{C}=\mathrm{TAC}$. ${ }^{*} \mathrm{P}<$ 0.05 vs. sham $D v l-1^{+/+} ; \dagger \mathrm{P}<0.05$ vs. sham $D v l-1^{-/} ; \ddagger$ $\mathrm{P}<0.05$ vs. $D v l-1^{+/+}, 7$ days after TAC; All $\mathrm{n}=5-6$. 
Attenuated increase in cardiomyocyte CSA, ANF and BNP expression in Dvl-1 ${ }^{-/-}$ LV upon pressure overload

Histological analysis showed no significant difference in cardiac myocyte crosssectional area (CSA) between the two sham groups. At 7 days after TAC, the CSA was increased by $35 \%$ in $D v l-1^{+/+}$and $18 \%$ in $D v l-1^{-/}$hearts (Fig. 1A). The expression of ANF and BNP is generally used as a molecular marker for the development of cardiac hypertrophy. Real-Time PCR analysis showed statistically significant increases in ANF mRNA levels in both groups at 7 days after TAC when compared to sham (Fig. 1B). However, the increase in ANF expression was significantly attenuated in the $\mathrm{Dvl}-\mathrm{I}^{-/}$ compared to the $D v l-1^{+/+}$LVs. The upregulated expression of BNP was only significant in the $D v l-1^{+/+}$mice at 7 days after TAC; although a trend towards an increased BNP expression was also observed in the $D v l-1^{-/-}$group, no statistical significance was reached (Fig. 1C).

\section{Increased Fz2 and unaltered Dvl-1, -2 and -3 expression in Dvl-1 ${ }^{-/-} \mathrm{LV}$ after TAC}

Previously, we have shown that the Fz2 expression was upregulated after induction of cardiac hypertrophy in rats ${ }^{21}$. Therefore, we investigated whether the absence of the Dvl-1 gene affected the expression of different components of the Wnt/Fz pathway upon TAC. Both in $D v l-1^{-/-}$and $D v l-1^{+/+}$LVs, a significant increase in Fz2 transcripts was observed (Fig. 2A), which did not differ between the two groups. Next, we determined the amounts of transcripts of the three Dvl isoforms in the $D v l-1^{-/-}$and $D v l$ $1^{+/+}$LVs by Real-Time PCR, and studied the effect of 7 days of TAC on their expression. As expected, $D v l-1^{-/}$LVs were completely devoid of Dvl-1 transcripts (Fig 2B), whereas the gene was readily expressed in LVs of the $D v l-1^{+/+}$group. No significant differences were observed in Dvl-2 and Dvl-3 expression between the $D v l$ $1^{-/}$and $D v l-1^{+/+}$groups (Fig. 2C and 2D). In addition, TAC did not affect the expression of any of the three Dvl isoforms. 
A

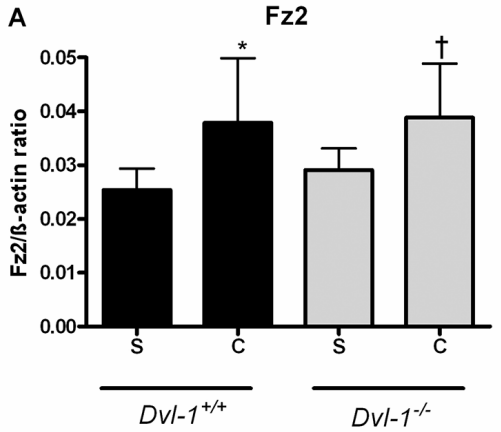

C

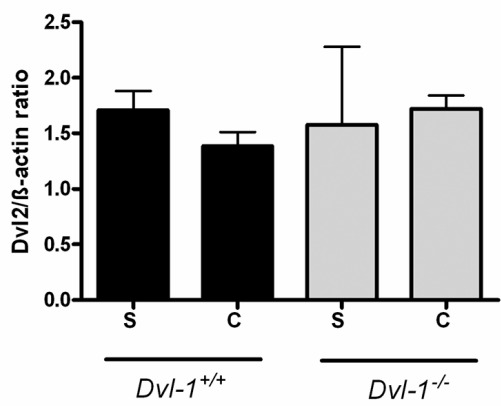

B

Dvl-1

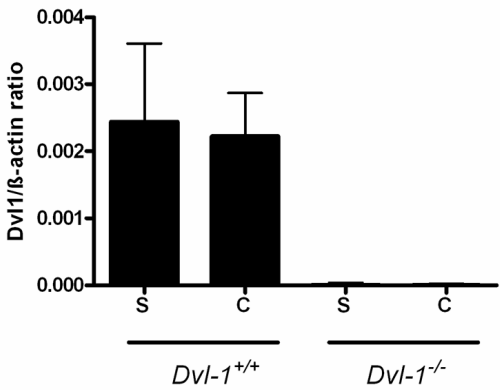

D

Dvl-3

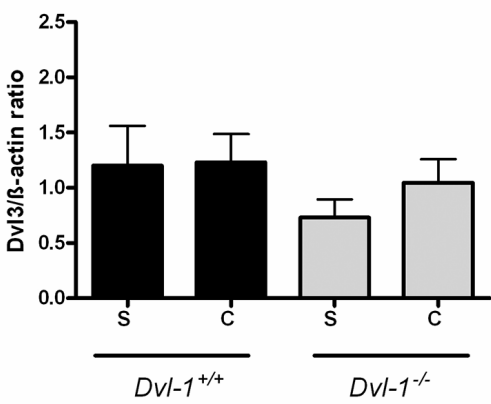

Figure 2. Expression of frizzled-2 (Fz2, A) and the three isoforms of dishevelled, Dvl-1 (B), -2 (C) and -3 (D), after 7 days of TAC and sham operated animals, normalized to $\beta$-actin expression. For abbreviations and symbols, see legend to Figure 1; All n=5-6.

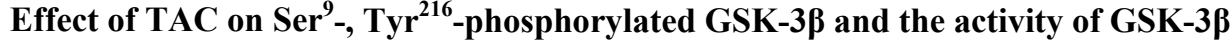

Because GSK-3 $\beta$ is considered to control $\beta$-catenin protein degradation, we analyzed the amounts of total GSK-3 $\beta$, as well as its inactive Ser $^{9}$-phosphorylated (pSer ${ }^{9}$-GSK$3 \beta)$ and active $\mathrm{Tyr}^{216}$ - phosphorylated ( $\mathrm{T}^{2} \mathrm{r}^{216}$-GSK-3 $\beta$ ) form by Western blotting. As shown in Fig. 3B, the pSer ${ }^{9}-$ GSK-3 $3 /$ total GSK-3 $\beta$ ratio was not significantly different in sham-operated $D v l-1^{-/}$and $D v l-1^{+/+}$LVs. At day 7 after TAC, the pSer ${ }^{9}$ GSK$3 \beta /$ total GSK-3 $\beta$ ratio tended to increase in both groups, although no statistical significance was reached. In contrast, TAC induced a significant increase in the pTyr ${ }^{216}$-GSK-3 $\beta /$ total GSK-3 $\beta$ ratio in $D v l-1^{-/-}$LVs, but had no effect in the $D v l-1^{+/+}$ LVs (Fig. 3C). As shown in Fig. 3D, GSK-3 $\beta$ activity was significantly upregulated in 
$D v l-1^{-/}$LVs after TAC, whereas in $D v l-1^{+/+}$LVs no significant effect of TAC on GSK$3 \beta$ activity was observed. Moreover, in the sham-operated $D v l-1^{-/-}$mice the base-line activity of GSK-3 $\beta$ was significantly lower than in the sham-operated $D v l-1^{+/+}$mice.

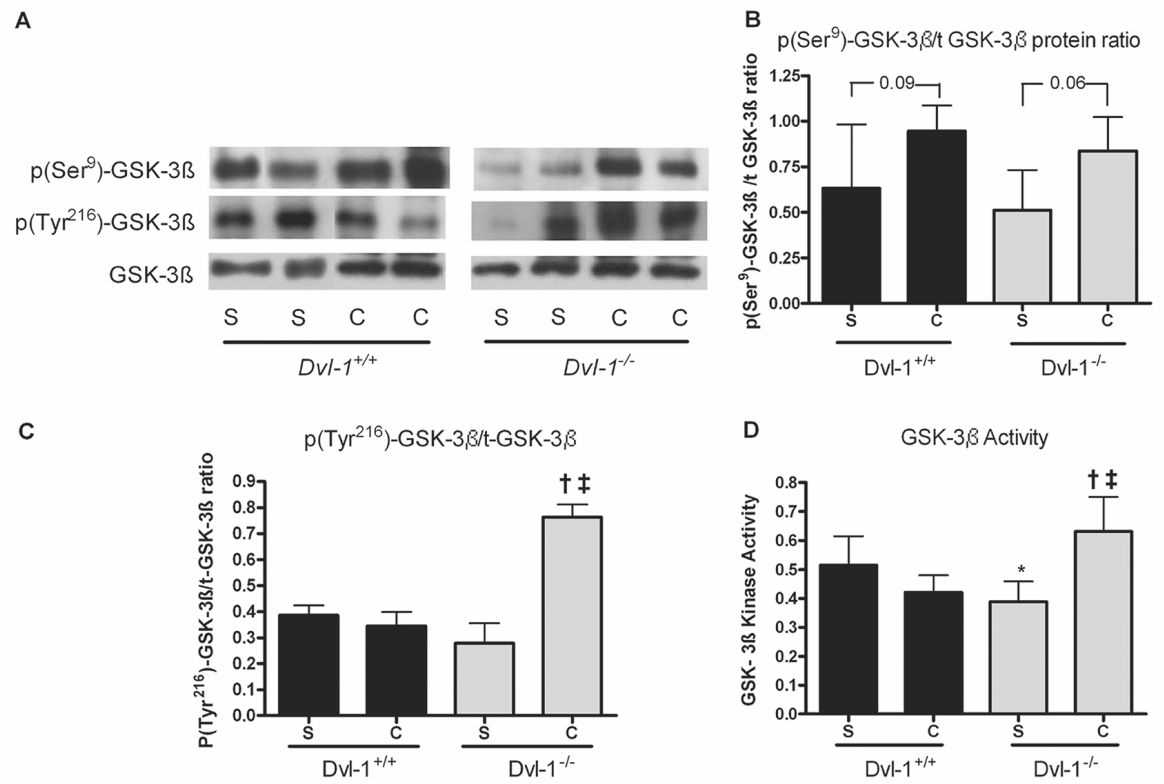

Figure 3. GSK-3 $\beta$ activity as determined by Western Blotting and Kinase Assay at 7 days after TAC. A: Representative Western blots of pSer ${ }^{9}$ GSK-3 $\beta$ (inactive form), pTyr $^{216}$-GSK-3 $\beta$ (active form) and total GSK-3 $\beta$ protein expression. Densitometric analysis of the $\mathrm{pSer}^{9}-\mathrm{GSK}-3 \beta(\mathbf{B})$ and $\mathrm{pTyr}^{216}-\mathrm{GSK}-3 \beta$ protein $(\mathbf{C})$, expressed relative to total (t) GSK-3 $\beta$ protein. D: GSK-3 $\beta$ kinase activity assay showed a significantly lower activity in shamoperated $D v l-1^{-/}$compared to $D v l-1^{+/+}$mice, and a significant increase upon 7 days of TAC exclusively in the $D v l-I^{-}$ ${ }^{-}$mice. For abbreviations and symbols, see legend to Figure 1; All $\mathrm{n}=5-6$.

\section{Reduced amounts of $\beta$-catenin protein in Dvl- ${ }^{-/-} \mathrm{LV}$ after pressure overload}

Next, we examined the expression of $\beta$-catenin by Real-Time PCR (Fig. 4A) and Western Blotting (Fig. 4B and 4C). The amount of $\beta$-catenin transcripts did not differ significantly between the LVs of sham-operated $D v l-1^{-/}$and $D v l-1^{+/+}$mice. Seven days after TAC, a significant decrease in the amount of $\beta$-catenin transcripts was observed in the $\mathrm{D} v \mathrm{l}-\mathrm{I}^{+/+}$group but not in the $\mathrm{D} v \mathrm{l}-\mathrm{I}^{-/}$group (Fig. 4A). In Fig. 4B, representative examples of $\beta$-catenin Western Blots are shown. A quantitative analysis of the amounts of $\beta$-catenin protein, normalized to $\alpha$-tubulin, is shown in Fig. $4 \mathrm{C}$. 
A

B-catenin mRNA expression

B

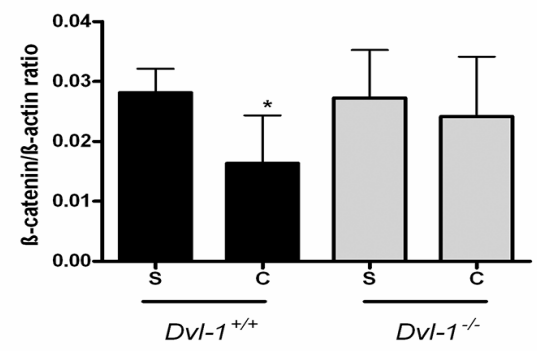

$D V l-1^{+/+}$

B-catenin

$\alpha$-tubulin

$D v 1-1^{-1-}$

B-catenin

$\alpha$-tubulin

C

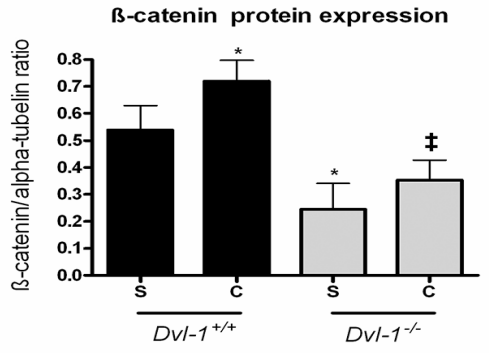

Figure 4. Expression of $\beta$-catenin, determined by real-time PCR (A) and Western blotting $(\mathbf{B}, \mathbf{C})$ at 7 days after TAC. A: TAC induced a significant reduction in $\beta$-catenin mRNA transcripts in $D v l-1^{+/+}$, but not in $D v l-H^{-\alpha}$ mice. B: Representative Western blots of the $\beta$-catenin and $\alpha$-tubulin expression. C: Quantification of the Western blot signals, expressed as $\beta$-catenin $/ \alpha-$ tubulin ratios. The amount of $\beta$-catenin was lower in the sham-operated $\mathrm{Dvl}-\mathrm{T}^{-/}$ compared to $\mathrm{Dvl}-\mathrm{I}^{+/+}$mice, consistent with an interruption of the Wnt/Fz pathway in the $\mathrm{Dvl}-\mathrm{I}^{-/}$mice. TAC resulted in a significant increase in $\beta$-catenin protein only in the $\mathrm{Dvl}$ $I^{+/+}$mice. For abbreviations and symbols, see legend to Figure 1; All $\mathrm{n}=5-6$.

In sham-operated animals, we observed reduced levels of $\beta$-catenin protein in $D v l-1^{-/}$ LVs compared to the LVs of $D v l-1^{+/+}$littermates. After 7 days of TAC, the amount of $\beta$-catenin protein increased significantly in the $D v l-1^{+/+}$group, but not in the $D v l-1^{-/}$ group. We extended our study to TAC-induced changes in the expression of $\beta$-catenin target genes. After TAC, the c-myc and c-fos showed a tendency to increase, in contrast, c-jun and c-fos expression was downregulated after TAC (Figure III, available online) 
Dvl-1 inactivation reduced the amount of $\mathrm{Ser}^{473}$ - phosphorylated Akt.

Akt is one of the kinases that act as upstream regulators of GSK-3 $\beta^{5}$. However, Akt can stimulate the hypertrophic response through other mechanisms too ${ }^{3}$. Phosphorylation of Akt at $\mathrm{Ser}^{473}$ results in its activation. The amount of active $\mathrm{p}-\mathrm{Ser}^{473}$ Akt was studied by Western Blotting with a phospho-specific antibody (Fig 5B). No significant difference was observed in the $\mathrm{pSer}^{473}$-Akt/total Akt ratio between the LVs of sham-operated $\mathrm{Dvl}$ $1^{-/}$and $D v l-1^{+/+}$mice. After induction of hypertrophy, however, the ratio of $\mathrm{pSer}^{473}$ Akt /total Akt was significantly more increased in $D v l-1^{+/+} \mathrm{LVs}$ compared to $D v l-1^{-/-}$ LVs. This suggests that Dvl-1 plays a role in the activation of Akt by pressure overload.

A

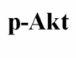

t-Akt
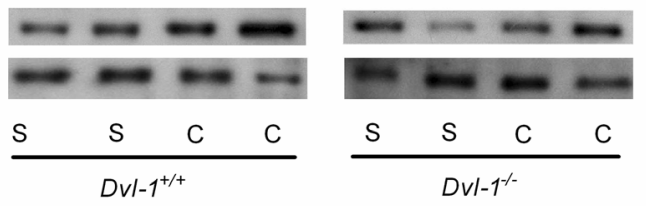

B

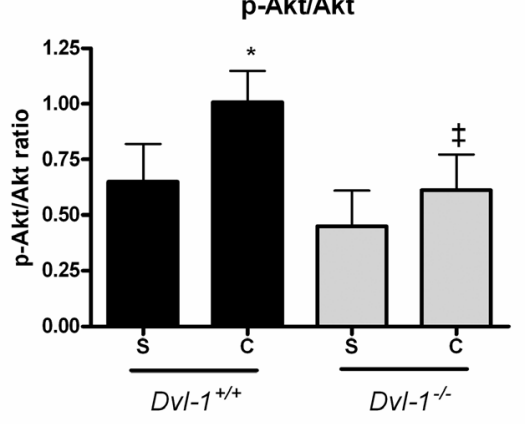

Figure 5. Western blot analysis of Akt and its active form, phospho$\mathrm{Ser}^{473} \mathrm{Akt}$, in sham-operated animals and after 7 days of TAC. A: Representative Western blots of total Akt and $\mathrm{pSer}^{473}$-Akt protein expression. B: Densitometric analysis of $\mathrm{pSer}^{473}$-Akt and $\mathrm{Akt}$ blots. The $\mathrm{pSer}^{473}$-Akt /total Akt ratio is shown. For abbreviations and symbols, see legend to Figure 1; All $n=5-6$.

\section{Discussion}

In the present study, we investigated the effect of the deletion of the Dvl-1 gene on the development of pressure-overload-induced cardiac hypertrophy in mice. We observed an attenuated onset of cardiac hypertrophy in the Dvl- $1^{-/ 2}$ mice, which was sustained for up to 35 days. 
Proteins from the Dvl family play a key role in the Wnt/Fz signaling pathway ${ }^{22}$. In the present study, expression of all three isoforms of the Dvl protein was observed in the mouse LV. Pressure overload did not induce a significant change in the amount of transcripts of any of the three Dvl isoforms. Moreover, the inactivation of the Dvl-1 gene did not result in a compensatory upregulation of the expression of Dvl-2 or-3 in the Dvl-1 ${ }^{-/-}$LVs. The upregulation of the Fz2 expression in the TAC mice confirms a previous observation from our laboratory, in which the upregulation of the Fz2 expression was observed after thoracic aortic banding in the rat $^{21}$.

GSK-3 $\beta$ is a downstream component of the $\mathrm{Wnt} / \mathrm{Fz}$ pathway ${ }^{15}$, but has also been recognized as a negative regulator of cardiac hypertrophy ${ }^{4}$. For the inhibition of GSK$3 \beta$ activity, two mechanisms have been described: The first mechanism is the phosphorylation of GSK-3 $\beta$ at the Ser ${ }^{9}$ residue by protein kinases such as Akt, as in the signaling pathway of insulin ${ }^{6}$. In the present study, we have determined the effect of TAC on the pSer $^{9}-\mathrm{GSK}-3 \beta /$ total GSK-3 $\beta$ ratio and observed a similar trend towards increase in both groups, despite significantly higher levels of $\mathrm{pSer}^{473}-\mathrm{Akt}$, the active form of $\mathrm{Akt}^{23}$, in the $\mathrm{Dvl}-1^{+/+}$group. This suggests that the Akt-mediated $\mathrm{Ser}^{9}$ phosphorylation of GSK-3 $\beta$ is of minor importance for the hypertrophic response after 7 days of TAC. This observation is in agreement with a study by Haq et al. ${ }^{24}$, in which Akt-induced Ser ${ }^{9}$-phosphorylation of GSK-3 $\beta$ was shown to peak at 3 days after TAC, but returned to baseline levels at 7 days after TAC in the rat.

The second mechanism of GSK-3 $\beta$ inhibition consists of a destabilization of the socalled $\beta$-catenin destruction complex, which consists of many proteins including Axin, the Adenomatous Polyposis Coli protein and GSK-3 $\beta$. Upon Wnt signaling the activated Dvl protein can bind to this complex, which results in a decreased GSK-3 $\beta$ activity ${ }^{17}$. The molecular details of this type of GSK-3 $\beta$ inhibition are poorly understood, but this mechanism is generally considered to form the link between $\mathrm{Wnt} / \mathrm{Fz}$ activation and the decreased $\beta$-catenin degradation in the canonical Wnt 
pathway $^{18,25}$. In the present study, we observed an increased GSK-3 $\beta$ kinase activity in $D v l-1^{-/}$mice following TAC. This was paralleled by an elevated amount of $\mathrm{pTyr}^{216}$ GSK-3 $\beta$, the active form of GSK-3 $\beta$, in this group. The elevated GSK-3 $\beta$ activity leads to an increased degradation of $\beta$-catenin, which explains the lower $\beta$-catenin protein levels in the $D v l-1^{-/}$TAC group compared to wildtype littermates. Our results underscore the concept that $\beta$-catenin levels are regulated at the protein level rather than through control of its transcription ${ }^{26}$, because no correlation between $\beta$-catenin transcript numbers and protein levels was observed.

Stabilization of $\beta$-catenin has been shown to be necessary and sufficient for the hypertrophic response of cardiomyocytes, both in vitro and in vivo ${ }^{24}$. The correlation between hypertrophic response and $\beta$-catenin protein levels could be confirmed in the present study. However, in this study hypertrophic stimuli that inactivated GSK$3 \beta$ through Ser $^{9}$ phosphorylation mediated by Akt (protein kinase B) were used ${ }^{24}$. From the present study, we conclude that the $\mathrm{Wnt} / \mathrm{Fz}$ pathway also plays a role in the control of GSK-3 $\beta$ kinase activity and in the stabilization of $\beta$-catenin in the hypertrophic response. Taken together, the two studies underscore the importance of GSK-3 $\beta$ activity in the regulation of cardiac hypertrophy, despite different underlying regulatory mechanisms.

As a next step, the transcription of the proto-oncogenes c-myc, c-fos and c-jun as well as cyclin D1, known to be controlled by $\beta$-catenin ${ }^{27-30}$, was analyzed. No consistent pattern of regulation was observed for these genes. An explanation for this may be that the time point ( 7 days after TAC) is quite late to detect the expression of protooncogenes, which are typically upregulated within several hours after the onset of a hypertrophic stimulus ${ }^{31,32}$. However, an alternative explanation may be that the increased GSK-3 $\beta$ activity in the $D v l-1^{-/}$LV exerts its anti-hypertrophic effect through other mediators than $\beta$-catenin. As shown in Fig. 6, several mediators involved in the regulation of the hypertrophic response have been reported to be phosphorylated by 
GSK-3 $\beta$, including GATA $4^{14}$, nuclear factor of activated T-cells (NFAT) ${ }^{33}$ and eukaryotic translation initiation factor $2 \mathrm{~B} \varepsilon(\mathrm{eIF} 2 \mathrm{~B} \varepsilon)^{34}$. Although the contribution of these mediators to the inhibition of the hypertrophic response observed in the $\mathrm{Dvl}-\mathrm{I}^{-/}$ mice is beyond the scope of this study, it further underscores the importance of GSK$3 \beta$ as a negative regulator of the hypertrophic response.

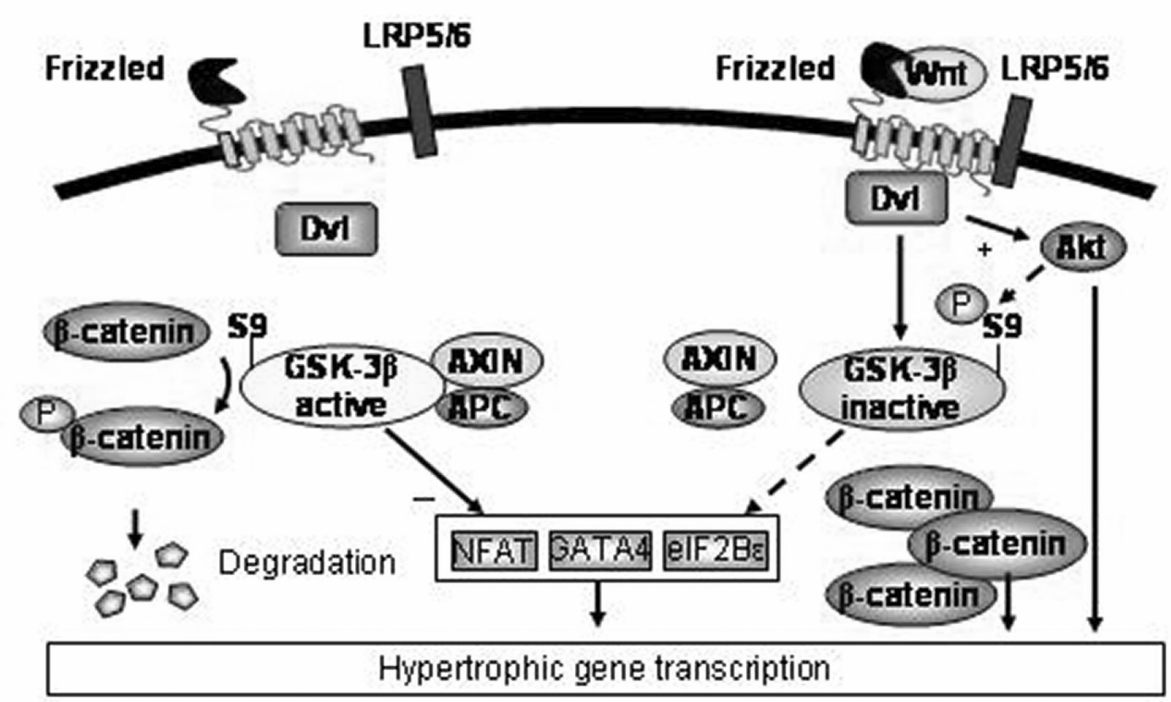

Figure 6. Schematic representation of the effect of activation of the $\mathrm{Wnt} / \mathrm{Fz}$ pathway on the expression of hypertrophy-associated genes. The effects of inactive (left part) and activated (right part) Wnt/Fz signaling are depicted. In the absence of Wnt stimulation, the level of free cytosolic $\beta$-catenin is kept low by GSK-3 $\beta$ phosphorylating $\beta$-catenin on serine and threonine residues at the amino-terminal region, thereby targeting it for ubiquitination and degradation in proteasomes. The phosphorylation of $\beta$-catenin by GSK-3 $\beta$ occurs in a complex with Axin, adenomatous polyposis coli (APC) protein and several other proteins (not shown), where Axin is a scaffold protein that increases the efficiency and the specificity of the $\beta$-catenin phosphorylation. Apart from $\beta$ catenin, other hypertrophy-associated targets, like nuclear factor of activated T-cells (NFAT), GATA4 and eukaryotic translation initiation factor $2 \mathrm{~B} \varepsilon(\mathrm{eIF} 2 \mathrm{~B} \varepsilon)$, can be phosphorylated and inactivated by GSK-3 $\beta$. In the right part of the scheme, the effect of activation of a Frizzled (Fz) 7 transmembrane receptor by a Wnt ligand is shown. In a complex with LRP 5 or 6, this leads to the activation of Dishevelled (Dvl). The activated Dvl protein inhibits the GSK-3 $\beta$ activity by two distinct mechanisms: first it changes the conformation and promotes the dissociation of the GSK-3ß/APC/Axin complex and second, it may increase Akt activity, resulting in phosphorylation of the Ser $^{9}$ residue of GSK-3 $\beta$. The inhibition of GSK-3 $\beta$ leads to stabilization and accumulation of $\beta$-catenin in the cytoplasm. $\beta$-Catenin can shuttle to the nucleus were it interacts with a transcription factor complex of the $\mathrm{T}$ cell factor/lymphoid enhancer factor (TCF/Lef) family. This can induce the transcription of genes involved in the hypertrophic response. Moreover, activated Akt by itself can also induce hypertrophic gene transcription and inactive GSK-3 $\beta$ no longer inhibits the hypertrophy-associated proteins NFAT, GATA4 and eIF2B $\varepsilon$, providing activation of diverse pro-hypertrophic pathways. 
In the present study, the fraction of activated, phosphorylated Akt was increased in the LVs of the $D v l-1^{+/+}$, but not the $D v l-1^{-/}$mice, after 7 days of TAC. Apart from its role in the phosphorylation of GSK-3 $\beta$ at the $\operatorname{Ser}^{9}$ residue, Akt itself has been shown to be a modulator of the hypertrophic response as part of the IGF-1 signaling pathway ${ }^{23}$. Interestingly, overexpression of Dvl-1 has been shown to increase the amount of activated Akt in vitro ${ }^{35}$. This suggests a direct link between the Wnt/Fz pathway and Akt activation, which may explain the attenuated activation of Akt in the hearts of the Dvl-1 $1^{-/}$mice (see Fig. 6).

\section{Perspective}

This study shows that interruption of Wnt signaling through disruption of the Dvl-1 gene can attenuate the onset of pressure overload-induced cardiac hypertrophy by a mechanism involving both GSK-3 $\beta$ and Akt. These observations open a new therapeutic perspective for intervention in the hypertrophic process: rather than inhibiting pro-hypertrophic pathways, as is today's clinical practice, augmenting the activity of endogenous negative regulators of hypertrophy like GSK-3 $\beta$ may open new avenues to control the hypertrophic process. The $\mathrm{Wnt} / \mathrm{Fz}$ pathway may provide novel therapeutic targets for which a new class of anti-hypertrophic drugs can be designed. 


\section{References}

1. Schluter, KD, Wollert, KC. Synchronization and integration of multiple hypertrophic pathways in the heart. Cardiovasc Res. 2004;63:367-372.

2. Levy, D, Garrison, RJ, Savage, DD, Kannel, WB, Castelli, WP. Prognostic implications of echocardiographically determined left ventricular mass in the Framingham Heart Study. $N$ Engl J Med. 1990;322:1561-1566.

3. Molkentin, JD, Dorn, IG, 2nd. Cytoplasmic signaling pathways that regulate cardiac hypertrophy. Annu Rev Physiol. 2001;63:391-426.

4. Hardt, SE, Sadoshima, J. Negative regulators of cardiac hypertrophy. Cardiovasc Res. 2004;63:500-509.

5. Hardt, SE, Sadoshima, J. Glycogen synthase kinase-3beta: a novel regulator of cardiac hypertrophy and development. Circ Res. 2002;90:1055-1063.

6. Cohen, P, Frame, S. The renaissance of GSK3. Nat Rev Mol Cell Biol. 2001;2:769-776.

7. Doble, BW, Woodgett, JR. GSK-3: tricks of the trade for a multi-tasking kinase. J Cell Sci. 2003;116:1175-1186.

8. Haq, S, Choukroun, G, Lim, H, Tymitz, KM, del Monte, F, Gwathmey, J, Grazette, L, Michael, A, Hajjar, R, Force, T, Molkentin, JD. Differential activation of signal transduction pathways in human hearts with hypertrophy versus advanced heart failure. Circulation. 2001;103:670-677.

9. Haq, S, Choukroun, G, Kang, ZB, Ranu, H, Matsui, T, Rosenzweig, A, Molkentin, JD, Alessandrini, A, Woodgett, J, Hajjar, R, Michael, A, Force, T. Glycogen synthase kinase-3beta is a negative regulator of cardiomyocyte hypertrophy. J Cell Biol. 2000;151:117-130.

10. Badorff, C, Ruetten, H, Mueller, S, Stahmer, M, Gehring, D, Jung, F, Ihling, C, Zeiher, AM, Dimmeler, S. Fas receptor signaling inhibits glycogen synthase kinase 3 beta and induces cardiac hypertrophy following pressure overload. J Clin Invest. 2002;109:373-381.

11. Antos, CL, McKinsey, TA, Frey, N, Kutschke, W, McAnally, J, Shelton, JM, Richardson, JA, Hill, JA, Olson, EN. Activated glycogen synthase-3 beta suppresses cardiac hypertrophy in vivo. Proc Natl Acad Sci U S A. 2002;99:907-912.

12. Seimi, SK, Seinosuke, K, Tsuyoshi, S, Tomomi, U, Tetsuaki, H, Miki, K, Ryuji, T, Kenji, I, Mitsuhiro, Y. Glycogen synthase kinase-3beta is involved in the process of myocardial hypertrophy stimulated by insulin-like growth factor-1. Circ J. 2004;68:247-253.

13. Morisco, C, Zebrowski, D, Condorelli, G, Tsichlis, P, Vatner, SF, Sadoshima, J. The Akt-glycogen synthase kinase 3beta pathway regulates transcription of atrial natriuretic factor induced by betaadrenergic receptor stimulation in cardiac myocytes. J Biol Chem. 2000;275:14466-14475.

14. Morisco, C, Seta, K, Hardt, SE, Lee, Y, Vatner, SF, Sadoshima, J. Glycogen synthase kinase 3beta regulates GATA4 in cardiac myocytes. J Biol Chem. 2001;276:28586-28597.

15. Dale, TC. Signal transduction by the Wnt family of ligands. Biochem J. 1998;329 ( Pt 2):209-223.

16. Nelson, WJ, Nusse, R. Convergence of Wnt, beta-catenin, and cadherin pathways. Science. 2004;303:1483-1487.

17. Kikuchi, A. Regulation of beta-catenin signaling in the Wnt pathway. Biochem Biophys Res Commun. 2000;268:243-248.

18. Dominguez, I, Green, JB. Missing links in GSK3 regulation. Dev Biol. 2001;235:303-313.

19. Lijam, N, Paylor, R, McDonald, MP, Crawley, JN, Deng, CX, Herrup, K, Stevens, KE, Maccaferri, G, McBain, CJ, Sussman, DJ, Wynshaw-Boris, A. Social interaction and sensorimotor gating abnormalities in mice lacking Dvl1. Cell. 1997;90:895-905.

20. van Eickels, M, Grohe, C, Cleutjens, JP, Janssen, BJ, Wellens, HJ, Doevendans, PA. 17beta-estradiol attenuates the development of pressure-overload hypertrophy. Circulation. 2001;104:1419-1423.

21. Blankesteijn, WM, Essers-Janssen, YP, Ulrich, MM, Smits, JF. Increased expression of a homologue of drosophila tissue polarity gene "frizzled" in left ventricular hypertrophy in the rat, as identified by subtractive hybridization. J Mol Cell Cardiol. 1996;28:1187-1191.

22. Wharton, KA, Jr. Runnin' with the Dvl: proteins that associate with Dsh/Dvl and their significance to Wnt signal transduction. Dev Biol. 2003;253:1-17. 
23. Ceci, M, Ross, J, Jr., Condorelli, G. Molecular determinants of the physiological adaptation to stress in the cardiomyocyte: a focus on AKT. J Mol Cell Cardiol. 2004;37:905-912.

24. Haq, S, Michael, A, Andreucci, M, Bhattacharya, K, Dotto, P, Walters, B, Woodgett, J, Kilter, H, Force, T. Stabilization of beta-catenin by a Wnt-independent mechanism regulates cardiomyocyte growth. Proc Natl Acad Sci U S A. 2003;100:4610-4615.

25. McManus, EJ, Sakamoto, K, Armit, LJ, Ronaldson, L, Shpiro, N, Marquez, R, Alessi, DR. Role that phosphorylation of GSK3 plays in insulin and Wnt signalling defined by knockin analysis. Embo J. 2005;24:1571-1583.

26. Rezvani, M, Liew, CC. Role of the adenomatous polyposis coli gene product in human cardiac development and disease. J Biol Chem. 2000;275:18470-18475.

27. Wong, NA, Pignatelli, M. Beta-catenin--a linchpin in colorectal carcinogenesis? Am J Pathol. 2002;160:389-401.

28. Anna, CH, Iida, M, Sills, RC, Devereux, TR. Expression of potential beta-catenin targets, cyclin D1, cJun, c-Myc, E-cadherin, and EGFR in chemically induced hepatocellular neoplasms from B6C3F1 mice. Toxicol Appl Pharmacol. 2003;190:135-145.

29. Tetsu, O, McCormick, F. Beta-catenin regulates expression of cyclin D1 in colon carcinoma cells. Nature. 1999;398:422-426.

30. Mann, B, Gelos, M, Siedow, A, Hanski, ML, Gratchev, A, Ilyas, M, Bodmer, WF, Moyer, MP, Riecken, EO, Buhr, HJ, Hanski, C. Target genes of beta-catenin-T cell-factor/lymphoid-enhancer-factor signaling in human colorectal carcinomas. Proc Natl Acad Sci U S A. 1999;96:1603-1608.

31. Boheler, KR, Schwartz, K. Gene expression in cardiac hypertrophy. Trends Cardiovasc Med. 1992;2:176-182.

32. Chien, KR, Zhu, H, Knowlton, KU, Miller-Hance, W, van-Bilsen, M, O'Brien, TX, Evans, SM. Transcriptional regulation during cardiac growth and development. Annu Rev Physiol. 1993;55:77-95.

33. Fiedler, B, Wollert, KC. Interference of antihypertrophic molecules and signaling pathways with the Ca2+-calcineurin-NFAT cascade in cardiac myocytes. Cardiovasc Res. 2004;63:450-457.

34. Hardt, SE, Tomita, H, Katus, HA, Sadoshima, J. Phosphorylation of eukaryotic translation initiation factor 2Bepsilon by glycogen synthase kinase-3beta regulates beta-adrenergic cardiac myocyte hypertrophy. Circ Res. 2004;94:926-935.

35. Fukumoto, S, Hsieh, CM, Maemura, K, Layne, MD, Yet, SF, Lee, KH, Matsui, T, Rosenzweig, A, Taylor, WG, Rubin, JS, Perrella, MA, Lee, ME. Akt participation in the Wnt signaling pathway through Dishevelled. J Biol Chem. 2001;276:17479-17483.

\section{Data supplement}

\section{Supplemental Figure and Legend}

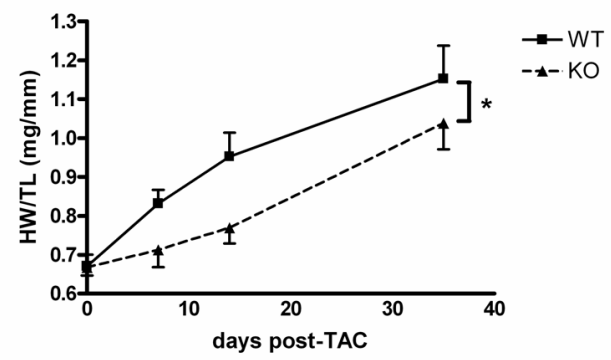

Online figure I. Time course of the development of cardiac hypertrophy in $\mathrm{Dvl}-\mathrm{I}^{+/+}$(continuous line) and $\mathrm{Dvl}-\mathrm{I}^{-/-}$ (Dashed line) mice. Two-way ANOVA analysis showed a significant difference in hypertrophy development for both time and genotype. ${ }^{*} \mathrm{P}<0.05$ 


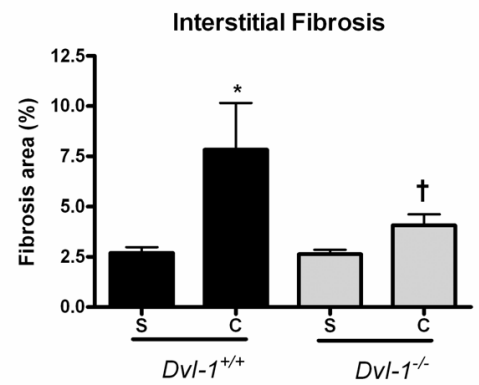

Online figure II. Interstitial collagen volume calculated in picrosirius red-stained cross-sections of the left ventricle in both $\mathrm{Dvl}-\mathrm{I}^{+/+}$and $\mathrm{Dvl}-\mathrm{I}^{-/}$mice after sham and 7 days after TAC. Quantitative analysis of the collagen deposition revealed that the fibrosis was significantly higher in $D v l-1^{+/+}$and $D v l-1^{-/}$TAC operated mice compared with shamoperated animals. $\mathrm{S}=$ Sham, $\mathrm{C}=\mathrm{TAC} .{ }^{*} \mathrm{P}<0.05$ vs. sham $D v l-1^{+/+} ; \dagger \mathrm{P}<0.05$ vs. sham $D v l-1^{-/} ; \ddagger \mathrm{P}<0.05$ vs. $D v l-$ $1^{+/+}, 7$ days after TAC; All $\mathrm{n}=5-6$.

A

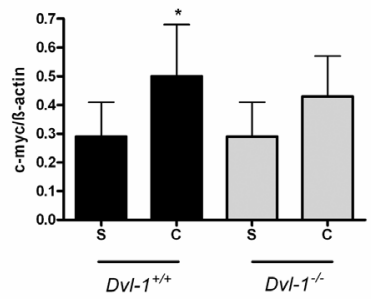

C

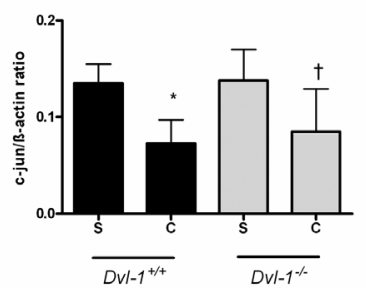

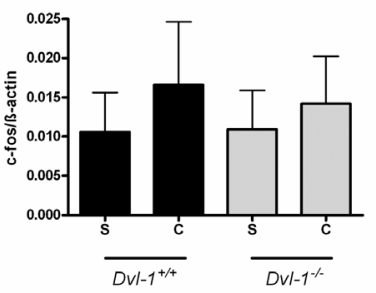

D

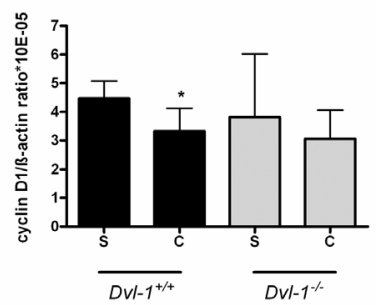

Online Figure III. Expression of the proto-oncogenes c-myc (A), c-fos (B) and c-jun (C) and cyclin D1 (D) at 7 days after TAC, determined by Real-Time PCR. Because stabilized cytosolic $\beta$-catenin is able to translocate to the nucleus and to initiate the transcription of target genes, like c-myc, c-fos, c-jun and cyclin D1, we extended our study to TAC-induced changes in the expression of $\beta$-catenin target genes. For c-myc and c-fos, TAC induced a trend towards an increased expression, which reached statistical significance for c-myc in the Dvl-1+/+ mice. Both c-jun and cyclin D1 showed a decreased expression after TAC in both Dvl-1+/+ and Dvl-1-/- mice (c-jun) and in Dvl-1+/+ mice (cyclin D1). S= Sham, C=TAC. * $\mathrm{P}<0.05$ vs. sham Dvl- $1+/+; \uparrow \mathrm{P}<0.05$ vs. sham Dvl-1-/-; $\uparrow \mathrm{P}<0.05$ vs. Dvl-1+/+, 7 days after TAC; All $\mathrm{n}=5-6$. 


\section{Appendix}

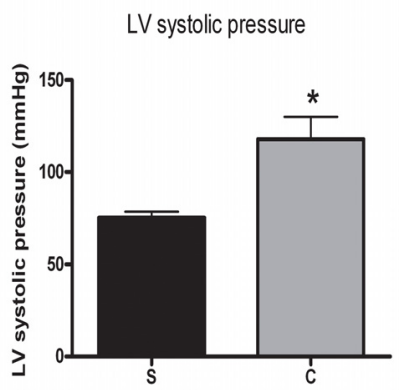

Measurement of the Left Ventricular (LV) systolic pressure 129/S6 mice at 7 days after TAC (C) or sham operation (S). Left ventricular systolic pressure was $\sim 40 \%$ higher in the TAC than in the sham group $(* \mathrm{P}<0.05, \mathrm{n}=6)$

\section{Methods expanded}

Animals: $D v l-1^{-/}$mice, generated as previously described ${ }^{1}$, were inbred ( $>10$ generations) into a 129/S6 background. These mice are viable, fertile and structurally normal, but show a reduced social interaction, abnormal sensorimotor gating and an atypical sleeping pattern. The wildtype littermates $\left(D v l-1^{+/+}\right)$were used as controls. Animals of both sexes were used at an age of 10-12 weeks and a body weight of 18-28 g; they had free access to standard food and tap water. Genotypes were identified by PCR of genomic tail DNA. All experimental procedures were approved by the Committee for Animal Research of Maastricht University and were in accordance with the guide for care and use of laboratory animals, the published by the National Institutes of Health (NIH) Guide for the Care and Use of Laboratory Animals.

Thoracic aortic constriction (TAC) model: $D v l-1^{-/}$and littermate $D v l-1^{+/+}$mice were randomly distributed over the TAC-group and sham-operated control group. Animals were anesthetized by intramuscular injection with ketamine (100 mg/kg body weight) and subcutaneous injection with xylazine $(10 \mathrm{mg} / \mathrm{kg}$ body weight), and TAC was induced as described previously ${ }^{2}$ and connected to a volume-cycled rodent ventilator (Hugo Sachs Electronik rodent ventilator type 845; March-Hugstetten, Germany) after endotracheal intubation. Body temperature was maintained at $37^{\circ} \mathrm{C}$ throughout the experiment using a heating pad. Anaesthesia was maintained with $1.5-2.5 \%$ isoflurane. The chest cavity was entered at the second intercostal space at the left upper sternal border through a small incision. The thymus was gently deflected out of the field of view to expose the aortic arch. The thoracic aorta was constricted between the carotid arteries by a 7-0 silk suture ligature tied firmly against a 27-gauge needle. The latter was promptly removed to yield a constriction of 0.4 $\mathrm{mm}$ in diameter. Sham operated mice underwent a similar surgical procedure without constriction of the aorta. The chest was closed with a 5-0 silk suture, and mice were allowed to recover from anaesthesia with 
supplemental heat to keep the body temperature at $37{ }^{\circ} \mathrm{C}$. For the effect of TAC on the intraventricular systolic blood pressure see Appendix.

Two-dimensional guided M-mode echocardiography. Animals were anaesthetized with an intramuscular injection of ketamine $(100 \mathrm{mg} / \mathrm{kg})$ and subcutaneous injection of xylazine $(5 \mathrm{mg} / \mathrm{kg})$, the anterior chest was shaved, the mice were mechanically ventilated (Hugo Sachs Electronik), body temperature was maintained at $37^{\circ} \mathrm{C}$ throughout the experiment using a heating pad and prewarmed ultrasonic gel was applied. Twodimensional (2D) guided M-mode echocardiography in the mouse was performed using a 20-MHz probe connected to an AU4 Idea device (Esaote Biomedica, Firenze, Italy). The heart was imaged in the 2D mode in the short-axis view. From the M-mode echocardiogram, the thickness of the left ventricular posterior wall (LVPW) in systole and diastole was measured.

Histological analysis. Hearts from $\mathrm{Dvl}-\mathrm{I}^{-/}$and littermate $\mathrm{Dvl}-\mathrm{I}^{+/+}$mice were arrested in diastole by perfusion with a saturated $\mathrm{KCl}$-solution in PBS for $3 \mathrm{~min}$., cut longitudinally, fixed in $1 \%$ paraformaldehyde, and embedded in paraffin. Four $\mu \mathrm{m}$ sections were cut and stained with haematoxylin and eosin (H\&E) for myocyte cross-sectional area or picrosirius red to identify interstitial fibrosis. Myocyte cross-sectional areas were measured from hearts of sham and TAC operated $D v l-I^{-/}$and $D v l-I^{+/+}$animals using a computerized morphometric system (version Leica Qwin3.1; Leica, Cambridge, England). All sections were measured at the same magnification (20X) in 5 different areas of the left ventricle of the heart. Myocyte cross-sectional area was measured per nucleus; the outline of 100-200 myocytes was traced in each section. The picroserius red-stained slides were scanned and quantitative evaluation was performed at 3 different sections in the left ventricle by using a computerized morphometric system (version Leica Qwin3.1; Leica, England). Percentage of collagen was determined in the left ventricle, the ratio of positive Sirius red-stained area to LV area was calculated. An examiner blinded to the genotype of the animals obtained all measurements.

Real-Time PCR. Left ventricular tissue was homogenized with a PRO200 tissue homogenizer (PRO Scientific, Monroe CT, USA) and isolated by using Ultraspec ${ }^{\mathrm{TM}}$-II RNA isolation system (BioTecx Laboratories, Houston TX, USA) according to the manufacturer's instructions. RNA was further purified by DNase digestion using the DNA-Free RNA kit ${ }^{\mathrm{TM}}$ (Zymo Research, Orange CA, USA) to remove genomic DNA. First strand cDNA was synthesized by adding $100 \mathrm{ng}$ of DNase-treated total RNA to Ready-To-Go You Prime First-Strand Beads (Amersham Biosciences Europe, Freiburg, Germany). Random hexamers were used as primers. The reactions were incubated at $65^{\circ} \mathrm{C}$ for 10 minutes, at $37^{\circ} \mathrm{C}$ for 1 hour and at $95^{\circ} \mathrm{C}$ for 2 minutes. The resulting cDNA was either immediately used as template for Real-Time PCR or stored at $-20{ }^{\circ} \mathrm{C}$. Real-Time PCR primers were chosen with the assistance of the computer program Primer Express software (version 1.5; Applied Biosystems, Foster City CA, USA) based on known mouse sequences obtained from Genbank. The designed primers were used to quantify the expression of mRNA levels of atrial natriuretic factor (ANF), brain natriuretic peptide (BNP), $\beta$-catenin, dishevelled-1, -2 and -3 (Dvl-1, -2,-3), Frizzled 2 (Fz2), c-fos, c-myc, c-jun and cyclin D1. On the ABI Prism 7700 Sequence Detection System 
(Applied Biosystems), the expression was determined by measuring the binding of the fluorescence dye SYBR Green I to double stranded cDNA, using SYBRGreen PCR Master Mix kit (Eurogentec, Seraing, Belgium). Cardiac gene expression was normalized to the housekeeping gene $\beta$-actin. All samples were run in duplicate. Data analyses were performed using the Sequence Detection System software (Applied Biosystems). Primer sets for ANF, BNP, Dvl-1, -2 and -3, Fz2, $\beta$-catenin, c-fos, c-myc, c-jun, cyclin D1 and $\beta$-actin are listed in Appendix Table I.

Western immunoblot analyses. Total protein extracts were prepared as follows: left ventricular tissue was put into $1 \mathrm{ml}$ ice-cold Laemmli buffer (6.6\% Glycerol; $1.5 \% \mathrm{SDS} ; 41.5 \mathrm{mM}$ Tris/ $\mathrm{HCl} \mathrm{pH}=8.0)$ and homogenized with a PRO200 tissue homogenizer (PRO Scientific). After sonification and centrifugation, the supernatant was collected and stored at $-80^{\circ} \mathrm{C}$. The protein content of supernatant was measured by using the BCA protein Assay (Pierce biotechnology Inc., Rockford IL, USA). For Western blotting, $20 \mu \mathrm{g}$ of total protein was denatured by boiling in Laemmli sample buffer and separated on a $10 \%$ SDS-PAGE gel, and transferred onto a HybondC nitrocellulose membrane (Amersham Biosciences Europe). Protein loading and transfer were confirmed by Ponceau-S Staining (Sigma, St Louis MO, USA). After blocking in 5\% non-fat dry milk (Biorad, Hercules CA, USA), 0.1\% Tween 20 in Tris-buffered Saline for 1 hour, membranes were incubated overnight with the following primary antibodies at $4^{\circ} \mathrm{C}$ : $\beta$-catenin and GSK-3 $\beta$, (BD Transduction

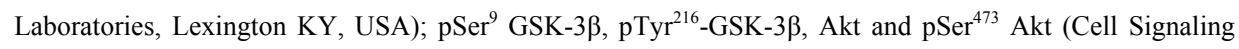
Technology, Beverly MA, USA); $\alpha$-tubulin (Santa Cruz Biotechnology, Santa Cruz CA, USA). Anti-rabbit $\mathrm{IgG}$ and anti-mouse IgG Horseradish Peroxidase-conjugated antibodies (DAKO, Glostrup, Denmark) were used as the secondary antibodies as appropriate and the membranes were developed by Supersignal West Pico chemiluminescence kit (Pierce biotechnology Inc.) for $\beta$-catenin, GSK-3 $\beta$ and Enhanced Chemiluminescence (ECL) Plus Western Blotting Detection System (Amersham Biosciences Europe) for Phospho GSK-3 $\beta$, Akt, p-Akt and $\alpha$-tubulin.

GSK-3ק kinase assay. Total GSK-3 $\beta$ was immunoprecipated from $200 \mu \mathrm{g}$ protein extracts in lysis buffer ( $0.5 \%$ nonidet P-40, $150 \mathrm{mM} \mathrm{NaCl}, 50 \mathrm{mM}$ Tris $\mathrm{pH}$ 7.4, 10\% Glycerol, $1 \mathrm{mM}$ EDTA, $1 \mathrm{mM} \mathrm{Na}_{3} \mathrm{VO}_{4}, 5 \mathrm{mM}$ $\mathrm{NaF}, 1 \mathrm{mM} \beta$-glycerophasphate, $1 \mathrm{mM}$ Na-pyro-phosphate, $1 \mathrm{mM}$ dithiothreitol, $10 \mu \mathrm{g} / \mathrm{ml}$ Leupeptin, $1 \%$ Apropeptin). The samples were precleared with protein G-Sepharose beads (Amersham Biosciences Europe) for 1 hour and then subjected to immunoprecipitation with anti-mouse GSK-3 $\beta$ antibody (BD Transduction Laboratories, USA) overnight at $4{ }^{\circ} \mathrm{C}$ with gentle agitation, than incubated with protein G-Sepharose for 1 hour at $4{ }^{\circ} \mathrm{C}$ with gentle agitation. Immunocomplexes were recovered by centrifugation and washed once with lysis buffer and twice in kinase buffer ( $8 \mathrm{mM} \mathrm{pH} 7.4$ MOPS, $10 \mathrm{mM}$ MgAcetate, $0.2 \mathrm{mM}$ EDTA, $1 \mathrm{mM}$ $\mathrm{Na}_{3} \mathrm{VO}_{4}, 1 \mathrm{mM}$ dithiothreitol, $2.5 \mathrm{mM} \beta$-glycerophasphate, $10 \mu \mathrm{g} / \mathrm{ml}$ Leupeptin, $1 \%$ Apropeptin). Kinase activity was assayed in $40 \mu \mathrm{l}$ of total reaction buffer containing $62.5 \mu \mathrm{M}$ GSK-3 Peptide Substrate (Biomol P-151, Exeter, UK) $20 \mathrm{mM} \mathrm{MgCl} 2,125 \mu \mathrm{M}$ ATP and $10 \mu \mathrm{Ci}\left[\gamma^{3}{ }^{32} \mathrm{P}\right]$ ATP (Amersham Biosciences Europe). After $30 \mathrm{~min}$ of incubation at $30^{\circ} \mathrm{C}, 25 \mu \mathrm{l}$ aliquots were spotted onto $1.5 \mathrm{~cm} \mathrm{X} 1.5 \mathrm{~cm}$ pieces of Whatman 
P81 Phosphocellulose paper (Whatman Nederland B.V., 's Hertogenbosch, Netherlands), and 30 s later, the filter papers were washed 5 times in $0.75 \%$ phosphoric acid. The filter papers were counted in a liquid scintillation counter. Quantification of kinase assay was achieved by counting the amount of ${ }^{32} \mathrm{P}$ incorporated into the substrate.

\section{Reference Methods Expanded}

1. Lijam N, Paylor R, McDonald MP, Crawley JN, Deng CX, Herrup K, Stevens KE, Maccaferri G, McBain CJ, Sussman DJ, Wynshaw-Boris A. Social interaction and sensorimotor gating abnormalities in mice lacking Dvl1. Cell. 1997;90:895-905.

2. van Eickels M, Grohe C, Cleutjens JP, Janssen BJ, Wellens HJ, Doevendans PA. 17beta-estradiol attenuates the development of pressure-overload hypertrophy. Circulation. 2001;104:1419-1423. 
Table I: sequences of the primers used in the Real-Time PCR analyses Name

Primer sequence

Lengt

$\mathrm{h}$

\begin{tabular}{|c|c|c|}
\hline$\beta$-actin forward & TGCGTGACATCAAAGAGAAG & 20 \\
\hline$\beta$-actin Reverse & CGGATGTCAACGTCACACTT & 20 \\
\hline ANF forward & CATCATGGGCTCCTTCTCCAT & 21 \\
\hline ANF Reverse & TGTACACAGGATTTGGTCCAATATG & 25 \\
\hline BNP Forward & AGGACCAAGGCCTCACAAAA & 20 \\
\hline BNP Reverse & TTGAGATATGTGTCACCTTGGAATTT & 26 \\
\hline Fz2 Forward & CGGCACCAAGACGGAGAA & 18 \\
\hline Fz2 Reverse & GTACCGTGTAGAGCACCGAGAA & 22 \\
\hline Dvll Forward & CCTTCCATCCAAATGTTGC & 19 \\
\hline Dvl1 Reverse & GTGACTGACCATAGACTCTGTGC & 23 \\
\hline Dv12 Forward & ACTGTGCGGTCTAGGTTTTGAGTC & 24 \\
\hline Dvl2 Reverse & GGAAGACGTGCCCAAGGA & 18 \\
\hline Dvl3 Forward & AGGGCCCCTGTCCAGCT & 17 \\
\hline Dvl3 Reverse & AAAAGGCCGACTGATGGAGAT & 21 \\
\hline$\beta$-catenin Forward & GTTAAACTCCTGCACCCACCAT & 22 \\
\hline$\beta$-catenin Reverse & TAGTCGTGGAATAGCACCCTGTT & 23 \\
\hline c-myc Forward & CCGCCGCTGGGAAAC & 15 \\
\hline c-myc Reverse & TCCTGGCTCGCAGATTGTAAG & 21 \\
\hline c-fos Forward & TGGCCTCCCTGGATTTGAC & 19 \\
\hline c-fos Reverse & TCCACGTTGCTGATGCTCTT & 20 \\
\hline c-jun Forward & CCCCTATCGACATGGAGTCTCA & 22 \\
\hline c-jun Reverse & GAGTTTTGCGCTTTCAAGGTTT & 22 \\
\hline cyclin D1 Forward & GGTTCCTGTTCACAATACCTCATG & 24 \\
\hline cyclin D1 Reverse & ACAGGACGATCGCCATCAG & 19 \\
\hline
\end{tabular}


CHAPTER 


\section{Chapter 4}

\section{Lithium treatment does not augment the hypertrophic response but induces heart failure after aortic banding in rats}

V.A.M. van de Schans; A.E. Strzelecka; H.T.M. Vervoort; H. Laeremans; B.J.A. Janssen; J. F.M. Smits; W. M. Blankesteijn 


\begin{abstract}
Canonical Wnt signaling is re-activated during the cardiac hypertrophic response. Hypertrophic stimuli lead to inactivation of Glycogen Synthase Kinase-3 $\beta$ (GSK-3 $\beta$ ) and to stabilization of $\beta$-catenin, a second messenger protein of the canonical Wnt pathway. GSK-3 $\beta$ is a well known anti-hypertrophic kinase that is inactivated by hypertrophic stimuli. On the other hand, stabilized $\beta$-catenin binds to Tcf/Lef family of transcription factors and plays an essential role in the expression of $\beta$-catenin/Tcf/Lef-dependent genes, involved in the hypertrophic cardiomyocyte response. The aim of the present study was to determine the effects of pharmacological modulation of GSK-3 $\beta$ activity and the transcriptional $\beta$-catenin/Tcf activity on pressure overload-induced cardiac hypertrophy in mice.

To this end, mice were treated with $\mathrm{LiCl}$, a potent inhihitor of GSK-3 $\beta$, or with ASA (Acetyl Salicylic Acid), which blocks the transcriptional $\beta$-catenin/Tcf activity. After 4 weeks of pretreatment, mice were subjected to thoracic aortic constriction (TAC) and the hypertrophic response was studied.

In this study, we demonstrated that treatment with a high dose of $\mathrm{LiCl}$ in combination with pressure overload is fatal. Furthermore, we showed a reduced GSK-3 $\beta$ activity, an upregulation of $\beta$-MHC mRNA expression and an increased protein level of $\beta$-catenin after TAC in $\mathrm{LiCl}$ treated animals $(600 \mathrm{mg} / \mathrm{l})$. In contrary, ASA treatment resulted in less inactivation of GSK-3 $\beta$ activity and an attenuated interstitial fibrosis after pressure overload.
\end{abstract}




\section{Introduction}

A functional circulatory system is essential for the survival and growth of the embryo and therefore it is the first organ system to become active during development. The molecular mechanisms regulating the initiation of the cardiac gene program have gained much interest over the last years ${ }^{1}$, in particular the fetal genes, such as ANF that are reexpressed during adult cardiac remodeling ${ }^{2}$. Canonical Wnt signaling is indispensable for the normal development of the heart ${ }^{3,4}$ and is involved in cardiac hypertrophic response $^{5,6}$.

Canonical Wnt signaling inhibits the kinase activity of the $\beta$-catenin destruction complex involving Axin, adenomatous polyposis coli (APC) and Dishevelled (Dvl ${ }^{7}$, resulting in a slower cytoplasmic turnover of $\beta$-catenin ${ }^{8}$. As a consequence, $\beta$-catenin accumulates in the cytoplasm and travels to the nucleus where it engages the DNA-binding proteins of the Tcf/Lef family of high mobility group (HMG)-box proteins ${ }^{9}$, ${ }^{10}$ which leads to activation of the transcription of target genes ${ }^{11-13}$. Without Wnt stimulation, GSK-3 $\beta$ phosphorylates $\beta$-catenin and this phosphorylation targets $\beta$-catenin for proteasomal degradation ${ }^{14}$.

GSK-3 $\beta$ is a central component of the canonical Wnt pathway and is known for its antihypertrophic properties. Active GSK-3 $\beta$ phosphorylates $\beta$-catenin, targeting it for degradation, thereby inhibiting the transcriptional activity of $\beta$-catenin/Tcf signaling. Haq et al. ${ }^{15}$ observed that inhibition of GSK-3 $\beta$ acitvity by $\mathrm{LiCl}$ promotes features of the hypertrophic response.

Also the role of $\beta$-catenin in the hypertrophic response has been subject of study by several groups ${ }^{16-19}$. Haq et al. ${ }^{20}$ showed that $\beta$-catenin is stabilized by hypertrophic stimuli in vitro and in vivo and that the transcriptional activity of $\beta$-catenin is necessary for the hypertrophic response. Cardiomyocyte-specific deletion of $\beta$-catenin resulted in an attenuated hypertrophic response upon aortic banding in vivo ${ }^{16,18}$. Furthermore, cardiac-specific transgenic expression of a dominant inhibitory mutant of Lef-1, which blocks expression of $\beta$-catenin/Tcf/Lef-dependent genes, resulted in a dramatic reduction of cardiomyocyte growth ${ }^{18}$. This demonstrates the essential role of $\beta$-catenin/Tcf 
signaling in the hypertrophic response. Downregulation of the $\beta$-catenin/Tcf signaling in colorectal cancer (CRC) cells by Acetyl Salicylic Acid (ASA) resulted in reduced transcription of target genes ${ }^{21}$. ASA stabilizes $\beta$-catenin in its transcriptionally inactive, serine/threonine-phosphorylated form, thereby preventing its function as a cotranscription factor ${ }^{21,22}$. Because ASA is used as treatment of acute coronary syndromes thereby reducing the risk of vascular events like nonfatal myocardial infarction, nonfatal stroke or vascular death ${ }^{21}$.

Inhibiting the Wnt signaling pathway could serve as a novel therapeutic approach. Therefore it is important to study the role of components of Wnt signaling during the cardiac hypertrophic response. The present study was designed to explore the effect of pharmacological inhibition of GSK-3 $\beta$ and of $\beta$-catenin/Tcf signaling on the hypertrophic response of the heart induced by pressure overload. Mice received a 4 week pretreatment with $\mathrm{LiCl}$ because of its well known inhibitory effect on GSK-3 $\beta^{23}$, before aortic banding was performed. As a control, we treated animals with $\mathrm{NaCl}$ in the same concentration in the drinking water. Hypertrophic parameters as well as Wnt signaling components were analyzed. Furtermore, we explored the effect of a 4 week pretreatment with ASA on cardiac adaptations during the hypertrophic response and the influence of this treatment on canonical Wnt components.

\section{Methods}

An expanded Methods section detailing some techniques and procedures mentioned here is added as a supplement at the end of Chapter 3.

\section{Animals.}

129S6 mice of both sexes were used (10-12 weeks of age at the start of the study, body weight 24-30 g). Animals had free access to food and water. The animals were randomly divided into five different groups: control, treatment with LithiumChloride (LiCl) (800 $\mathrm{mg} / \mathrm{l}$ or $600 \mathrm{mg} / \mathrm{l})$, SodiumChloride $(\mathrm{NaCl})(600 \mathrm{mg} / \mathrm{l})$ and Acetyl Salicylic Acid (ASA, 
$180 \mathrm{mg} / \mathrm{l})$. To ensure solubility of ASA, we prepared a fresh solution of $325 \mathrm{mg} / \mathrm{l}$ of lysine-acetylsalicylate every day, this is equivalent of $180 \mathrm{mg} / 1 \mathrm{ASA}^{24}$. The drugs were administered by mixing it with the drinking water and given ad libitum for 4 weeks before transverse aortic constriction (TAC) operation (see below). The treatment ( $\mathrm{LiCl}$, $\mathrm{NaCl}$ and ASA) regimens continued after the mice had been subjected to TAC, and 14 or 28 days after TAC surgery mice were sacrificed. All experimental procedures were approved by the Committee for Animal Research of Maastricht University.

\section{Thoracic aortic constriction (TAC) model.}

Mice (of the control or the treated groups) were randomly distributed over the TACgroup and sham-operated control group. Animals were anesthetized by intramuscular injection with ketamine (100 $\mathrm{mg} / \mathrm{kg}$ body weight) and subcutaneous injection with xylazine (10 mg/kg body weight), and TAC was induced as described previously ${ }^{25}$.

\section{Two-dimensional guided M-mode echocardiography.}

Animals were anaesthetized and two-dimensional (2D) guided M-mode echocardiography on the mouse was performed using a $20-\mathrm{MHz}$ probe connected to an AU4 Idea device (Esaote Biomedica, Firenze, Italy).

\section{Measurement of cardiac function.}

Haemodynamic measurements were performed at 14 and 28 days after TAC. The animals were anaesthetized with urethane $(2.5 \mathrm{mg} / \mathrm{g}$ body weight i.p.), followed by intubation of the trachea $(1.1 \mathrm{~mm}$ stainless steel) and connected to a volume-cycled rodent ventilator (Hugo Sachs). Body temperature was maintained at $37^{\circ} \mathrm{C}$ throughout the experiment using a thermally controlled heating pad and monitored with a rectal probe. The mice were then allowed to stablize for 30 minutes prior to hemodynamic measurements. A high-fidelity catheter tip micromanometer (Mikro-tip, 1.4F, SPR-671; Millar Instruments, Houston, TX, USA) was inserted through the right carotid artery into the left ventricular cavity. Ventricular pressure was measured. Maximal positive pressure 
development $(+\mathrm{dp} / \mathrm{dt})$ and heart rate were determined on a beat-to-beat basis and onesecond averages were stored on disk. The heart was then stimulated by an i.v. rampinfusion of dobutamine (Sigma, St Louis MO, USA) using a micro-injection pump (Model 200 Series, KdScientific, Boston, MA, USA). The infusion rate of dobutamine was increased every $2 \mathrm{~min}$ by $0.5 \mathrm{ng} / \mathrm{g} / \mathrm{min}$ (last step $=5 \mathrm{ng} / \mathrm{g} / \mathrm{min}$ ).

\section{Histological analysis.}

Hearts from all groups were fixed in $1 \%$ paraformaldehyde, and embedded in paraffin. Four $\mu \mathrm{m}$ sections were cut and stained with haematoxylin and eosin (H\&E) for myocyte cross-sectional area or picrosirius red to identify interstitial fibrosis. Myocyte crosssectional areas were measured using a computerized morphometric system (version Leica Qwin3.1; Leica, Cambridge, England). All sections were measured in 5 different areas of the left ventricle of the heart. Myocyte cross-sectional area was measured per nucleus; the outline of 100-200 myocytes was traced in each section. An examiner blinded to the genotype of the animals performed all measurements. Percentage of collagen was determined in the left ventricle; the ratio of positive Sirius red-stained area to LV area was calculated. An examiner blinded to the groups of the animals obtained all measurements.

\section{Real-time PCR.}

Total RNA was isolated from left ventricular (LV) tissue, purified by DNAse digestion and transcribed into cDNA using random hexamer primers. The designed primers were used to quantify the expression of mRNA levels of atrial natriuretic factor (ANF), $\beta$ Myosin heavy chain ( $\beta$-MHC), Frizzled 2 (Fz-2) and Dishevelled-1 (Dvl-1). Amplification and detection were performed using the MyIQ system of Biorad (Biorad, Hercules, CA, USA). Cardiac gene expression was normalized to the housekeeping gene $\beta$-actin. All samples were run in duplicate. Data analyses were performed using the Sequence Detection System software (Applied Biosystems). 


\section{Western immunoblot analyses.}

Total protein extracts $(20 \mu \mathrm{g})$ were separated on a 10\% SDS-PAGE gel and transferred to HybondC nitrocellulose membrane (Amersham Biosciences, Little Chalfond, UK). The membranes were incubated overnight at $4^{\circ} \mathrm{C}$ with the following primary antibodies: $\beta$-catenin (BD Transduction Laboratories, Lexington KY, USA); Akt and $\mathrm{pSer}^{473} \mathrm{Akt}$ (Cell Signaling Technology, Beverly MA, USA); $\alpha$-tubulin (Santa Cruz Biotechnology, Santa Cruz CA, USA). Anti-rabbit IgG and anti-mouse IgG Horseradish Peroxidaseconjugated antibodies (DAKO, Glostrup, Denmark) were used as secondary antibodies as appropriate.

\section{GSK-3ß kinase assay.}

Total GSK-3 $\beta$ was immunoprecipated from $200 \mu \mathrm{g}$ protein extracts of the heart in lysis buffer. The samples were precleared with protein G-Sepharose beads (Amersham Biosciences) and subjected to immunoprecipitation with anti-mouse GSK-3 $\beta$ antibody (BD Transduction Laboratories) overnight at $4{ }^{\circ} \mathrm{C}$ with gentle agitation, then incubated with protein G-Sepharose for 1 hour at $4{ }^{\circ} \mathrm{C}$ with gentle agitation. Kinase activity was assayed in $40 \mu \mathrm{l}$ of total reaction buffer containing GSK-3 Peptide Substrate (Biomol P151, Exeter, UK) and $10 \mu \mathrm{Ci}\left[\gamma^{-32} \mathrm{P}\right]$ ATP (Amersham Biosciences). After $30 \mathrm{~min}$ of incubation at $30^{\circ} \mathrm{C}, 25 \mu$ laliquots were spotted onto $1.5 \mathrm{~cm} \mathrm{X} 1.5 \mathrm{~cm}$ pieces of Whatman P81 Phosphocellulose paper (Whatman Nederland B.V., 's Hertogenbosch, The Netherlands). Quantification of kinase assay was achieved by counting the amount of ${ }^{32} \mathrm{P}$ incorporated into the substrate in the scintillation counter.

\section{Statistical Analysis.}

All data are presented as means \pm SEM. One-way ANOVA with Tukey's Multiple Comparison test was used to compare the means by group or by time point; if not possible, Student's t-test was performed. P-values $<0.05$ were considered to indicate statistical significance. 


\section{Results}

\section{Treatment with $800 \mathrm{mg} / \mathrm{l}$ vs. $600 \mathrm{mg} / \mathrm{l} \mathrm{LiCl}$}

Treatment of mice with $800 \mathrm{mg} / \mathrm{l} \mathrm{LiCl}$ in tap water was lethal in of 5 out of 6 animals during the first hours after TAC (Fig. 1A). The treatment itself $(800 \mathrm{mg} / 1 \mathrm{LiCl})$ started 4 weeks before the TAC surgery, was well tolerated and did not result in any signs of intoxication. Because of the high mortality rate after TAC surgery, we reduced LiClconcentrations in the water from $800 \mathrm{mg} / \mathrm{l}$ to $600 \mathrm{mg} / \mathrm{l}$. After TAC surgery, postmortem analysis showed no difference in heart weight to tibia length (HW/TL) ratio between the $800 \mathrm{mg} / \mathrm{l}$ treated- and $600 \mathrm{mg} / \mathrm{l}$ treated groups (Fig 1B). However, lung weight to tibia length (LW/TL) ratio showed a trend towards an increase in the $800 \mathrm{mg} / 1$ compared to non-treated animals. The trend in increased LW/TL ratio in the $800 \mathrm{mg} / \mathrm{l}$ treated group was due to pulmonary edema, suggesting acute left-sided heart failure in the $800 \mathrm{mg} / \mathrm{l}$ treated mice.
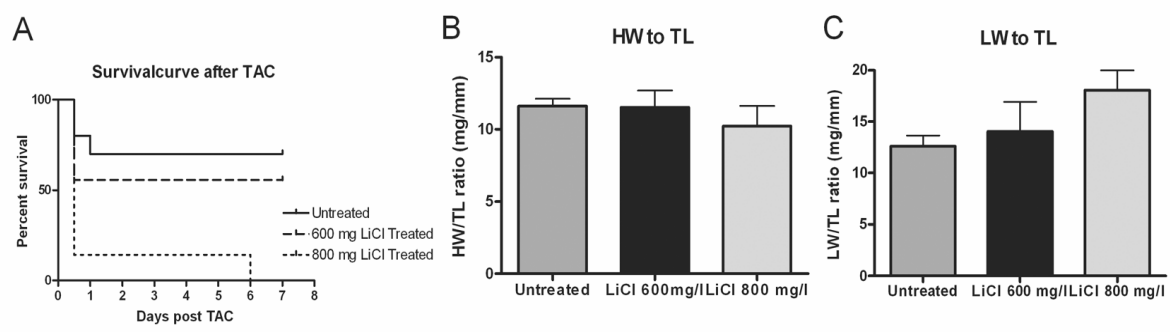

Figure 1 A: Kaplan-Meier survival analysis. Percentages of surviving of $\mathrm{LiCl} 800 \mathrm{mg} / 1+\mathrm{TAC}(\mathrm{n}=7)$ and $\mathrm{LiCl}$ $600 \mathrm{mg} / 1+\mathrm{TAC}(\mathrm{n}=9)$, and non-treated+TAC $(\mathrm{n}=10)$ mice were plotted. Panel B showes Heart Weight to tibia length ratios (HW to TL) and panel $\mathbf{C}$ shows Lung weight to tibia length ratios (LuW to TL)

\section{Morphometric, echocardiographic and hemodynamic measurements}

Table 1 summarizes morphometric and echocardiographic data of the different treated groups at different time points in this study. After induction of pressure overload, HW/TL ratio increased significantly in all groups at all time points compared to their sham operated animals. No differences in HW/TL ratio were observed between the groups after TAC operation at 14 and 28 days. In the $\mathrm{LiCl}$ treated animals, the $\mathrm{LW} / \mathrm{TL}$ ratio significantly increased after TAC surgery at the two time points compared with 
their sham. As a control for possible salt-induced effects of LiCL treatment, we treated animals with $\mathrm{NaCl}$ in the same concentration as $\mathrm{LiCl}$ in the drinking water. After induction of pressure overload, we observed the same morphometric changes in the $\mathrm{NaCl}$ treated animals as in the non-treated group.

To study the hypertrophic remodeling, echocardiographic measurements were performed. Posterior Wall thickness in diastole (PWthd) was significantly elevated in all treated TAC groups compared with their sham operated animals except for the $\mathrm{LiCl}$ treated group 28 days after TAC operation. The PWth in systole (PWths) was only significantly elevated in the $\mathrm{LiCl}$ treated group 14 days after TAC and in the untreated group 28 days after TAC compared to their corresponding sham group.

Fig 2 contains data on left ventricular function, determined as the rate of LV pressure development and dissipation $(+\mathrm{dp} / \mathrm{dt}$ and $-\mathrm{dp} / \mathrm{dt})$ and systolic pressure. Without dobutamine stimulation, there was a significant decrease in $-\mathrm{dp} / \mathrm{dt}$ in the $\mathrm{LiCl}$ treated group compared to the untreated group at day 28 after TAC surgery (Fig 2C). ASA treatment resulted in significant decrease in ventricular contraction during dobutamine stimulation after TAC compared to sham (Fig 2B). Ventricular relaxation after dobutamine stimulation was significantly increased 28 days after TAC in the LiCl treated animals compared to their sham controls (Fig 2D). Systolic pressure was significantly increased in untreated and ASA treated operated animals compared to their sham-controls (Fig 2E), and this was also observed after dobutamine stimulation (Fig $2 \mathrm{~F})$. 
Table 1

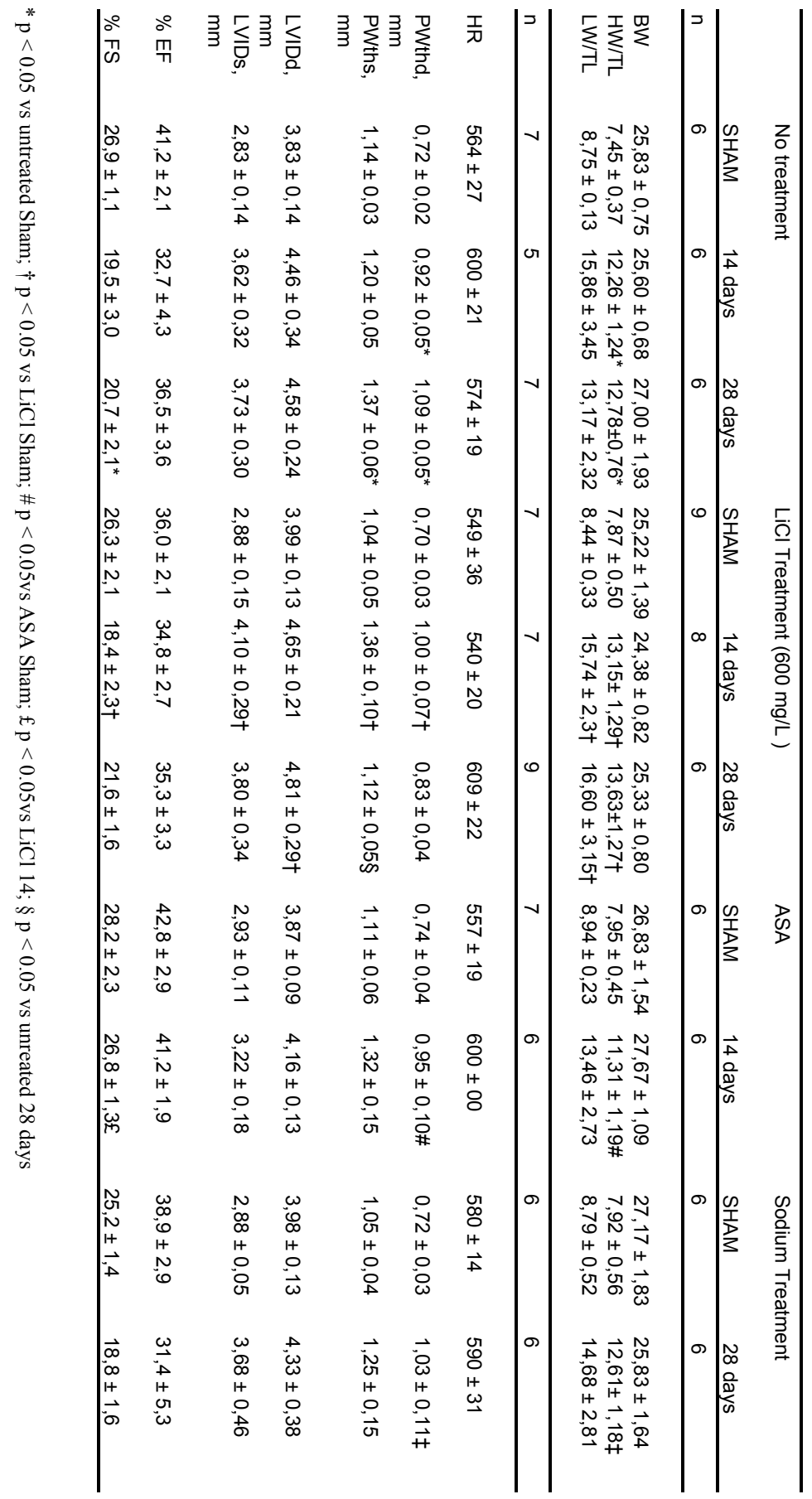



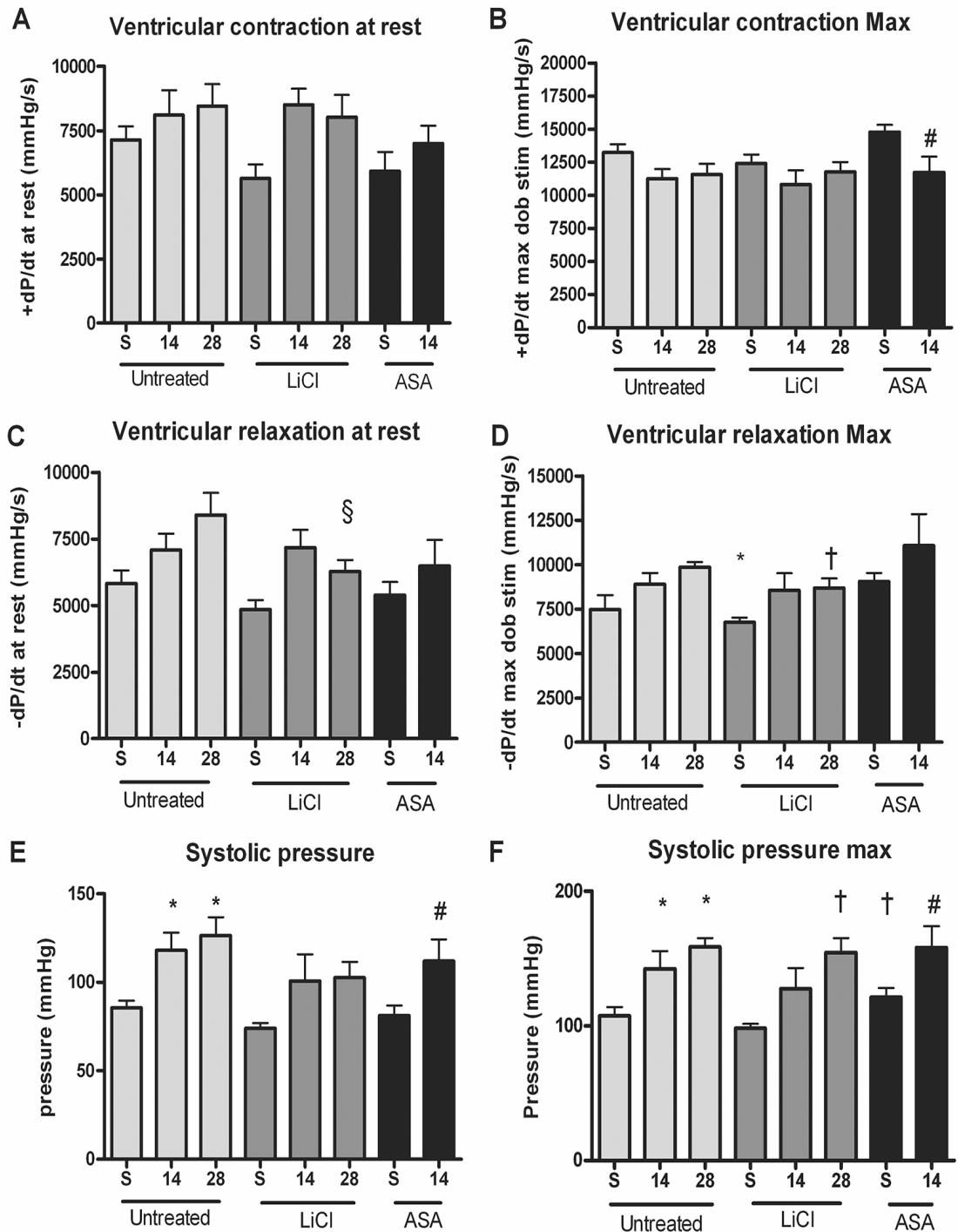

F

Systolic pressure max

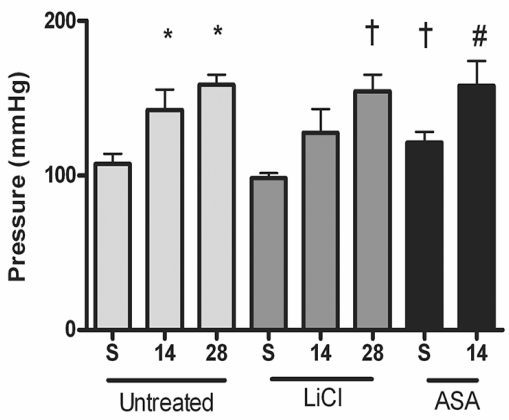

Figure 2 Hemodynamic parameters, determined at 14 and 28 days after induction of pressure overload or sham operation in non-treated, LiCl- and ASA-treated animals. Panel A: $+\mathrm{dP} / \mathrm{dt}$ values in unstimulated left ventricles; Panel B: Maximal $+\mathrm{dP} / \mathrm{dt}$ contraction after dobutamine stimulation. Panel $\mathrm{C}$ : $-\mathrm{dP} / \mathrm{dt}$ values in unstimulated left ventricles; Panel D: Maximal -dP/dt values after dobutamine stimulation. Panel E and F: Systolic pressure at rest and after dobutamine stimulation. Values are expressed as means \pm S.E.M. ${ }^{*} \mathrm{P}<0.05$ vs untreated Sham, $\uparrow \mathrm{P}<0.05$ vs LiCl Sham, \# $\mathrm{P}<0.05$ vs ASA Sham, $\S \mathrm{P}<0.05$ vs Untreated 28 days, $\$ \mathrm{P}<0.05$ vs Untreated 14 days, $£ \mathrm{P}<0.05$ vs LiCl 14. All $n=4$ to 8 animals/group. 


\section{Cardiac hypertrophy development and markers}

Growth of the cardiomyocyte can be defined by an increase in the myocyte crosssectional area (CSA). A significant increase in CSA was observed in the untreated and LiCl-treated groups at day 28 after TAC and in the ASA-treated group at day 14 after TAC (Fig 3A). The amount of interstitial fibrosis is illustrated in Fig 3B. All groups showed significantly increased levels of interstitial fibrosis, quantified by morphometry following Sirius Red staining, compared to their sham groups. At day 14 after TAC, a significantly lower level of fibrosis was observed in the ASA treated mice compared to untreated and $\mathrm{LiCl}$ treated animals (Fig 3B). We also examined the differences in the expression of the hypertrophic gene program and found that ANF expression was significantly increased in all TAC groups compared to their sham group (Fig 3C). At day 14 after TAC surgery, the increase in ANF mRNA levels was significantly greater in the $\mathrm{LiCl}$ treated group compared with the untreated group (Fig 3C). Fig 3D shows the $\beta$-MHC mRNA expression. In the $\mathrm{LiCl}$ and ASA treated group, there was a significant upregulation of $\beta$-MHC mRNA transcripts 14 and 28 days after induction of pressure overload compared to their shams. $\mathrm{LiCl}$ treatment resulted in a significantly increased $\beta$-MHC expression compared to untreated mice at 28 days after induction of TAC.

\section{$\beta$-catenin and Akt}

Examination of $\beta$-catenin protein levels by Western Blotting is shown in Fig 4A. Protein levels of $\beta$-catenin were significantly upregulated in the $\mathrm{LiCl}$ treated TAC operated group compared to the $\mathrm{LiCl}$ treated sham group (Fig 4A). There was a trend towards an increased amount of $\beta$-catenin protein levels in the $\mathrm{LiCl}$ treated group compared to the untreated group at 28 days after TAC, which just failed to reach statistical significance. In Fig 4B, phosphorylation of the $\mathrm{Ser}^{473}$ residue of Akt, which results in its activation, is shown. Western blot analysis showed that 28 days after induction of TAC, the $\mathrm{Ser}^{473}$ phosphorylation of Akt was significantly increased in the $\mathrm{LiCl}$ treated mice compared to the $\mathrm{LiCl}$ treated sham mice (Fig 4B) 
A
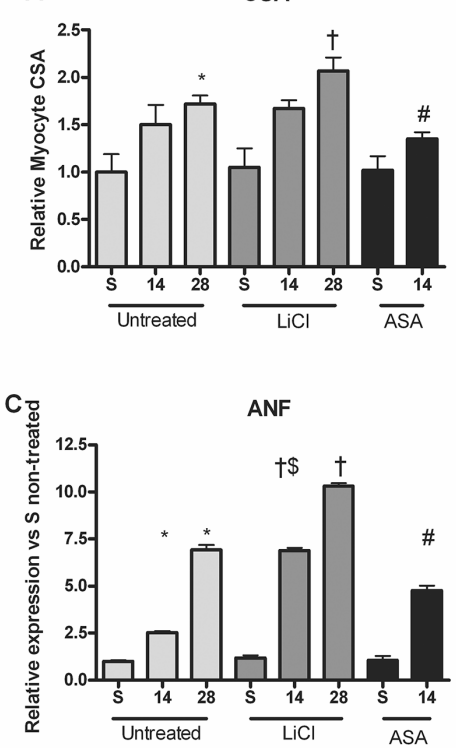
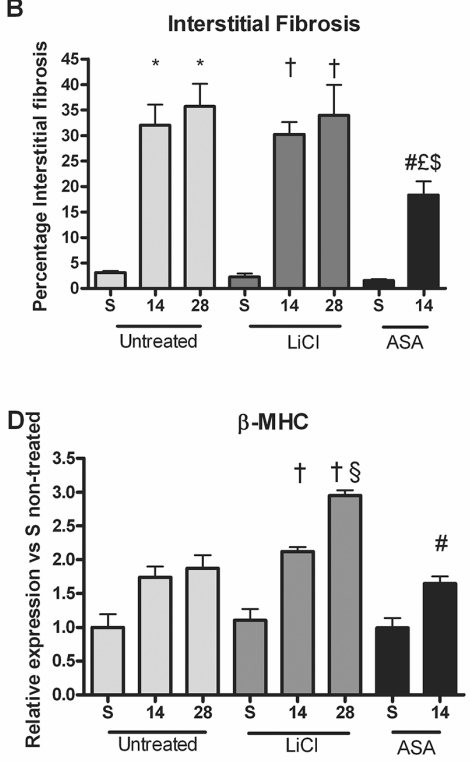

Figure 3 Determination of cardiac hypertrophy parameters: cross sectional area, interstitial fibrosis and expression of marker genes. Panel A present the Cross sectiona area (CSA); Panel B shows the Interstitial Fibrosis as determined by morphometry following picosirius red staining. Expression of mRNA transcripts was determined by real-time PCR for ANF (Panel C) and $\beta$-MHC (Panel D), both normalized to the housekeeping gene CyclophilinA. For abbreviations and symbols, see legend to Figure 2.

\section{GSK-3ß, the anti-hypertrophic protein}

Measurement of the GSK-3 $\beta$ kinase activity, utilizing phospho-glycogen synthase as the substrate, is depicted in Fig 5 . The difference in GSK-3 $\beta$ kinase activity at baseline between the untreated and $\mathrm{LiCl}$ treated sham groups is insignificant. At day 14 after induction of pressure overload, the reduced GSK-3 $\beta$ kinase activity is significantly different between the groups. We also observed a significant difference in GSK-3 $\beta$ kinase activity between the $\mathrm{LiCl}$ treated sham group and the ASA treated sham group. 


\section{Upstream components of Wnt/ß-catenin signaling}

In Fig 6A, the numbers of Fz-2 mRNA transcripts is shown to be significantly elevated at 28 days after TAC in the untreated and $\mathrm{LiCl}$ treated groups compared with their shams. A similar significant upregulation of Fz-2 mRNA transcripts is found in the ASA treated group at 14 days after TAC. Dvl-1 mRNA expression is presented in fig 6B. Significantly increased Dvl-1 mRNA transcripts were found in the $\mathrm{LiCl}$ treated group between 28 days of pressure overload and sham operated animals (Fig 6B).
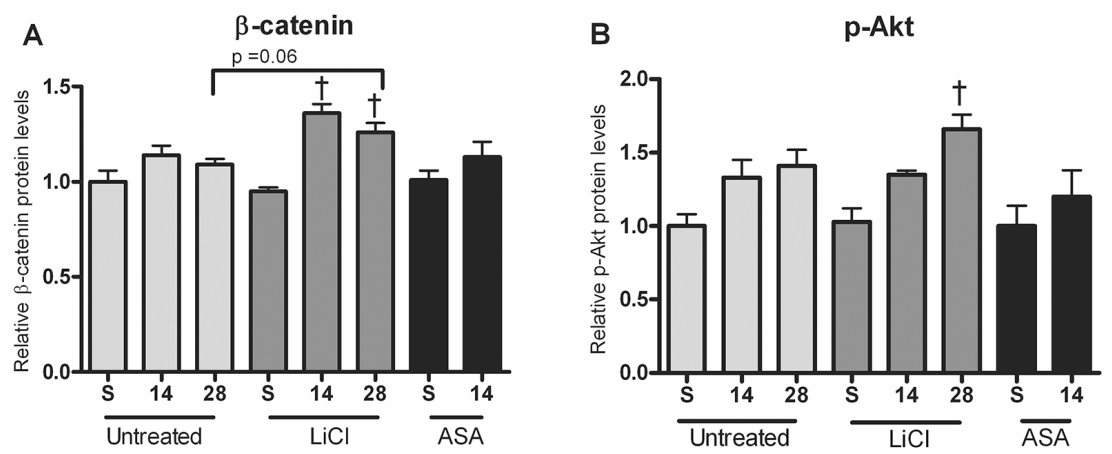

Figure 4 Protein expression of $\beta$-catenin and phospho-Akt. Quantification of the Western blot signals, expressed as $\beta$-catenin/ $\alpha$-tubulin ratios (Panel A) and phospho-Akt/Akt ratio (Panel B) after aortic banding or after sham surgery. For abbreviations and symbols, see legend of Figure 2.

\section{Discussion}

One of the main findings of this study is that TAC in $\mathrm{LiCl}$ treated animals $(600 \mathrm{mg} / \mathrm{l})$ leads to reduced GSK-3 $\beta$ activity, an upregulation $\beta$-MHC and ANF mRNA expression and an increased protein level of $\beta$-catenin. Furthermore, this study shows that pressure overload induced by TAC in combination with ASA treatment resulted in a well preserved GSK-3 $\beta$ activity and attenuated interstitial fibrosis.

At the start of this study, we added $800 \mathrm{mg} \mathrm{LiCl} / 1$ in the tap water of the mice. The mice did not show any abnormalities during the 4 week pretreatment, but 5 out of 6 
mice died shortly after pressure overload (one to tree hours), showing severe shortness of breath before death. Autopsy of the mice showed enlarged lungs, filled with fluid, representing acute LV failure. The reason for the difference in survival between the 600 $\mathrm{mg} / \mathrm{l}$ and $800 \mathrm{mg} / \mathrm{l}$ treated mice is not clear but one can speculate that the relationship between GSK-3 $\beta$ activity and $\mathrm{Li}^{+}$has important consequences. $\mathrm{Li}^{+}$enters the heart cells quickly and leaves slowly ${ }^{26}$. The direct inhibitory effect of $\mathrm{Li}^{+}$on GSK-3 $\beta$ is by acting as a competitive inhibitor of $\mathrm{Mg}^{2+27}$. It seems possible that $\mathrm{Li}^{+}$induces a rise in $\mathrm{Mg}^{2+}$ concentration in the heart cells by displacing $\mathrm{Mg}^{2+}$ from $\mathrm{MgATP}^{26}$. An efflux of $\mathrm{Mg}^{2+}$ can induce elevation of intracellular $\mathrm{Ca}^{2+}$ concentration ${ }^{28,29}$.

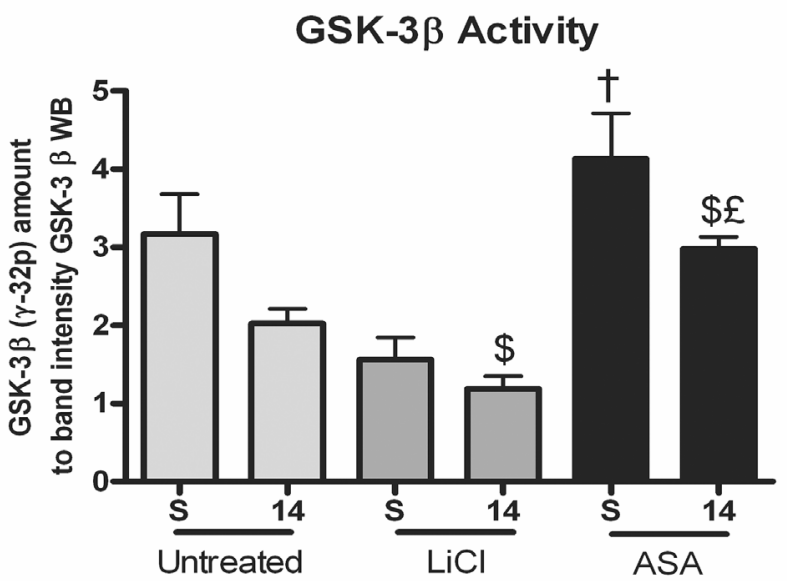

Figure 5. Measurement of the GSK-3 $\beta$ kinase activity in non-treated, LiCl- and ASAtreated animals after aortic banding or after sham surgery. For abbreviations and symbols, see legend of Figure 2 .

$\mathrm{LiCl}$ reduces GSK-3 $\beta$ activity not only by a direct effect but also indirectly ${ }^{27}$. The indirect effect is by increasing the phosphorylation of the inhibitory serine of GSK-3 $\beta$, by the inhibition of a protein phosphatase, that activates GSK-3 $\beta$ by removing a phospate from the regulatory serine ${ }^{27}$. In this study, we showed that induction of pressure overload reduced the activity of GSK-3 $\beta$ by $50 \%$ after chronic LiCl treatment. Moreover, Chalecka-Franaszek et al. showed that long term treatment with $\mathrm{LiCl}$ activates Akt by enhancing its phosphorylation, triggered by PI3K signaling, and that $\mathrm{LiCl}$ induces GSK-3 $\beta$ phosphorylation as a result of this Akt activation ${ }^{30}$. We also 
showed that $\mathrm{LiCl}$ treatment increased Akt activity 28 days after induction of pressure overload, indicating its role in GSK-3 $\beta$ inactivation and thereby leading to the stabilization of $\beta$-catenin. These data suggest that the stabilization of $\beta$-catenin is achieved via inactivation of GSK-3 $\beta$ and that this, in turn, occurs via an augmented activation of Akt.

The role of $\beta$-catenin in cardiomyocyte growth is well established ${ }^{19}, \beta$-catenin is sufficient to induce hypertrophic growth when expressed in cardiomyocytes in vitro and in vivo, as shown by Haq et al. ${ }^{20}$. The $\beta$-catenin-mediated TCF signaling regulate myocyte shape and size, especially cross-sectional growth ${ }^{16}$. Here, we report that after induction of pressure overload, $\beta$-catenin protein levels were increased in $\mathrm{LiCl}$ treated mice compared to the untreated group, confirming that inhibition of GSK-3 $\beta$ activity results in stabilization of $\beta$-catenin. Canonical Wnt signaling also leads to the stabilization of $\beta$-catenin ${ }^{17}$. Interruption of the canonical Wnt pathway by Dvl-1 gene ablation was shown by our group to lead to an attenuated hypertrophic response, but these mice had reduced $\beta$-catenin levels ${ }^{17}$.
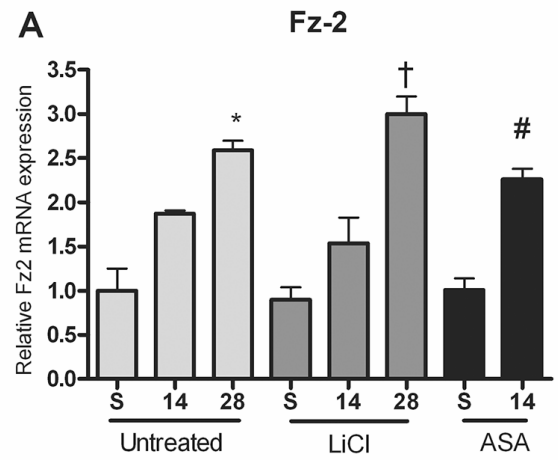

B

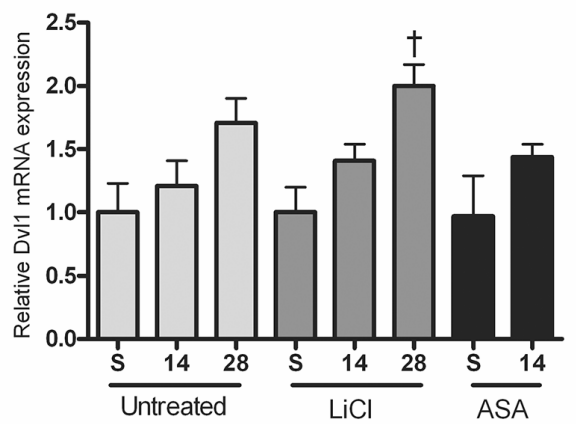

Figure 6. Expression of mRNA transcripts of components of the Wnt/Frizzled pathway. Expression of mRNA transcripts is determined by real-time PCR for Fz2 (Panel A) and Dvl-1 (Panel B), normalized to the housekeeping gene Cyclophilin A. For abbreviations and symbols, see legend to Figure 2.

Re-expression of canonical Wnt signaling was previously reported during the hypertrophic response, as shown by subtractive hybridization experiment in our lab. 
We identified the upregulation of Fz-2 expression after pressure overload hypertrophy in the rat ${ }^{31}$. In the present study, we showed that after induction of pressure overload, there is an upregulation of Fz-2 and Dvl-1 mRNA transcripts in spite of the treatment, indicating the involvement of canonical Wnt signaling in the hypertrophic response leading to the stabilization of $\beta$-catenin.

In this study, we used ASA to downregulate the transcriptional $\beta$-catenin/TCF signaling activity. The mice were provided a continuous administration of $500 \mu \mathrm{g} / \mathrm{day}$ of ASA corresponds roughly to $1500 \mathrm{mg} / \mathrm{day}$ in humans ${ }^{24}$. We observed a trend towards an attenuated hypertrophic response with an attenuated increase in intertitial fibrosis, but no effect on $\beta$-catenin protein level was noticed. Dihlmann et al. ${ }^{21}$ pointed out the participation of GSK- $3 \beta$ in the inhibition process of ASA on the transcriptional $\beta$-catenin/TCF signaling activity and this by the use of $\mathrm{LiCl}$. The mechanism for the indirect effect of ASA on GSK-3 $\beta$ still remains to be determined. In the present study, we measured GSK-3 $\beta$ activity not via Ser $^{9}$ phosphorylation but via a kinase-assay, which provides information about the actual phosphorylation capacity of GSK-3 $\beta$. In control mice, ASA treatment resulted in increased GSK-3 $\beta$ activity and even after induction of pressure overload, the GSK-3 $\beta$ activity was still higher in the ASA-treated mice compared to untreated mice. These results suggest that ASA treatment activates the phophorylation capacity of GSK-3 $\beta$.

Mining the Wnt pathway as target for therapeutic intervention in cardiomyocyte growth is a promising strategy for treatment of the cardiac hypertrophic response. Accumulating data about drugs blocking aberrant $T c f / \beta$-catenin signaling, such as ASA, have great potential as effective cancer therapeutics ${ }^{32}$. In contrast with cancer, in the hypertrophic response no mutations in APC, Axin or $\beta$-catenin have been described. So, intervention at the level of Tcf/ $\beta$-catenin signaling does not seem the method of choice for treatment of cardiac hypertrophy. Also the role of GSK-3 $\beta$ as an antihypertrophic kinase is well established ${ }^{33}$, 34. Inhibition of GSK-3 $\beta$ is not only 
oncogenic, but also leads to stabilization of $\beta$-catenin, leading to hypertrophic growth of the cardiomyocyte, eventually leading to heart failure.

Taken together with the fact that both canonical Wnt as non-canonical Wnt signaling is involved in cardiovascular remodeling, there is a need for compounds that intervene more upstream in the Wnt pathway, such as compounds blocking Fz activation, inhibiting the interaction of Dvl with Fz receptors. 


\section{Reference}

1. van den Hoff MJ, Kruithof BP, Moorman AF. Making more heart muscle. Bioessays. Mar 2004;26(3):248-261.

2. McMullen JR, Jennings GL. Differences between pathological and physiological cardiac hypertrophy: novel therapeutic strategies to treat heart failure. Clin Exp Pharmacol Physiol. Apr 2007;34(4):255-262.

3. Brade T, Manner J, Kuhl M. The role of Wnt signalling in cardiac development and tissue remodelling in the mature heart. Cardiovasc Res. Nov 1 2006;72(2):198-209.

4. Eisenberg LM, Eisenberg CA. Wnt signal transduction and the formation of the myocardium. Dev Biol. May 15 2006;293(2):305-315.

5. van de Schans VA, Smits JF, Blankesteijn WM. The Wnt/frizzled pathway in cardiovascular development and disease: Friend or foe? Eur J Pharmacol. May 13 2008;585(2-3):338-345.

6. Blankesteijn WM, Essers-Janssen YP, Verluyten MJ, et al. A homologue of Drosophila tissue polarity gene frizzled is expressed in migrating myofibroblasts in the infarcted rat heart. Nat Med. May 1997;3(5):541-544.

7. Cliffe A, Hamada F, Bienz M. A role of Dishevelled in relocating Axin to the plasma membrane during wingless signaling. Curr Biol. May 27 2003;13(11):960-966.

8. Nelson WJ, Nusse R. Convergence of Wnt, beta-catenin, and cadherin pathways. Science. Mar 5 2004;303(5663):1483-1487.

9. Reya T, Clevers H. Wht signalling in stem cells and cancer. Nature. Apr 14 2005;434(7035):843-850.

10. Behrens J, von Kries JP, Kuhl M, et al. Functional interaction of beta-catenin with the transcription factor LEF-1. Nature. 1996;382(6592):638-642.

11. Tetsu $\mathrm{O}$, McCormick $\mathrm{F}$. Beta-catenin regulates expression of cyclin D1 in colon carcinoma cells. Nature. Apr 1 1999;398(6726):422-426.

12. He TC, Sparks AB, Rago C, et al. Identification of $\mathrm{C}-M Y C$ as a target of the APC pathway. Science. 1998;281(5382):1509-1512.

13. Anna $\mathrm{CH}$, lida M, Sills RC, et al. Expression of potential beta-catenin targets, cyclin D1, c-Jun, c-Myc, E-cadherin, and EGFR in chemically induced hepatocellular neoplasms from B6C3F1 mice. Toxicol Appl Pharmacol. Jul 15 2003;190(2):135-145.

14. Kimelman $\mathrm{D}, \mathrm{Xu} \mathrm{W}$. beta-catenin destruction complex: insights and questions from a structural perspective. Oncogene. Dec 4 2006;25(57):7482-7491.

15. Haq S, Choukroun G, Kang ZB, et al. Glycogen synthase kinase-3beta is a negative regulator of cardiomyocyte hypertrophy. J Cell Biol. 2000;151(1):117-130.

16. Qu J, Zhou J, Ping Yi X, et al. Cardiac-specific haploinsufficiency of beta-catenin attenuates cardiac hypertrophy but enhances fetal gene expression in response to aortic constriction. J Mol Cell Cardiol. Sep 2007;43(3):319-326.

17. van de Schans VA, van den Borne SW, Strzelecka AE, et al. Interruption of Wnt signaling attenuates the onset of pressure overload-induced cardiac hypertrophy. Hypertension. Mar 2007;49(3):473-480.

18. Chen X, Shevtsov SP, Hsich E, et al. The beta-catenin/T-cell factor/lymphocyte enhancer factor signaling pathway is required for normal and stress-induced cardiac hypertrophy. Mol Cell Biol. Jun 2006;26(12):4462-4473.

19. Zelarayan L, Gehrke C, Bergmann MW. Role of beta-catenin in adult cardiac remodeling. Cell Cycle. Sep 1 2007;6(17):2120-2126.

20. Haq S, Michael A, Andreucci M, et al. Stabilization of beta-catenin by a Wnt-independent mechanism regulates cardiomyocyte growth. Proc Natl Acad Sci U S A. Apr 15 2003;100(8):4610-4615.

21. Dihlmann S, Klein S, Doeberitz Mv MK. Reduction of beta-catenin/T-cell transcription factor signaling by aspirin and indomethacin is caused by an increased stabilization of phosphorylated beta-catenin. Mol Cancer Ther. Jun 2003;2(6):509-516. 
22. Dihlmann S, von Knebel Doeberitz M. Wnt/beta-catenin-pathway as a molecular target for future anti-cancer therapeutics. Int J Cancer. Feb 10 2005;113(4):515-524.

23. Grimes CA, Jope RS. The multifaceted roles of glycogen synthase kinase 3beta in cellular signaling. Prog Neurobiol. Nov 2001;65(4):391-426.

24. Paul A, Calleja L, Camps J, et al. The continuous administration of aspirin attenuates atherosclerosis in apolipoprotein E-deficient mice. Life Sci. Dec 15 2000;68(4):457-465.

25. van Eickels M, Grohe C, Cleutjens JP, et al. 17beta-estradiol attenuates the development of pressure-overload hypertrophy. Circulation. Sep 18 2001;104(12):1419-1423.

26. Gow IF, Flatman PW, Ellis D. Lithium induced changes in intracellular free magnesium concentration in isolated rat ventricular myocytes. Mol Cell Biochem. Aug 1999;198(1-2):129133.

27. Jope RS. Lithium and GSK-3: one inhibitor, two inhibitory actions, multiple outcomes. Trends Pharmacol Sci. Sep 2003;24(9):441-443.

28. Chakraborti S, Chakraborti T, Mandal M, et al. Protective role of magnesium in cardiovascular diseases: a review. Mol Cell Biochem. Sep 2002;238(1-2):163-179.

29. Zaugg CE, Buser PT. When calcium turns arrhythmogenic: intracellular calcium handling during the development of hypertrophy and heart failure. Croat Med J. Feb 2001;42(1):24-32.

30. Chalecka-Franaszek E, Chuang DM. Lithium activates the serine/threonine kinase Akt-1 and suppresses glutamate-induced inhibition of Akt-1 activity in neurons. Proc Natl Acad Sci U S A. Jul 20 1999;96(15):8745-8750.

31. Blankesteijn WM, Essers-Janssen YP, Ulrich MM, et al. Increased expression of a homologue of drosophila tissue polarity gene "frizzled" in left ventricular hypertrophy in the rat, as identified by subtractive hybridization. J Mol Cell Cardiol. May 1996;28(5):1187-1191.

32. Barker N, Clevers H. Mining the Wnt pathway for cancer therapeutics. Nat Rev Drug Discov. Dec 2006;5(12):997-1014.

33. Hardt SE, Sadoshima J. Negative regulators of cardiac hypertrophy. Cardiovasc Res. Aug 15 2004;63(3):500-509.

34. Kerkela R, Woulfe K, Force T. Glycogen synthase kinase-3beta-actively inhibiting hypertrophy. Trends Cardiovasc Med. Apr 2007;17(3):91-96. 


\section{Chapter 5}

\section{Effect of AT-1 antagonist treatment on Wnt signaling in spontaneously} hypertensive heart failure-prone rats

G.M.S Cohuet., V.A.M. van de Schans, J.J.R. Hermans, G. Maes, J.F.M. Smits, W.M. Blankesteijn, H.A.J. Struijker Boudier 


\section{Abstract}

Objective: The aim of the present study was to investigate the effect of treatment with AT1 receptor blockers (ARBs) on the development of cardiac hypertrophy in Spontaneously Hypertensive rats prone to Heart Failure (SHHF) and on the expression of components of the Wnt signal transduction cascade.

Methods: Twelve week-old SHHF were treated with equipotent doses of losartan, olmesartan for 4 weeks whereas one group was not treated. The hypertrophy development was assessed with echocardiography. The expression of markers for cardiac hypertrophy and components of Wnt signaling were determined with real-time PCR.

Results: At the 16 week time point, non-treated SHHF showed an increased heart weight and increased wall thickness, compared to normotensive WiF rats. Moreover, molecular markers of cardiac hypertrophy, like atrial natriuretic factor (ANF) and the proto-oncogenes c-fos and c-jun, were significantly higher expressed in the non-treated SHHF. ARB treatment could attenuate the hypertrophic response, but olmesartan had a more pronounced anti-hypertrophic effect than losartan. Components of Wnt signaling, including Fz-1, Fz-2 and Dvl-1, were upregulated in the non-treated SHHF, whereas Wnt-5a expression was downregulated. Interestingly, both ARBs were equipotent in preventing these changes in gene expression

Discussion: From our data we conclude that losartan is less effective in preventing the hypertrophic response in SHHR than olmesartan. The similar effects of these two ARBs on expression of components of the Wnt signaling suggests that these drugs can affect Wnt component expression by a direct effect, and not simply by reducing the hypertrophic response. The mechanism behind this direct modulation remains to be elucidated. 


\section{Introduction}

Cardiac hypertrophy is a response of the heart to increased workload and is often induced by hypertension. It is well accepted that in the long run this adaptive response can progress to heart failure ${ }^{1,2}$. In chapter 2 of this thesis, we have studied the expression patterns of components of Wnt signaling during the development of cardiac hypertrophy and observed a re-expression of the frizzled $2(\mathrm{Fz}-2)$ and dishevelled 1 (Dvl-1) genes. Moreover, in mice lacking the Dvl-1 gene an attenuated hypertrophic response upon pressure overload was observed (chapter 3). From these chapters we have concluded that the Wnt pathway actively contributes to the development of cardiac hypertrophy and may serve as a novel therapeutic target in the treatment of cardiac hypertrophy.

At present, one of the standard pharmacotherapeutic approaches in cardiac hypertrophy is the administration of a drug that inhibits the renin-angiotensin system (RAS). Examples of such drugs are angiotensin converting enzyme (ACE) inhibitors and AT-1 receptor blockers (ARBs). These drugs not only offer an effective and long-term reduction in blood pressure but have also been shown in large clinical trials to stop or even reverse the cardiac hypertrophy development, thereby prevent the development of heart failure ${ }^{3-5}$. However, the mechanism by which ARBs work is not yet fully elucidated and there is still controversy on the question whether ARBs are equally effective as ACE inhibitors ${ }^{6-9}$.

Recently, cross talk between classical G-protein coupled receptors (like the AT1 receptor) and canonical Wnt signaling has been described ${ }^{10}$. This cross talk could be of interest to explain the full mechanism of action of RAS inhibitors in the therapy of cardiac hypertrophy. However, this cross talk so far mainly has been studied in transformed cell lines and no in vivo studies have been presented to data on this subject.

The aim of the present study was to investigate the effect of ARB treatment on Wnt signaling during the development of cardiac hypertrophy. To this end, we used lean spontaneously hypertensive rats prone to heart failure (SHHF). This model was chosen 
because it allows to study various stages of cardiac remodeling ultimately leading to heart failure ${ }^{11,12}$. These rats were treated with the ARBs losartan or olmesartan for 4 weeks, starting at the age of 12 weeks, when these rats start to develop hypertension and cardiac hypertrophy ${ }^{13}{ }^{14}$. At the end of the 4-week treatment, we determined the effects of the drugs on blood pressure, markers of cardiac hypertrophy and expression of components of Wnt signaling.

\section{Materials and methods}

\section{Animals and Surgery.}

Lean male 12 weeks old SHHF rats (Charles River, Netherlands) were used in this study. They were housed under a 12-h light/dark cycle and had free access to food and water. After randomization, 40 SHHF rats were equally distributed in 5 different groups ( $\mathrm{n}=8 /$ group) and treated s.c. via osmotic minipumps for 4 weeks with either olmesartan $(50 \mu \mathrm{g} / \mathrm{kg} / \mathrm{h})$ or losartan $(500 \mu \mathrm{g} / \mathrm{kg} / \mathrm{h})$. The last group of SHHF and one group of normotensive control rats (Wistar Furth (WiF)) received vehicle $(\mathrm{NaCl}, 130$ $\mathrm{mM} ; \mathrm{KCl}, 5.6 \mathrm{mM} ; \mathrm{CaCl}_{2}, 2.2 \mathrm{mM} ; \mathrm{MgCl}_{2}, 1.2 \mathrm{mM}$ and $\mathrm{NaH}_{2} \mathrm{PO}_{4}, 1.2 \mathrm{mM}$ ). Minipumps were implanted subcutaneously under ketamine (50 mg/kg, i.m.)-xylazine (10 mg/kg, s.c.) anesthesia. Olmesartan was a generous gift of Sankyo, Tokyo, JAPAN, whereas losartan was donated by Merck Sharp and Dohme. The experiments were performed according to the guidelines of the Maastricht University and were approved by the institutional animal ethics committee.

\section{Angiotensin II dose-response curves.}

In order to establish whether the doses of olmesartan and losartan used were equipotent, 3 groups of spontaneously hypertensive rats (SHR) were added ( $\mathrm{n}=4$ per group). Briefly, SHR were treated s.c. via osmotic minipumps for 4 weeks with either olmesartan $(50 \mu \mathrm{g} / \mathrm{kg} / \mathrm{h})$, losartan $(500 \mu \mathrm{g} / \mathrm{kg} / \mathrm{h})$ or vehicle $(\mathrm{NaCl}, 130 \mathrm{mM} ; \mathrm{KCl}, 5.6$ $\mathrm{mM} ; \mathrm{CaCl}_{2}, 2.2 \mathrm{mM} ; \mathrm{MgCl}_{2}, 1.2 \mathrm{mM}$ and $\mathrm{NaH}_{2} \mathrm{PO}_{4}, 1.2 \mathrm{mM}$ ). On treatment-day 26 , 
under anesthesia with ketamine (50 mg/kg, i.m.)-xylazine (10 mg/kg, s.c.), a femoral artery and vein were canulated in order to (1) infuse increasing doses of angiotensin II (Ang II) into the femoral vein (0-0.035-0.35-3.5-35-350-3500-35000 ng AII) and (2) measure directly the associated pressor response through the femoral artery (HDAS, hemodynamic data acquisition system, IDEE, Maastricht University, The Netherlands). Dose-response curves were made and EC50 of Ang II response was evaluated to compare the efficacy of the AT-1 blockade potency of the chosen doses.

Table 1: Equipotency of olmesartan $(50 \mu \mathrm{g} / \mathrm{kg} / \mathrm{h})$ and losartan $(500 \mu \mathrm{g} / \mathrm{kg} / \mathrm{h})$ on AT-1 receptor antagonism

\begin{tabular}{ll}
\hline & EC 50 (ng AngII) \\
\hline SHR non-treated & $10.9 \pm 1.3$ \\
SHR-olmesartan & $48.3 \pm 5.1 *$ \\
SHR-losartan & $58.6 \pm 6.1 *$ \\
\hline
\end{tabular}

* $\mathrm{p}<0.001$ vs SHR non-treated

\section{Echocardiography.}

Animals were anaesthetized with pentobarbital (60 mg/kg, i.p.). One echocardiogram was taken prior to the osmotic minipump implantation and a second after 4 weeks of treatment. The in vivo transthoracic echocardiography of the left ventricle was performed using a Hewlett-Packard $15 \mathrm{MHz}$ linear array transducer (15-6L) interfaced with a Sonos 5500 echocardiography system (Philips, Eindhoven, The Netherlands). Two-dimensional B-Mode echocardiograms were recorded $(90-120 \mathrm{~Hz})$ from the longitudinal axis as well as from the transversal axis in order to measure systolic (s) and end-siastolic (d) parameters using EnConcert Software (Agilent Technologies, Andover, MA, USA). From the long-axis, we determined left ventricular area (LVA). The end-diastolic and end-systolic volumes (EDV and ESV) were calculated using the formula: $8 \mathrm{X}(\mathrm{LVAd} / \mathrm{s})^{2} /(3 \pi \mathrm{X} \mathrm{LVLd} / \mathrm{s})$, respectively. Stroke volume was defined as the difference EDV-ESV and ejection fraction (EF) as $100 \mathrm{X}(\mathrm{EDV}-\mathrm{ESV}) / \mathrm{EDV}$. From the transversal-axis B-Mode records, we measured the LV wall thickness (LVWT), LV internal chamber diameter (LVID). 


\section{Hemodynamic measurement.}

After echocardiography on treatment day 28, rats were equipped with a catheter through the femoral artery in the abdominal aorta for direct blood pressure measurement (HDAS, Hemodynamic data acquisition system, IDEE, University of Maastricht, The Netherlands) ${ }^{15}$.

\section{Real time PCR.}

Left ventricular tissue was homogenized with a PRO200 tissue homogenizer (PRO Scientific, Monroe, CT, USA) and isolated by using Ultraspec ${ }^{\mathrm{TM}}$-II RNA isolation system (BioTecx Laboratories, Houston TX, USA) according to the manufacturer's recommendation. RNA was further purified by DNase digestion using the DNA-Free RNA kit ${ }^{\mathrm{TM}}$ (Zymo Research, Orange, CA, USA) to remove genomic DNA. First strand cDNA was synthesized by adding $100 \mathrm{ng}$ of DNase-treated total RNA to Ready-To-Go You Prime First-Strand Beads (Amersham Biosciences Europe, Freiburg, Germany). Random hexamers were used as primers. The reactions were incubated at $65^{\circ} \mathrm{C}$ for 10 minutes, at $37^{\circ} \mathrm{C}$ for 1 hour and at $95^{\circ} \mathrm{C}$ for 2 minutes. The resulting cDNA was either immediately used as template for real-time PCR or stored at $-20^{\circ} \mathrm{C}$. Real-time PCR primers were chosen with the assistance of the computer program Primer Express software (version 1.5; Applied Biosystems, Foster City, CA, USA). The designed primers were used to quantify the expression of mRNA levels of atrial natriuretic factor (ANF), brain natriuretic peptide (BNP), $\alpha$-Myosin heavy chain $(\alpha-\mathrm{MHC}), \beta$-Myosin heavy chain ( $\beta$-MHC), Frizzled 1 (Fz-1), Fz-2, Wnt-5a, Dishevelled-1 (Dvl-1), $\beta$ catenin. The expression was determined by measuring the binding of the fluorescence dye SYBR Green I, using SYBRGreen PCR Master Mix kit (Eurogentec, Seraing, Belgium) and and real-time PCR was started with 10 minutes at $95^{\circ} \mathrm{C}$, than cycled between $95^{\circ} \mathrm{C} / 10 \mathrm{~s}$ and $57^{\circ} \mathrm{C}-60^{\circ} \mathrm{C} / 15 \mathrm{sec}$ for 40 cycles in the MyIQ system of Biorad (Biorad, Hercules, CA, USA). Cardiac gene expression was normalized to the housekeeping gene Cyclophilin. All samples were run in duplicates. Data analyses were performed using the MyIQ System software (Biorad, USA). 


\section{Statistical Analysis.}

All data are presented as means \pm SE. One-way ANOVA with Tukey's multiple comparison test was used to compare the means. Echocardiographic parameters were analyzed with two-way ANOVA for repeated measurements versus day 0. P-values $<0.05$ were considered to indicate statistical significance.

\section{Results}

\section{Hemodynamic measurements and organ weights}

In Table 1, the EC50-values for angiotensin II (AII) in animals treated with either olmesartan $(50 \mu \mathrm{g} / \mathrm{kg} / \mathrm{h})$ or losartan $(500 \mu \mathrm{g} / \mathrm{kg} / \mathrm{h})$ are shown. Administration of both ARBs caused a 5-fold increase in the EC50-value for the AII pressor response. This experiment shows that the two antagonists were administered in equipotent doses.

Mean arterial pressures (MAPs), heart rates and relative organ weights are indicated in Table 2. Non-treated SHHF rats had a significantly higher MAP that the normotensive Wistar Furth (WiF) control rats. These blood pressures were in the same range as those observed for spontaneously hypertensive rats (SHR) of the same age ${ }^{12,16}$. Treatment with either of the two ARBs reduced blood pressure significantly, although the reduction was more pronounced during treatment with olmesartan (37\% reduction) than during losartan (15\% reduction).

Myocardial hypertrophy was assessed by comparing the heart weight to body weight (HW/BW) or left ventricle weight to body weight (VW/BW) ratios between the treated groups and the positive and negative controls. The SHHF rats were significantly heavier than their age-matched normotensive WiF controls. Although the increase in HW/BW observed in SHHF did not reach significance compared to $\mathrm{WiF}$, the VW/BW ratio was significantly higher in the non-treated SHHF rats than in WiF. Lung weight and kidney weight to body weight ratios were not affected in the ARB-treated groups 
but were significantly lower in the untreated SHHF group compared to the WiF group. This is possibly due to the significantly increased BW in the untreated SHHF group.

Table 2: body weigth, relative organ weight data and mean arterial pressure

\begin{tabular}{lllll} 
& Wistar Furth & $\begin{array}{l}\text { SHHF } \\
\text { non-treated }\end{array}$ & SHHF-losartan & SHHF-olmesartan \\
\hline MAP & $73 \pm 4$ & $163 \pm 4^{* * *}$ & $138 \pm 7 * * * \dagger \uparrow \$ \$ \$$ & $102 \pm 4^{* * *} \dagger \dagger \dagger$ \\
HR & $282 \pm 15$ & $351 \pm 9^{* *}$ & $341 \pm 15^{* *}$ & $365 \pm 23^{* * *}$ \\
BW & $327 \pm 6$ & $421 \pm 10^{* * *}$ & $402 \pm 14 * * *$ & $408 \pm 14 * * *$ \\
HW/BW & $3.22 \pm 0.12$ & $3.47 \pm 0.12$ & $3.50 \pm 0.25$ & $2.87 \pm 0.21 \dagger$ \\
LVW/BW & $2.86 \pm 0.11$ & $3.21 \pm 0.10^{*}$ & $3.15 \pm 0.18$ & $2.65 \pm 0.18 \dagger \dagger$ \\
LuW/BW & $4.05 \pm 0.07$ & $3.41 \pm 0.13 * * *$ & $3.56 \pm 0.19 *$ & $3.27 \pm 0.04 * * *$ \\
KW/BW & $3.38 \pm 0.09$ & $3.05 \pm 0.04 * *$ & $3.30 \pm 0.11 \dagger$ & $3.15 \pm 0.07 *$ \\
LiW/BW & $30 \pm 7$ & $30 \pm 6$ & $34 \pm 7 * *$ & $31 \pm 6$ \\
\hline
\end{tabular}

HW/BW: Heart Weight to Body Weight ratio; LV: Left Ventricle; K: Kidney; Lu: Lung; Li: Liver

$\dagger$ : vs SHHF non-treated, *: vs Wistar Furth, \$: vs SHHF-olmesartan

$* \mathrm{p}<0.05, \quad * * \mathrm{p}<0.01, * * * \mathrm{p}<0.001$

\section{Echocardiographic measurements}

Left ventricular dimensions and cardiac function assessed by echocardiography are summarized in Table 3. In 12 week-old SHHF, Left Ventricular Area in diastole (LVAd) was significantly smaller than in WiF (data not shown) but 4 weeks later, this difference was inverted and a larger LVAd was observed in the untreated SHHF. Treatment with the ARBs did not have any effect on this parameter. Similar observations were obtained for Left Ventricular Length in diastole (LVLd), which also was significantly elevated after the study period of 4 weeks compared to WiF. Treatment with the ARBs did not significantly prevent this increase in LVLd, but the values remained in the range of those obtained in the WiF. The LV Internal Diameter in diastole (LVIDd) was significantly smaller in the 12 week-old SHHF compared to WiF (not shown) but at 16 weeks was found to be significantly larger in the untreated SHHF compared to the WiF. Olmesartan reduced the LVIDd in SHHF to a dimension comparable to that in WiF rats whereas losartan did not have any effect on this parameter. 
A significantly greater LV Wall Thickness in diastole (LVWTd) was observed in the untreated SHHF compared to $\mathrm{WiF}$ at the end of the study period, indicative for left ventricular hypertrophy. Treatment with losartan reduced the LVWTd significantly, but this reduction was even more pronounced after treatment with olmesartan, which reduced this parameter to values observed in the normotensive $\mathrm{WiF}$ rats.

Table 3: Left ventricular dimensions and cardiac function assessed by echocardiography after 4 weeks of treatment.

\begin{tabular}{lllll}
\cline { 2 - 5 } & Wistar Furth & $\begin{array}{l}\text { SHHF } \\
\text { non-treated }\end{array}$ & SHHF-losartan & $\begin{array}{l}\text { SHHF- } \\
\text { olmesartan }\end{array}$ \\
\hline LVAd $\left(\mathrm{mm}^{2}\right)$ & $61 \pm 2 *$ & $66 \pm 2 \dagger \dagger$ & $62 \pm 3 \dagger \$ \$$ & $63 \pm 2 \dagger \#$ \\
LVLd $(\mathrm{mm})$ & $13.8 \pm 0.2 *$ & $14.9 \pm 0.4 \dagger+$ & $14.3 \pm 0.3 \$ \$$ & $14.3 \pm 0.2 \#$ \\
LVIDd $(\mathrm{mm})$ & $4.4 \pm 0.1 *$ & $5.2 \pm 0.2 \dagger$ & $5.1 \pm 0.2 \dagger \$$ & $4.8 \pm 0.3$ \\
LVWTd & $2.2 \pm 0.1$ & $3.3 \pm 0.2 \dagger \dagger$ & $2.8 \pm 0.1 \$ \$ \dagger \uparrow$ & $2.3 \pm 0.1 \#$ q \\
$(\mathrm{mm})$ & & & & \\
\hline EDV $\left(\mathrm{mm}^{3}\right)$ & $230 \pm 11$ & $252 \pm 14+$ & $214 \pm 23 \$ \$$ & $239 \pm 17 \#$ \\
ESV $\left(\mathrm{mm}^{3}\right)$ & $75 \pm 6$ & $73 \pm 6 \dagger$ & $56 \pm 11 \$ \$$ & $70 \pm 3 \#$ \\
SV $\left(\mathrm{mm}^{3}\right)$ & $154 \pm 11$ & $179 \pm 12 \dagger$ & $160 \pm 15 \$ \$$ & $169 \pm 16 \#$ \\
EF $(\%)$ & $67 \pm 3$ & $71 \pm 2$ & $75 \pm 3 \dagger$ & $70 \pm 2$ \\
\hline
\end{tabular}

* vs Wistar Furth day $0 \mathrm{p}<0.01 ; \dagger$ vs Wistar Furth day $28 \mathrm{p}<0.05$; $\dagger$ vs Wistar Furth day $28 \mathrm{p}<0.01 ; \ddagger$ vs SHHF non-treated day $0 \mathrm{p}<0.01$; $\uparrow$ vs SHHF non-treated day $28 \mathrm{p}<0.01 ; \$$ vs SHHF-losartan day $0 \mathrm{p}<0.05 ; \$ \$$ vs SHHFlosartan day $0 \mathrm{p}<0.01$; \# vs SHHF-olmesartan day $0 \mathrm{p}<0.01$

At 12 weeks, both end-diastolic and end-systolic volume (EDV and ESV, respectively) were significantly smaller in the SHHF group compared to the WiF group (not shown). However, in the SHHF group both EDV and ESV increased significantly between 12 and 16 weeks of age so they became similar to the WiF values at the end of the study. A similar pattern was observed for stroke volume (SV). The Ejection Fraction (EF) was comparable between SHHF and WiF groups. At the end of the study, a significantly greater EF was observed in the losartan group whereas in the other groups, it did not significantly differ from the WiF controls.

\section{Markers of cardiac hypertrophy}

To assess the cardiac hypertrophy of the SHHF rats at a molecular level, we determined the expression of LV hypertrophy-associated genes by Real-Time PCR (Fig 1). 
Compared with the normotensive WiF rats, the ANF mRNA levels (Fig. 1A) were 15fold higher in the untreated SHHF group. Treatment with losartan and olmesartan caused a significant reduction in ANF mRNA levels, albeit that only olmesartan could reduce the ANF levels almost to those observed in the WiF control group. A similar pattern was observed for the expression of BNP (Fig. 1B), a parameter that is used clinically as a predictor for morbidity and mortality. The expression patterns of the cytoskeletal proteins $\beta-\mathrm{MHC}$ and $\alpha-\mathrm{MHC}$ are shown in Fig $1 \mathrm{C}$ and $\mathrm{D}$, respectively.
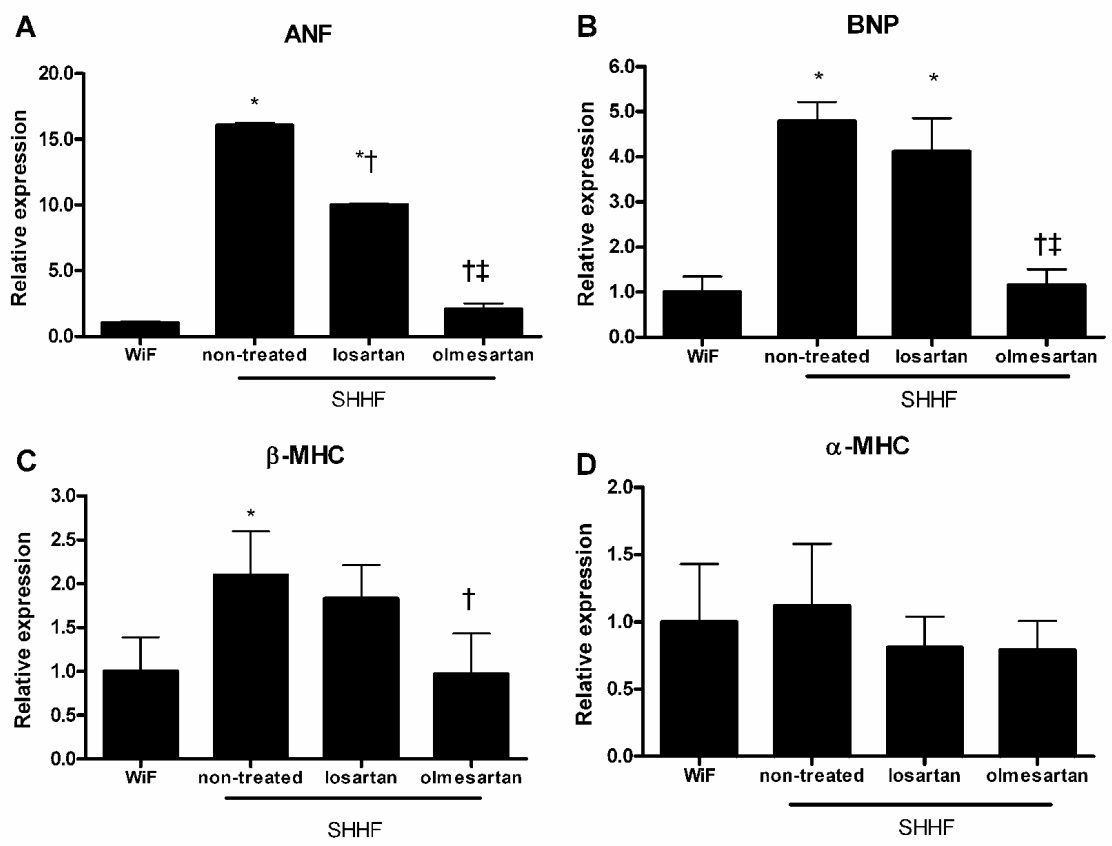

Figure 1. Expression of markers of cardiac hypertrophy. The expression was determined in 16-week old rats which were treated with and ARBs or placebo between week 12 and 16. The data are expressed relative to the normotensive $\mathrm{WiF}$ control hearts. In panel $\mathrm{A}$, the marked increase in atrial natriuretic factor (ANF) expression in the untreated SHHF is shown, which could partially be reversed by losartan treatment and almost completely by olmesartan treatment. The expression of brain natriuretic peptide (BNP) and $\beta$-myosin heavy chain ( $\beta$-MHC), shown in panel $\mathrm{B}$ and $\mathrm{C}$ respectively, follows a similar pattern. No difference in expression of $\alpha-\mathrm{MHC}$ was observed between the groups (panel D). 
There was a significant upregulation of $\beta-\mathrm{MHC}$ expression in the untreated SHHF group, which was slightly reduced after losartan treatment and completely reversed to control levels in the olmesartan group. No significant differences in $\alpha-\mathrm{MHC}$ expression were observed.

\section{Expression of components of the Wnt pathway}

In the 16-week old untreated SHHR a $\sim 3$-fold upregulation of the amounts of Fz-1 and Fz-2 mRNA was observed, compared to age-matched WiF control rats (Fig 2A and B). Interestingly, treatment with either losartan or olmesartan reduced the mRNA levels of Fz-1 and Fz-2 to levels that did not differ significantly from the control WiF group. A similar pattern was observed for the expression of the Dvl-1 gene (Fig 2C). The expression of the Wnt-5a gene showed the opposite pattern, with a reduction of the expression in the untreated SHHF group, which could partially be reversed in both ARB-treated groups (Fig 2D).

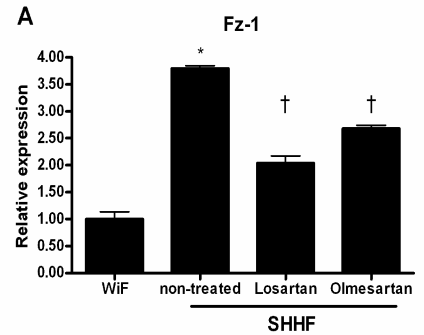

C

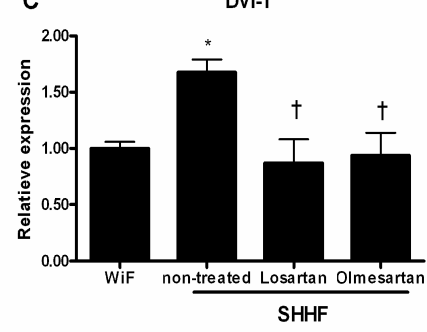

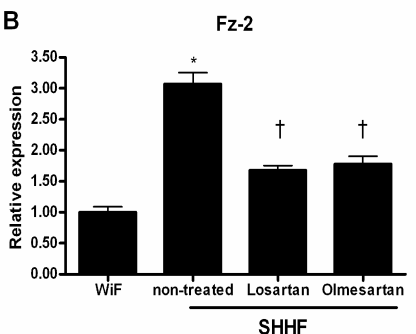

D

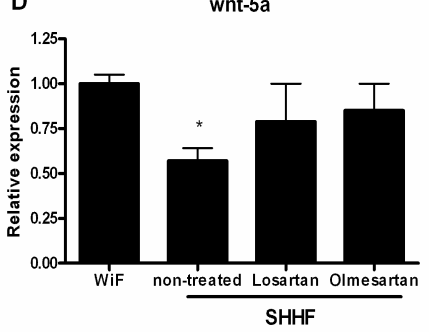

Figure 2. Expression of components of the Wnt signaling pathway. Significant increases in Frizzled -1 (Fz-1), Fz-2 and dishevelled-1 (Dvl-1) expression were observed in the non-treated SHHF rats compared to normotensive $\mathrm{WiF}$ rats (Panel 2A-C). Both losartan and olmesartan treatment resulted in a similar regression of the expression of these genes. On the other hand, Wnt-5a expression was decreased in the non-treated SHHF, but this could also be normalized to the same extent by treatment with either of the ARBs. 


\section{Expression of collagen I and III}

Collagen type I mRNA transcripts (Fig 3A) were similar in all 4 groups, whereas Collagen type III mRNA expression (Fig. 3B) was significantly upregulated in nontreated SHHF rats compared to the normotensive $\mathrm{WiF}$ rats. Treatment with either losartan or olmesartan reduced Collagen type III mRNA expression to the same levels observed in the normotensive $\mathrm{WiF}$ animals.
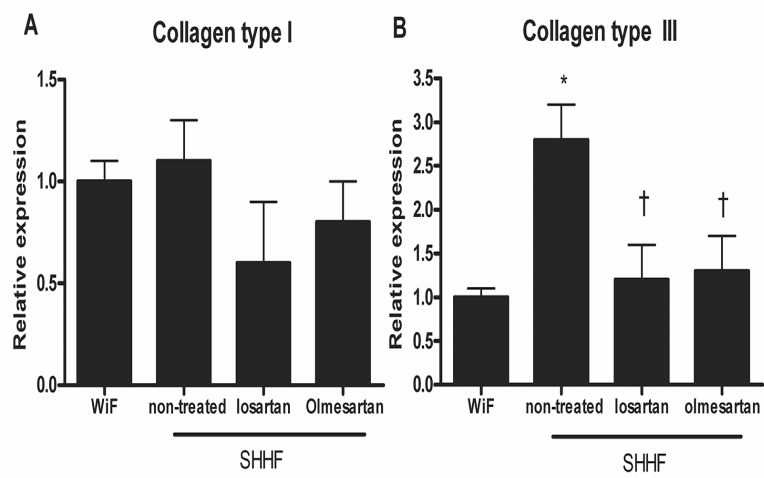

Figure 3. Expression patterns of collagen I and III. No significant differences in collagen I expression were observed in the four groups (Panel A), whereas collagen III expression was significantly upregulated in the non-treated SHHF rats compared to normotensive $\mathrm{WiF}$ controls. However, treatment with either losartan or olmesartan could reduce the expression of collagen III to levels not significantly different from the control values (Panel B).

\section{Expression of the proto-oncogenes c-fos and c-jun}

One of the hallmarks of cardiac hypertrophy is the re-expression of fetal genes like cfos and c-jun (Fig 4). There was a significant upregulation of c-fos (Fig 4A) and c-jun (Fig 4B) mRNA expression in non-treated SHHF animals compared to normotensive $\mathrm{WiF}$ rats. After treatment with ARBs, a significant decrease in the mRNA expression of c-fos and c-jun was observed. There was no difference in the reduction of c-fos and c-jun mRNA expression between losartan and olmesartan.

\section{Discussion}

The aim of the present study was to investigate the effect of ARB treatment on Wnt signaling during the development of cardiac hypertrophy in SHHF rats. To this end, 
treatment of these animals was started at the age of 12 weeks, when hypertension starts to become manifest in these animals. The main finding of the present study was that, although losartan was less effective in counteracting the hypertrophic response than olmesartan, both ARBs showed marked and similar effects on the expression of components of the Wnt signal transduction pathway.

This study shows clear beneficial effects of ARB treatment in the regression of cardiac hypertrophy since wall thickness detected by echocardiography was reduced. Nevertheless, despite the use of equipotent doses, treatment with olmesartan was found to have additional advantages: (1) its efficacy to lower blood pressure in the SHHF is better than losartan, (2) it decreases ventricular hypertrophy assessed by LVW to BW ratio whereas losartan does not. This might be due to a difference in tissue absorption or clearance of the two ARBs. Schwocho et al. ${ }^{17}$ showed that the absolute bioavailability of olmesartan is similar to that of losartan but the terminal elimination half-life of olmesartan is somewhat longer than the half-lives of most drugs in the class 18-20. However, it is not clear whether this can fully explain the lower efficacy of losartan, observed in this study.

SHHF rats are known to display extensive cardiac remodeling and heart failure later in life. Clearly, in the 16 weeks old rats that have been used in this study only an early stage of (compensatory) cardiac remodeling has occurred. First, echocardiographic data did not prove any increase of ESV and EDV, or decrease in SV or FS in SHHF rats compared to $\mathrm{WiF}$ rats. These results are in accordance with previous study that showed no depression of cardiac function in male SHHF before the age of 12 months $^{12,21}$. Second, gene expression of collagen type I (representing around $80 \%$ of the total collagen) in SHHF rats was not elevated. Heyen et al. showed that there was no sign of myocardial fibrosis (interstitial and perivascular) before 9 months of age in SHHF and that expression of collagen type I was not different than control Lewis rats before the onset of $\mathrm{HF}^{12}$. On the other hand, even in 16 week old SHHF rats, the expression of 
collagen type III, more reticulate than type I, which form thick bundles, is clearly upregulated in the SHHF. Angiotensin II receptor blocade by either losartan or olmesartan reverses this upregulation completely. Furthermore, expression of BNP, an established marker of heart failure is more than 4-fold higher in the SHHF model and similar results were observed by Heyen et al. ${ }^{12}$. This upregulation was reversed to control levels by olmesartan whereas losartan only reduced it partially. The switch form $\alpha$-MHC to $\beta$-MHC represents a change from myosin species with fast enzymatic kinetics to one with slower kinetics. The slower enzyme effects energy transduction for contraction with higher economy and this is considered to be adaptive for a heart subjected to increased $\operatorname{load}^{22}$. In our study, we observed a significant reduction in $\beta$ MHC mRNA transcripts after treatment with olmesartan compared to non-treated SHHF animals whereas the $\alpha$-MHC mRNA levels were not different among the 4 groups.
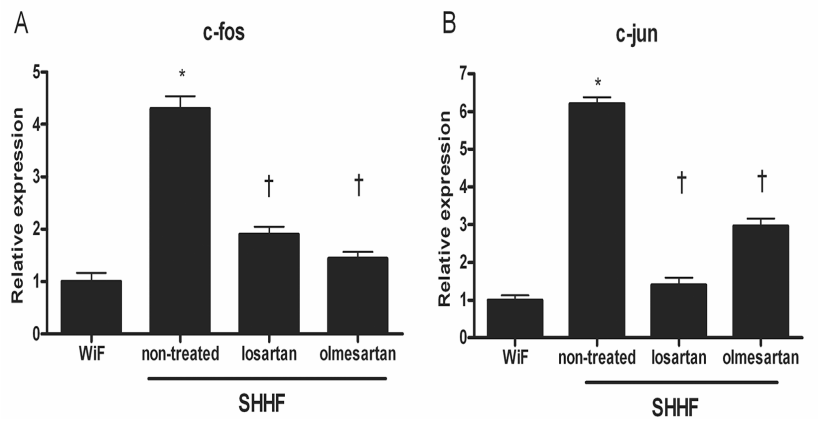

Figure 4. Expression of the proto-oncogenes c-fos and cjun. The expression of both oncogenes was found to be significantly upregulated in the untreated SHHF, compared to normotensive WiF controls. Treatment with either of the two ARBs significantly reduced the levels of c-fos and c-jun expression to levels not significantly different from contol.

The proto-oncogenes c-fos and c-jun may play a critical role in mediating the mechanical signals that initiate protein synthesis and cell growth in the hypertrophic heart ${ }^{23}$. The c-jun and c-fos proteins form dimers, named "the activator protein 1" (AP1) complex that bind DNA through specific response elements to transactivate or transrepress transcription of genes ${ }^{24}$. The expression of the proto-oncogenes c-fos and c-jun were upregulated in non-treated hypertensive SHHF and both the ARBs reduced 
the mRNA transcript levels of c-fos and c-jun almost to the level of the normotensive WiF rats.

The aim of this study was to investigate whether changes in gene expression of components of Wnt signaling pathway correlate with ARB-elicited reversal of cardiac hypertrophy in SHHF rats. In the untreated SHHF Fz-1, Fz-2 and Dvl-1 expression were significantly upregulated, which is in agreement with earlier observations in other models of cardiac hypertrophy ${ }^{25-27}$ Here, we showed that treatment with either of the two ARBs reduced the expression of Fz-1, Fz-2 and Dvl-1 mRNA transcripts, whereas the expression of Wnt-5a was upregulated. Despite the fact that olmesartan appears to be more effective in reducing the cardiac hypertrophic response, the effect of both olmesartan and losartan on the regulation of the expression of components of Wnt signaling were the same. This suggests that the response of Wnt signaling to ARB treatment is not secondary to the regression of cardiac hypertrophy, but that ARBs can act in a more direct fashion on the expression of Wnt signaling components. The mechanism behind this proposed direct link between angiotensin signaling and expression of Wnt signaling components is unclear and will need further investigation.

In conclusion, AT-1 blockade by olmesartan can reduce the development of cardiac hypertrophy in SHHR, as characterized by increased heart weight, ANF, BNP and $\beta$ MHC, collagen III mRNA levels. Losartan appeared to be less effective than olmesartan in this respect, despite the fact that both ARBs were administered in an equipotent dose. The effect of the ARBs on expression of ANF, BNP and Collagen III mRNA transcripts was clearly dependent on the reduction in cardiac hypertrophy whereas the changes in expression of mRNA transcripts of the Wnt-signaling components appeared to make use of a different, hypertrophy-independent mechanism that awaits further investigation. 


\section{Reference}

1. Ho KK, Pinsky JL, Kannel WB, et al. The epidemiology of heart failure: the Framingham Study. J Am Coll Cardiol.1993;22(4 Suppl A):6A-13A.

2. Levy $D$, Larson MG, Vasan RS, et al. The progression from hypertension to congestive heart failure. Jama.1996;275(20):1557-1562.

3. Tamura T, Said S, Harris J, et al. Reverse remodeling of cardiac myocyte hypertrophy in hypertension and failure by targeting of the renin-angiotensin system. Circulation.2000;102(2):253-259.

4. Gagnon C, Legault F, Geraldes P, et al. Diverse effects of Ace inhibitors and angiotensin II receptor antagonists on prevention of cardiac hypertrophy and collagen distribution in spontaneously hypertensive rats. Int J Cardiol.2004;97(3):373-381.

5. Sanada S, Kitakaze M, Node K, et al. Differential subcellular actions of ACE inhibitors and AT(1) receptor antagonists on cardiac remodeling induced by chronic inhibition of NO synthesis in rats. Hypertension.2001;38(3):404-411.

6. McMurray JJ, Ostergren J, Swedberg K, et al. Effects of candesartan in patients with chronic heart failure and reduced left-ventricular systolic function taking angiotensin-convertingenzyme inhibitors: the CHARM-Added trial. Lancet.2003;362(9386):767-771.

7. Pitt B, Poole-Wilson PA, Segal R, et al. Effect of losartan compared with captopril on mortality in patients with symptomatic heart failure: randomised trial--the Losartan Heart Failure Survival Study ELITE II. Lancet.2000;355(9215):1582-1587.

8. Cohn JN, Tognoni G. A randomized trial of the angiotensin-receptor blocker valsartan in chronic heart failure. N Engl J Med.2001;345(23):1667-1675.

9. Granger CB, McMurray JJ, Yusuf S, et al. Effects of candesartan in patients with chronic heart failure and reduced left-ventricular systolic function intolerant to angiotensin-convertingenzyme inhibitors: the CHARM-Alternative trial. Lancet.2003;362(9386):772-776.

10. Force T, Woulfe K, Koch WJ, et al. Molecular scaffolds regulate bidirectional crosstalk between Wnt and classical seven-transmembrane-domain receptor signaling pathways. Sci STKE.2007;2007(397):pe41.

11. Tamura T, Said S, Gerdes AM. Gender-related differences in myocyte remodeling in progression to heart failure. Hypertension.1999;33(2):676-680.

12. Heyen JR, Blasi ER, Nikula K, et al. Structural, functional, and molecular characterization of the SHHF model of heart failure. Am J Physiol Heart Circ Physiol.2002;283(5):H1775-1784.

13. Park S, McCune SA, Radin MJ, et al. Verapamil accelerates the transition to heart failure in obese, hypertensive, female SHHF/Mcc-fa(cp) rats. J Cardiovasc Pharmacol.1997;29(6):726733.

14. Hohl CM, Hu B, Fertel RH, et al. Effects of obesity and hypertension on ventricular myocytes: comparison of cells from adult SHHF/Mcc-cp and JCR:LA-cp rats. Cardiovasc Res.1993;27(2):238-242.

15. Nelissen-Vrancken HJ, Struijker-Boudier HA, Smits JF. Renal hemodynamic effects of nonhypotensive doses of angiotensin-converting enzyme inhibitors in hypertension and heart failure rats. J Cardiovasc Pharmacol.1992;19(2):163-168.

16. Slama M, Ahn J, Varagic J, et al. Long-term left ventricular echocardiographic follow-up of SHR and WKY rats: effects of hypertension and age. Am J Physiol Heart Circ Physiol.2004;286(1):H181-185.

17. Schwocho LR, Masonson HN. Pharmacokinetics of CS-866, a new angiotensin II receptor blocker, in healthy subjects. J Clin Pharmacol.2001;41(5):515-527.

18. van Lier JJ, van Heiningen PN, Sunzel M. Absorption, metabolism and excretion of 14Ccandesartan and 14C-candesartan cilexetil in healthy volunteers. J Hum Hypertens.1997;11 Suppl 2:S27-28. 
19. De Cesare D, Vallone D, Caracciolo A, et al. Heterodimerization of c-Jun with ATF-2 and c-Fos is required for positive and negative regulation of the human urokinase enhancer. Oncogene.1995;11(2):365-376.

20. Sekiguchi $\mathrm{K}$, Li X, Coker M, et al. Cross-regulation between the renin-angiotensin system and inflammatory mediators in cardiac hypertrophy and failure. Cardiovasc Res.2004;63(3):433442.

21. Reffelmann T, Kloner RA. Transthoracic echocardiography in rats. Evalution of commonly used indices of left ventricular dimensions, contractile performance, and hypertrophy in a genetic model of hypertrophic heart failure (SHHF-Mcc-facp-Rats) in comparison with Wistar rats during aging. Basic Res Cardiol.2003;98(5):275-284.

22. Schaub MC, Hefti MA, Harder BA, et al. Various hypertrophic stimuli induce distinct phenotypes in cardiomyocytes. J Mol Med.1997;75(11-12):901-920.

23. Schunkert $H$, Jahn $L$, Izumo $S$, et al. Localization and regulation of $c$-fos and c-jun protooncogene induction by systolic wall stress in normal and hypertrophied rat hearts. Proc Natl Acad Sci U S A.1991;88(24):11480-11484.

24. Omura $\mathrm{T}$, Yoshiyama M, Yoshida $\mathrm{K}$, et al. Dominant negative mutant of c-Jun inhibits cardiomyocyte hypertrophy induced by endothelin 1 and phenylephrine. Hypertension.2002;39(1):81-86.

25. Blankesteijn WM, Essers-Janssen YP, Ulrich MM, et al. Increased expression of a homologue of drosophila tissue polarity gene "frizzled" in left ventricular hypertrophy in the rat, as identified by subtractive hybridization. J Mol Cell Cardiol.1996;28(5):1187-1191.

26. van de Schans VA, van den Borne SW, Strzelecka AE, et al. Interruption of Wnt signaling attenuates the onset of pressure overload-induced cardiac hypertrophy. Hypertension.2007;49(3):473-480.

27. Castoldi G, Redaelli S, van de Greef WM, et al. Angiotensin II modulates frizzled-2 receptor expression in rat vascular smooth muscle cells. Clin Sci (Lond).2005;108(6):523-530. 
CHAPTER 5
112 


\section{Chapter 6}

\section{Anti-Hypertrophic Remodeling}

of the Heart

\section{in Cyp1A1-mRen2 transgenic rats.}

V.A.M. van de Schans, J.F.M Smits, W.M. Blankesteijn, B.J.A. Janssen 
114

\section{Abstract}

Background. When the aryl hydrocarbon, indole-3-carbinol (I3C), is added to the food $(6 \mathrm{~g} / \mathrm{kg})$ of male transgenic rats TGR(Cypla1-mRen2), the additional mouse renin-2 gene is activated and fulminant hypertension develops (systolic blood pressure $>250$ $\mathrm{mmHg}$ ). The hypertension can be toggled off by withdrawal of $\mathrm{I3C}$. We studied hypertrophic cardiac remodeling 6 weeks after induction of hypertension $(n=5)$ and 5 weeks after withdrawal of I3C when blood pressure (measured by the tail cuff method) had returned to control levels $(n=4)$. Left ventricular (LV) functional (echocardiography), histological (collagen) and molecular data were compared to those obtained in TGR(Cypla1-mRen2) rats not treated with I3C $(\mathrm{n}=5)$.

Results. In TGR(Cypla1-mRen2) rats I3C-induced hypertension was associated with concentric cardiac hypertrophic remodeling without fibrosis. LV end-diastolic and stroke volumes were decreased and LV wall thickness increased significantly from $0.15 \pm 0.01$ to $0.20 \pm 0.01 \mathrm{~cm}$. Relative to controls, mRNA expression levels of the hypertrophic markers Atrial natriuretic factor (ANF) and $\beta$-myosin heavy chain ( $\beta$ MHC) were significantly increased by 10 and 2.5 times, respectively, whereas the mRNA level of a marker for LV dilatation (Thrombospondin 2) was not altered. The

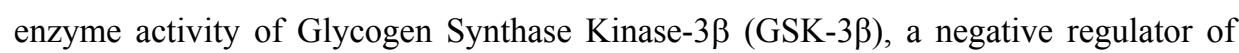
LV hypertrophy, was significantly lowered ( $74 \pm 2 \%$ of control). Five weeks after I3C was withdrawn in induced rats, blood pressure and LV wall thickness returned to values observed in non-treated rats and was associated with a normalization of ANF and $\beta$-MHC expression, and GSK-3 $\beta$ enzyme activity.

Conclusion. Despite a 6 weeks period of malignant hypertension and the development of concentric cardiac hypertrophy, reversal of hypertrophic remodeling of the heart is fully preserved in TGR(Cypla1-mRen2) rats. 


\section{Introduction}

Cardiac hypertrophy is a compensatory enlargement of the heart when its workload is exceeding the normal capacity. Physiological hypertrophy (e.g.. exercise-induced) is characterized by increases in left ventricular (LV) chamber size, wall thickness and mass, and acts to enhance cardiac function during exercise ${ }^{1}$. This type of hypertrophy is not associated with increased risk for cardiac malfunction. In contrast, pathological hypertrophy (in most cases due to increased afterload) predisposes to a significant increase in risk of adverse consequences, such as myocardial ischemia, systolic and diastolic dysfunction and involves many alterations in myocardial structure and function $^{2,3}$. Accordingly, myocardial hypertrophy is an early milestone during the clinical course of hypertension and heart failure and an important risk factor for subsequent cardiac morbidity and mortality ${ }^{4}$.

Malignant hypertension is a severe form of hypertension. In patients, this is characterized by extremely high blood pressures, pressure diuresis and natriuresis, severe renal vasoconstriction and ischemia, activation of the renin-angiotension system (RAS), micro-angiopathy, hemolytic anemie and development of retinopathy ${ }^{5}$.

The first transgenic rat in hypertension research was the transgenic TGR(mRen2)27 created by Mullins et al. ${ }^{6}$. One of the drawbacks of this animal model is that the development of hypertension can not be controlled in time. Already at a very young age (5 weeks) these rats develop an agiotensin II-dependent fulminant hypertension (systolic blood pressures $>230 \mathrm{mmHg}$ ). Therefore Mullins et al. subsequently created a transgenic rat strain: TGR(Cypla1-mRen2) that allowed a time-controllable induction of malignant hypertension. This was achieved by inserting the mouse Ren 2 renin gene, fused to an 11.5-Kb fragment of the cytochrome P-450 1a1 (Cyp1a1) promotor, into the genome of the Fisher 344 rat $^{7}$. In this transgenic model, activation of the Cyp1al promoter by dietary administration of indole-3-carbinol (I3C) results in induction of the expression of the mRen2 renin gene and the development of ANG II-dependent hypertension ${ }^{7}$. The height of the blood pressure can be titrated by the dose of $13 \mathrm{C}^{8}$. When $\mathrm{I} 3 \mathrm{C}$ is mixed through the regular rat chow at $3 \mathrm{~g} / \mathrm{kg}$ or higher, rats develop 
malignant hypertension that is characterized by loss of body weight, polyuria, polydypsia as a result of salt and water depletion ${ }^{7,9,10}$. The hypertension can be toggled off by withdrawing I3C from the food. This has been demonstrated by the return of blood pressure to control levels after single bolus injections of $\mathrm{I}^{2} \mathrm{C}^{7}$. Previously we have shown that non-inducible homozygous TGR(mRen2)27 rats invariably develop cardiac hypertrophy at young age. However, with advancing age dilated cardiomyopathy and heart failure developed only in a subset (about 50\%) of these rats. This could be predicted by the early activation of the matricellular tromospondin-2 gene (TSP2). To date, it is unknown if prolonged exposure to I3C does induce dilated cardiomyopathy and heart failure in the inducible TGR(Cypla1-mRen2) strain too. Moreover, it is also not known if the heart is able to regress after a period of adaptation to fulminant hypertension.

Recently, the protein kinase Gycogen Synthase Kinase-3 $\beta$ (GSK-3 $\beta$ ) has been identified as a negative regulator of cardiac hypertrophy. Its role has been studied in several hypertrophic animal models but not in this inducible transgenic rat model ${ }^{11-17}$. GSK-3 $\beta$ is known as a nodal point that integrates various inputs from multiple signaling pathways and conducts signals downstream to multiple effectors ${ }^{18}$. One of these effectors is $\beta$-catenin. Phosphorylation of $\beta$-catenin by GSK-3 $\beta$ makes it a target for proteasomal degradation ${ }^{19}$. $\beta$-catenin is a central component of the canonical Wntpathway, and Wnt stimulation leads to increased cytosolic $\beta$-catenin levels and activation of transcription of target genes ${ }^{20-22}$. In the hypertrophic response, $\beta$-catenin is both necessary and sufficient to induce hypertrophic growth when expressed in cardiomyocytes in vitro and in vivo, as shown by Haq et al. ${ }^{23}$.

We studied cardiac remodeling in this TGR(Cyp1a1-mRen2) rat model during prolonged treatment with $\mathrm{I} 3 \mathrm{C}$ and questioned if dilated cardiomyopathy could be induced similarly as in the related non-inducible TGR(mRen2)27 rat strain. We also studied cardiac remodeling following withdrawal of the $\mathrm{I} 3 \mathrm{C}$ diet and examined if cardiac changes in GSK-3 $\beta$ activity are related to the induction and regression phase of hypertension. To this end, three groups of TGR(Cyp1a1-mRen2) animals were studied 
at adult age (30 weeks), one control group with normal rat chow, one I3C group (rat chow with $0.6 \%$ I3C for 6 weeks) and one regression group (5 weeks after withdrawal of a 6-week I3C treatment). In previous studies with this model, rats were given I3C at a maximum does of $0.3 \%$. In order to stress the heart maximally we used the highest dose of $\mathrm{I} 3 \mathrm{C}$ that could be mixed trough the food. Because several animals studies have shown that hearts of adult animals are more susceptible to damage than hearts of young animals $^{24}$, we chose to include adult animals ( $>3$ month) only.

\section{Methods}

\section{Animals.}

TGR(Cyp1a1-mRen2) transgenic rats were bred from a single breeding pair originally obtained from the Molecular Physiology Laboratory of the University of Edinburgh. The breeding, maintenance and study of the TGR(Cyp1a1-mRen2) transgenic rats was approved by the animal ethics committee of Maastricht University (The Netherlands). The experimental protocols were performed according to institutional guidelines. Animals were housed in pairs in standard cages on a 12/12 h light/dark cycle. All rats had free access to tap water and standard commerical rodent chow containing $0.25 \%$ sodium (Ssniff, Soest, Germany) prior to experimental procedures and TGR (Cypla1mRen2) transgenic rats were fed ad libitum either normal chow with (I3C group, $\mathrm{n}=5$ ) or without (control group, $\mathrm{n}=5$ ) $0.6 \%$ indole-3-carbinol (I3C) for 6 weeks. The third group of rats was fed normal chow with $0.6 \%$ I3C for 6 weeks after which $\mathrm{I} 3 \mathrm{C}$ was withdrawn for 5 weeks. To mask the flavour of the inducer (I3C), peanut oil added to the chow mixture with some water, resulting in a thick paste.

\section{Blood pressure and heart rate.}

Systolic Blood Pressure (SBP) was measured in conscious restrained animals by an indirect method using a tail cuff inflating unit linked to a blood pressure transducer (IICT Life Science, USA). The animals were trained for one week prior to the start of 
the experiments. Training consisted of placing the animals in the heated $\left(30^{\circ} \mathrm{C}\right)$ measuring chamber for 15 minutes and then inflating the cuff to take $3-5$ mock measurements. SBP was then measured on weekly intervals. Three to five SBP measurements were taken for each animal on each recording day and then averaged.
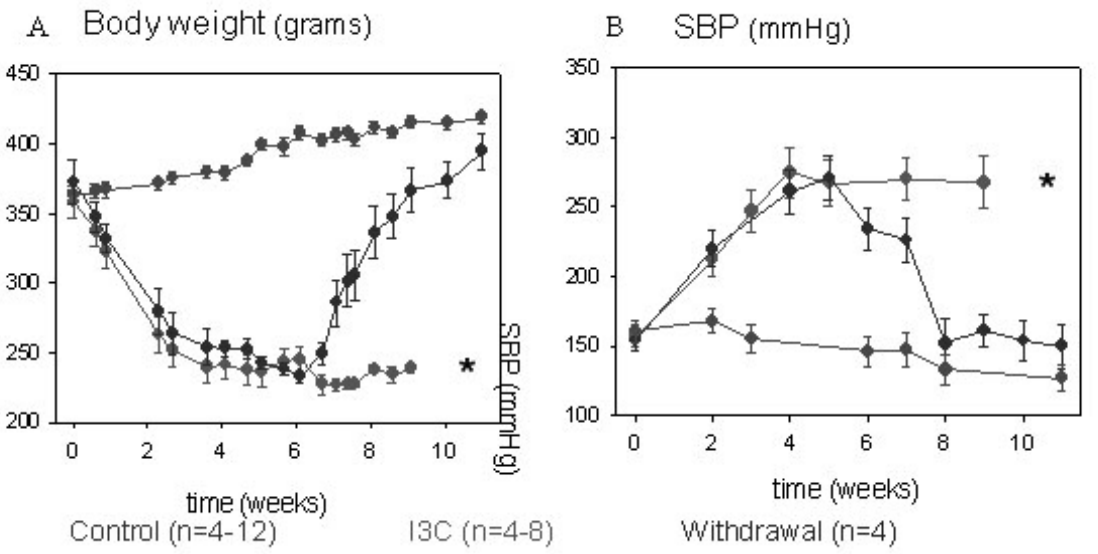

Figure 1. Body weight and Systolic Blood Pressure (SBP) in the control $(n=4-12)$, I3C treated $(n=4-8)$ and regression (withdrawal) group $(n=4)$. Values are expressed as means \pm S.E.M. and $* \mathrm{P}<0.05$ vs. control.

\section{Food consumption, water and urine volume.}

Four weeks after I3C treatment rats were individually housed in metabolic cages for 24 hours for monitoring of water and food intake and urine collection. Food consumption, water intake and urine volume were determined gravimetrically. This procedure was repeated in the withdrawal group, 4 weeks after I3C was withdrawn.

\section{Echocardiography.}

The in vivo transthoracic echocardiography of the rat left ventricle was performed using a Hewlett-Packard 15-MHz linear array transducer interfaced with a Sonos 5500 echocardiography system (Philips, Eindhoven, The Netherlands). Two-dimensional BMode echocardiograms were captured at a rate of 90-120 Hz from parasternal long-axis views as well as from mid-papillary short-axis views of the left ventricle. Digital recordings were analysed off-line during three cardiac cycles to obtain measurements 
taken in end-systole and diastole per animal per time point using Enconcert Software (Agilent Technologies, Andover, MA, USA). Echocardiographic measurements were performed under light isoflurane anaesthesia at 3 time points being a) before administration of I3C, b) 4-5 weeks after administration of I3C, and c) 4-5 weeks after I3C was withdrawn. During alle measurements body temperature was maintained at $37^{\circ} \mathrm{C}$, by placing the rats on a heating pad. At the end of the study rats were deeply anesthetized with isoflurane and organs were harvested. Hearts were divided into 2 pieces; one part was used for histology, the other part for RNA and protein isolation.

\section{Sirius Red staining.}

One part of the hearts wes fixed with $1 \%$ formalin overnight, and then embedded in paraffin. Four $\mu \mathrm{m}$ sections were cut and stained with Picrosirius Red to quantify interstitial fibrosis. A computerized morphometric system (Quantimet, version Leica Qwin3.1; Leica, England) was utilized to analyse the ratio of interstitial fibrosis to the total left ventricular area from randomly selected microscope fields of left ventricular sections.

\section{Real-Time PCR.}

LV-RNA was isolated using the Rneasy Mini Kit (Quiagen, Hilden, Germany). The RNA was transcribed into cDNA with Superscript III reverse-transcriptase, using 250 mg of random primers (Invitrogen Life Technologies, Breda, The Netherlands). RTPCR primers were designed from rat sequences available in GenBank using Primer Express (PE Applied Biosystems, Foster City CA, USA), the designed primers were used to quantify the expression of mRNA levels of atrial natriuretic factor (ANF), $\beta$ Myosin heavy chain ( $\beta$-MHC), Thrombospondin-1 and -2 (TSP1 and TSP2). Amplification and detection were performed using the MyIQ system of Biorad (Biorad, Hercules, CA, USA). Cardiac gene expression was normalized to the housekeeping gene Cyclophilin A. All samples were run in duplicates. Data analyses were performed using the MyIQ System software (Biorad). 


\section{Western immunoblot analyses.}

Total protein extracts were prepared as follows: left ventricular tissue was added to 1 $\mathrm{ml}$ ice-cold Laemmli buffer and homogenized with a PRO200 tissue homogenizer (PRO Scientific, Monroe CT, USA). After sonification and centrifugation, the supernatant was collected and stored at $-80^{\circ} \mathrm{C}$. The protein content of supernatant was measured by using the BCA protein Assay (Pierce Biotechnology Inc., Rockford IL, USA). For Western blotting, $20 \mu \mathrm{g}$ of total protein was denatured by boiling in Laemmli sample buffer and separated on a $10 \%$ SDS-PAGE gel, and transferred onto a HybondC nitrocellulose membrane (Amersham Biosciences Europe, Freiburg, Germany). After blocking in 5\% non-fat dry milk (Biorad), $0.1 \%$ Tween 20 in Trisbuffered saline for 1 hour, membranes were incubated overnight with the following primary antibodies at $4{ }^{\circ} \mathrm{C}$ : $\beta$-catenin, GSK-3 $\beta$ and $\mathrm{pTyr}^{216}$-GSK-3 $\beta$, (BD Transduction Laboratories, Lexington KY, USA); pSer $^{9}$ GSK-3 $\beta$ (Cell Signaling Technology, Beverly MA, USA); $\alpha$-tubulin (Santa Cruz Biotechnology, Santa Cruz CA, USA). Anti-rabbit IgG and anti-mouse IgG Horseradish Peroxidase-conjugated antibodies (DAKO, Glostrup, Denmark) were used as the secondary antibodies as appropriate and the membranes were developed by Supersignal West Pico chemiluminescence kit (Pierce Biotechnology Inc.).

\section{GSK-3ß kinase assay.}

Total GSK-3 $\beta$ was immunoprecipated from $200 \mu \mathrm{g}$ protein extracts in lysis buffer as previously described (see ref. ${ }^{25}$ ). Briefly, the samples were precleared with protein GSepharose beads (Amersham Biosciences) for 1 hour and then subjected to immunoprecipitation with anti-mouse GSK-3 $\beta$ antibody (BD Transduction Laboratories, plaats USA) overnight at $4{ }^{\circ} \mathrm{C}$ with gentle agitation, protein G-Sepharose was added and agitated for 1 hour at $4{ }^{\circ} \mathrm{C}$. Immunocomplexes were recovered by centrifugation and washed once with lysis buffer and twice in kinase buffer. Kinase activity was assayed in $40 \mu \mathrm{l}$ of total reaction buffer containing $62.5 \mu \mathrm{M}$ GSK-3 Peptide Substrate (Biomol P-151, Exeter, UK) $20 \mathrm{mM} \mathrm{MgCl}_{2}, 125 \mu \mathrm{M}$ ATP and $10 \mu \mathrm{Ci}$ 
$\left[\gamma_{-}{ }^{32} \mathrm{P}\right]$ ATP (Amersham Biosciences). After $30 \mathrm{~min}$ of incubation at $30^{\circ} \mathrm{C}, 25 \mu \mathrm{l}$ aliquots were spotted onto $1.5 \mathrm{~cm} \mathrm{X} 1.5 \mathrm{~cm}$ pieces of Whatman P81 Phosphocellulose paper (Whatman Nederland B.V., 's Hertogenbosch, Netherlands), and $30 \mathrm{~s}$ later, the filter papers were washed 5 times in $0.75 \%$ phosphoric acid. The filter papers were counted in a liquid scintillation counter. Quantification of kinase was achieved by counting the amount of ${ }^{32} \mathrm{P}$ incorporated into the substrate.

\section{Statistical analyses.}

Results are reported as mean \pm SEM. Differences between the 3 groups were tested using a one-way ANOVA With Tukey's multiple comparison test to identify the individual between-group differences. $\mathrm{P}<0.05$ was considered statistically significant.

Table 1: Morphological data relative to tibia length and Organ weights at the end of the study.

\begin{tabular}{lccc}
\hline & Control $(\mathrm{n}=7)$ & I3C-treated $(\mathrm{n}=6)$ & Regression $(\mathrm{n}=4)$ \\
\hline Absolute values & & & \\
\hline Body weight $(\mathrm{g})$ & $409 \pm 4$ & $217 \pm 9^{*}$ & $393 \pm 9$ \\
Heart weight $(\mathrm{g})$ & $0.97 \pm 0.02$ & $0.87 \pm 0.03^{*}$ & $1.09 \pm 0.04^{*} \dagger$ \\
Right kidney weight $(\mathrm{g})$ & $1.08 \pm 0.02$ & $1.19 \pm 0.05^{*}$ & $1.16 \pm 0.01$ \\
Left kidney weight (g) & $1.11 \pm 0.02$ & $1.21 \pm 0.05$ & $1.23 \pm 0.06^{*}$ \\
Liver weight (g) & $12.0 \pm 0.35$ & $12.6 \pm 0.66$ & $14.4 \pm 0.34^{*}$ \\
Lung weight (g) & $1.26 \pm 0.02$ & $1.10 \pm 0.06$ & $1.36 \pm 0.06$ \\
Tibia length (mm) & $58.2 \pm 0.3$ & $55.9 \pm 0.8^{*}$ & $57.6 \pm 0.9$ \\
& & & \\
\hline Ratio's relative to BW & & & \\
\hline Heart (g/kg) & $2.37 \pm 0.05$ & $4.04 \pm 0.13^{*}$ & $2.77 \pm 0.11^{*} \dagger$ \\
Right Kidney (g/kg) & $2.64 \pm 0.36$ & $5.49 \pm 0.28^{*}$ & $2.96 \pm 0.08 \dagger$ \\
Left Kidney (g/kg) & $2.73 \pm 0.33$ & $5.60 \pm 0.33^{*}$ & $3.14 \pm 0.18 \dagger$ \\
& & & \\
\hline Ratio's relative to Tibia & & & \\
\hline Heart (g/mm) & $1.67 \pm 0.02$ & $1.56 \pm 0.03^{*}$ \\
Right kidney (g/mm) & $1.85 \pm 0.02$ & $2.11 \pm 0.07^{*}$ & $2.02 \pm 0.03$ \\
Left kidney (g/mm) & $1.91 \pm 0.02$ & $2.16 \pm 0.08^{*}$ & $2.14 \pm 0.09^{*}$ \\
& & &
\end{tabular}




\section{Results}

\section{Blood pressure and heart rate}

Following 0.6\% I3C treatment, TGR(Cyplal-mRen2) developed within 2 weeks a significant and sustained increase in systolic blood pressure (SBP $>250 \mathrm{~mm} \mathrm{Hg}$ ), whereas in control rats SBP remained rather stable throughout the observation period (see Fig 1A). After withdrawal of I3C, SBP returned to control levels within 5 weeks. Heart rates were not different between groups (Control: $349.8 \pm 17.6$; I3C treated: $323.1 \pm 29.3$ and Regression group: $377.2 \pm 15.4$ ).

Table 1 shows the weights of the organs collected at the end of the study. Data are given in absolute and relative terms because of the differences in body weight between the 3 groups.

The increased blood pressure was accompanied by a gradual and significant loss of body weight averaging $\sim 37 \%$ after 6 weeks of I3C treatment (fig 1B and Table 2). Thereafter, rats maintained $\mathrm{BW}$ at about $250 \mathrm{~g}$. After withdrawal of the $\mathrm{I} 3 \mathrm{C}$, the TGR(Cyp1a1-mRen2) regained their body weight rapidly (fig 1B and Table 2). The data indicate that, both in absolute terms and relative to tibia length, heart weight was slightly but significantly reduced in I3C-treated rats, but was increased relative to bodyweight. Control animals gained approximately $50 \mathrm{~g}$ over the experimental period. In rats in which $\mathrm{I} 3 \mathrm{C}$ was withdrawn, heart weights were higher than those observed in I3C-treated rats and control rats, suggesting additional growth.

\section{Food Consumption, Water intake and Urine Volume}

The TGR(Cyplal-mRen2) food intake was higher when treated with I3C than when normal rat chow was provided (Fig. 2A). Fluid intake (Fig. 2B) was also significantly higher in $0.6 \%$ I3C-treated TGR(Cyplal-mRen2) than in control animals. SBP rose within 3 weeks to levels above $250 \mathrm{mmHg}$ (see Figure 1a). This was associated with a significant pressure-diuresis. Urine volume was about 7-fold higher in transgenic rats on I3C than in non-treated controls. Differential effects on changes in organ weight 
following induction and withdrawal of $\mathrm{I} 3 \mathrm{C}$ were also found for liver and lungs, suggesting I3C related specific activation of katabolic and anabolic pathways (Table 2).

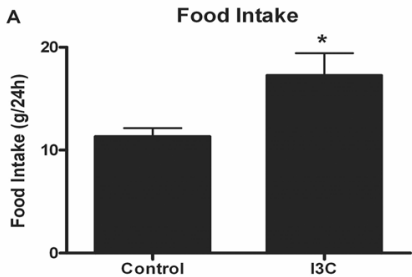

B
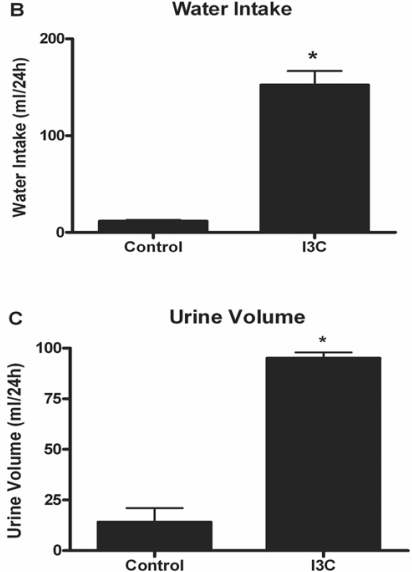

Figure 2. Food intake (A), Water intake (B) and urine volume (C) in control and I3C treated TGR(cypla1-Ren2). Measurements were performed over $24 \mathrm{~h}$ in metablic cages. Values are expressed as means \pm S.E.M. and $* \mathrm{P}<0.05$ vs. control.

\section{Echocardiographic measurements}

Echocardiographic data showed an increase in left ventricular (LV) wall thickness in diastole 4 weeks after treatment with $0.6 \%$ I3C (Fig 3A and 3B), whereas the LV outer diameter and LV length were not altered. Consequently end-diastolic LV Volume (EDV) was significantly reduced 4 weeks after $0.6 \%$ I3C treatment (Fig 3C and 3D). I3C treatment was also associated with a markedly reduced stroke volume (SV), which may be suggestive for diastolic heart failure (Fig 3E and 3F), no signs of congestion were observed. After cessation of the $0.6 \%$ I3C diet EDV and SV returned to levels observed in control animals (Fig 3B, 3D and 3F). 

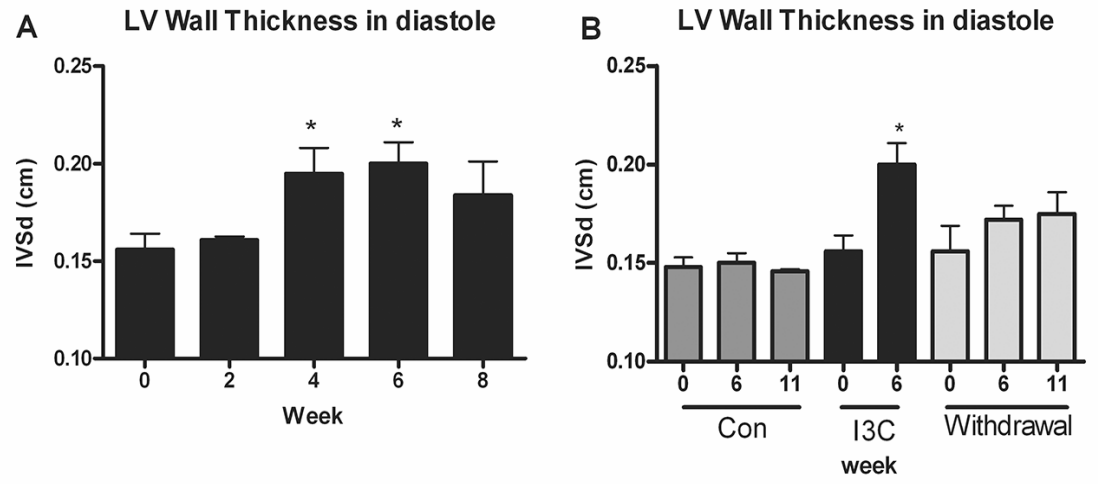

C End-diastolic LV Volume
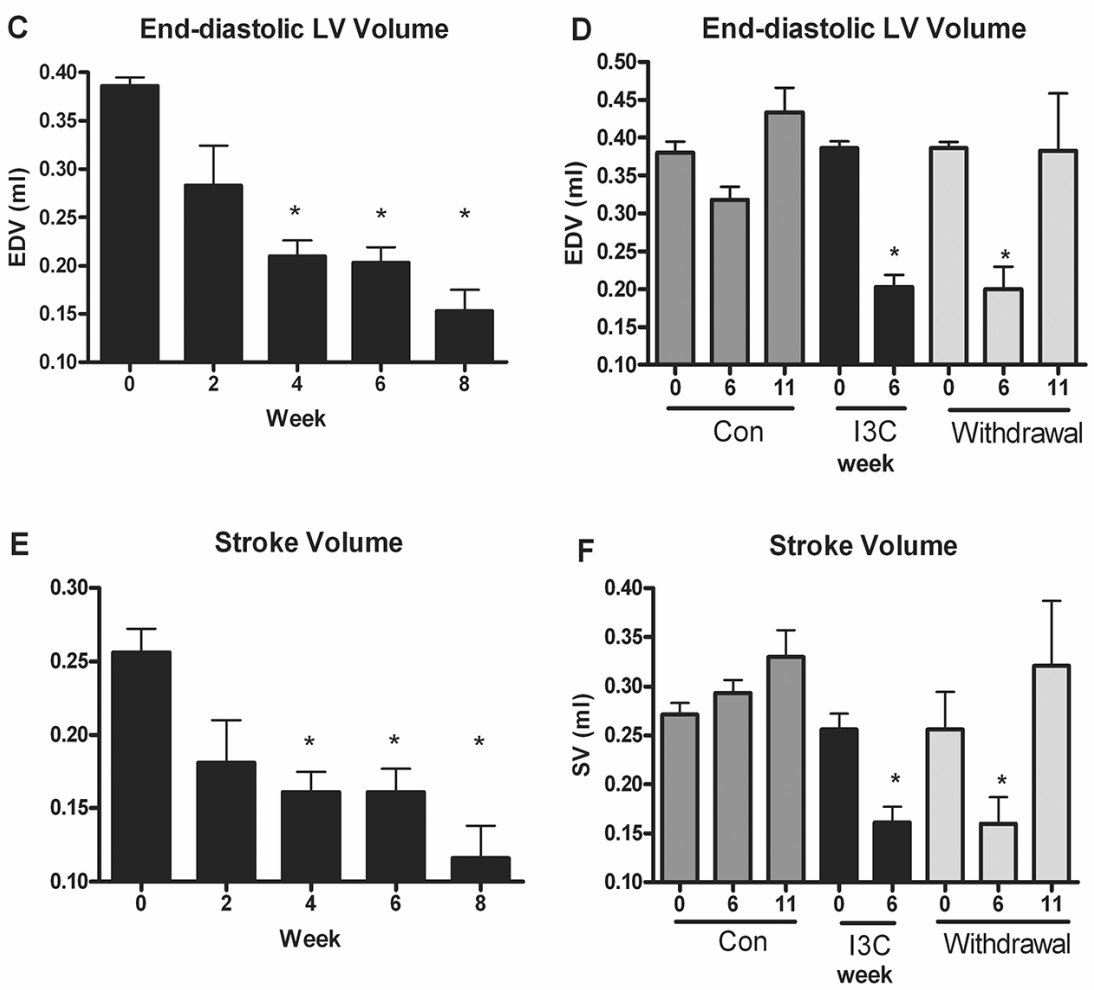

Figure 3. Echocardiographic measurements of TGR(cypla1-Ren2). Panel A, C and E presents echocardiographic data in time of $\mathrm{I} 3 \mathrm{C}$ treated rats, whereas Panel B, D and F shows the control (dark grey bars), I3C treated (black bars) and regression (Withdrawal) (light grey bars) group at week 0, week 6 and week 11. A and B) Left Ventriclar Wall thickness in Diastole; C and D) End diastolid Left Ventricle Volume (EDV); and E and F) Stroke Volume (SV). Values are expressed as means \pm S.E.M. and $* \mathrm{P}<0.05$ vs. control. 


\section{Fibrosis of the left ventricular heart}

Histopathological investigation of interstitial fibrosis in picrosirius red-stained crosssections of the left ventricle showed no difference in interstitial fibrosis between all the groups, $10 \%, 9.5 \%$ and $12,4 \%$ for Controle, I3C and the regression group. (Fig 4).

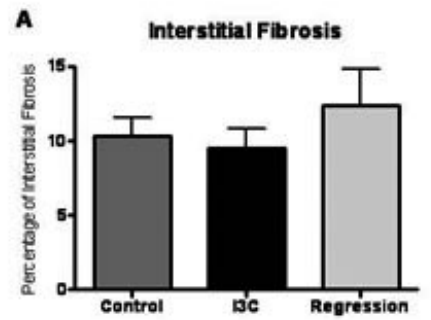

c

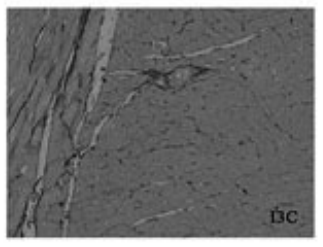

B

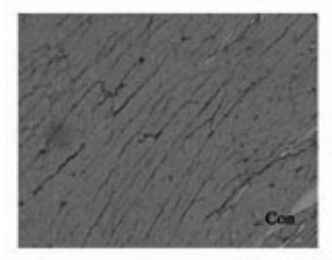

D

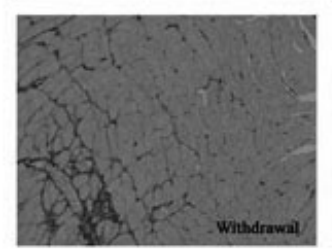

Figure 4. Sirius Red stained sections for collagen staining in the left ventricle of the heart of TGR(cypla1-Ren2). A shows the bar-graph of amount of Interstitial Fibrosis as determined by picosirius red staining, B) Control TGR(cypla1-Ren2), C) Treated I3C TGR(cyplalRen2) and D) regression (withdrawal) of I3C treatment in TGR(cyp1a1-Ren2). Values are expressed as means \pm S.E.M. and $* \mathrm{P}<$ 0.05 vs. controle. All $n=4-8$.

\section{Molecular markers of cardiac hypertrophy}

Real-Time PCR analysis demonstrated a significant increase in ANF and $\beta$-MHC mRNA levels in left ventricular tissue of $0.6 \%$ I3C treated TGR(Cypla1-mRen2) (Fig $5 \mathrm{~A}$ and $5 \mathrm{~B}$ ). Withdrawal of the $\mathrm{I} 3 \mathrm{C}$ diet was associated with a normalization of ANF and $\beta$-MHC mRNA levels. There was no difference in TSP1 and TSP2 mRNA transcript expression between the 3 groups.

\section{GSK-3ß, a negative regulator of cardiac hypertrophy}

In TGR(Cypla1-mRen2), 0.6\%-I3C induced hypertension was associated with a significant increase of the Serine ${ }^{9}\left(\mathrm{Ser}^{9}\right)$ phosphorylation of GSK-3 $\beta$, the inactive form of GSK-3 $\beta$ (Fig 6A). Following 4 weeks of withdrawal of I3C, there was a trend ( $p=$ 0.16) toward a decrease in $\operatorname{Ser}^{9}$ phosphorylation of GSK-3 $\beta$ in the regression group compared to the I3C-treated TGR(Cypla1-mRen2). Compared to control animals, the active form of GSK-3 $\beta$, the phosphorylated Tyrosine ${ }^{216}\left(\mathrm{Tyr}^{216}\right)$-GSK-3 $\beta$, was 
significantly decreased in $0.6 \%$ I3C-treated TGR(Cypla1-mRen2) (Fig 6B). After termination of the $\mathrm{I} 3 \mathrm{C}$ diet, the $\mathrm{Tyr}^{216}$-GSK-3 $\beta$ phosphorylation levels were still lower in the regression group than in the control group. In concordance with these aforementioned changes in protein density, the actual GSK-3 $\beta$ kinase activity was significantly lower in I3C-treated TGR(Cypla1-mRen2) than control rats (Fig 6C). $\beta$ Catenin, a transcription cofactor under the control of GSK-3 $\beta$, was significantly increased in the I3C treated TGR(Cyplal-mRen2) compared to controls animals (Fig 6D). The regression group showed a borderline significant decrease in $\beta$-catenin protein compared to the $0.6 \% \mathrm{I} 3 \mathrm{C}$-treated rats.

\section{Discussion}

The main finding of this study is that prolonged activation of the mREN2 gene in TGR(Cyp1a1-mRen2) resulted in concentric remodeling of the heart. Furhtermore, this study showed that this type of cardiac hypertrophy was fully reversible and associated with a reduction in the expression of the hypertrophic markers such as ANF and $\beta$ MHC, a re-activation of the anti-hypertrophic protein GSK-3 $\beta$.

Both in homozygous and inducible TGR, malignant hypertension develops as the result of overactivity of the RAS and is characterized by a rapid increase in BP and an intensive pressure diuresis associated with a profound loss of body weight ${ }^{7}$. Our data confirm these data and extend them to a longer observation period. The loss of body weight may be a consequence of the accentuated pressure diuresis accompanying the development of malignant hypertension. It is not expected that $\mathrm{I} 3 \mathrm{C}$ has a direct influence since feeding of $\mathrm{I3C}$ in similar amounts to non-inducible rats did not lead to weight $\operatorname{loss}^{26}$. Therefore the catabolic state is probably directly related to activation of the RAS system. Indeed, chronic administration of candesartan, a AT1-receptor antagonist, prevented the development of hypertension and the loss of body weight in $0.3 \%$ I3C-treated TGR(Cyp1a1-mRen 2$)^{27}$. 


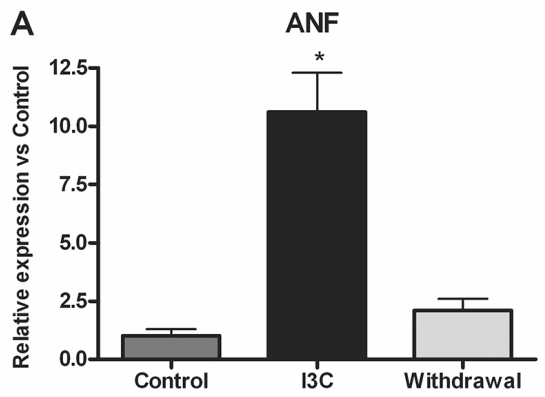

B $\quad \beta-\mathrm{MHC}$

C

TSP-1
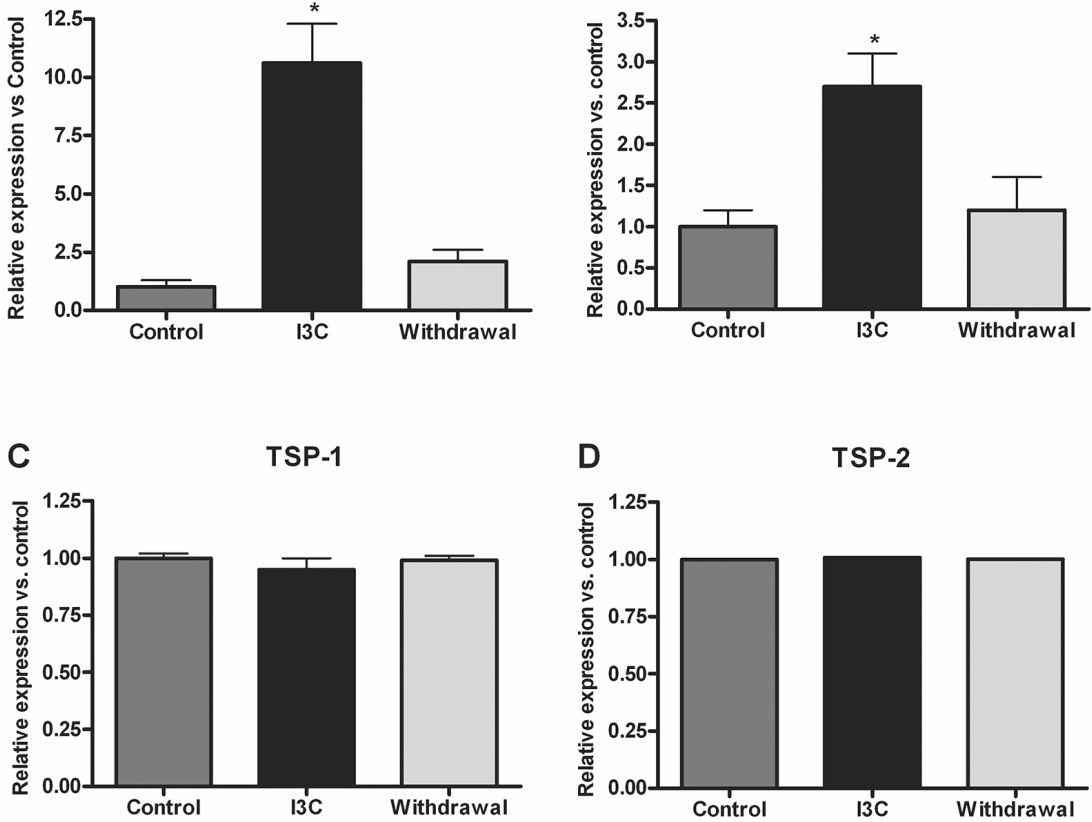

Figure 5. Characterization of different markers of cardiac hypertrophy in TGR(cyp1a1-Ren2): control (dark grey bars), I3C treated (black bars) and regression (light grey bars) group A: Expression of ANF, B: Expression of $\beta$ MHC, C: Expression of Thrombosponsin-1 (TSP-1), D: Expression of Trombo-spondin-2 (TSP-2), all normalized to the house-keeping gene Cyclophilin. Values are expressed as means \pm S.E.M. and $* \mathrm{P}<0.05$ vs. controle. All $\mathrm{n}=4$ 8.

A continuous dietary administration of $0.6 \%$ I3C for 6 weeks in TGR(Cyp1a1-mRen2) resulted in concentric hypertrophy, a diminished heart size with increased wall thickness and a decreased lumen. We did not see an increased left ventricular weight, whereas Vanourkova et al. ${ }^{28}$ showed that the hypertension in TGR(Cyp1a1-mRen2) was accompanied by a marked left ventricular hypertrophy reaching its maximum at day 8 after induction. The explanation for this difference is most likely that in the present study the period that the rats were on I3C diet was 3 weeks longer, allowing the heart and circulation to adapt to the total loss of bodyweight. In absolute terms, the heart retained its normal weight. In terms of $\mathrm{HW} / \mathrm{BW}$, there was a significant increase 
(see Table 1). Echocardiographic data showed a decreased EDV and SV in $0.6 \% \mathrm{I}$ C animals which may be an adaptive response to increased blood pressure (and also weight loss) and can lead to diastolic dysfunction ${ }^{29}$. Diastolic dysfunction refers to mechanical and functional abnormalities present during relaxation and filling, and the RAS may contribute to alterations in active relaxation and increased myocardial stiffness $^{30}$. But this is not likely in the present study since collagen levels were not altered. Angiotensin II (Ang II), the primary effector peptide of the RAS system, is present in the heart ${ }^{31}$ and promotes myocyte cell growth via the Angiotensin type I (AT1) receptor ${ }^{32}$. Cessation of the $\mathrm{I} 3 \mathrm{C}$ resulted in a return of the left ventricular Ang II levels to control values observed in non-induced rats $^{28}$. The great advantage of this inducible model is that the trigger of hypertension can be controlled whereas in other transgenic models, the TGR(mRen2)27, the trigger of hypertension is induced since fetal and neonatal programming and this may play a critical role in the pathogenesis. So, despite similar degrees of hypertension, cardiac phenotypes differ between strains (TGR(mRen2)27 vs TGR(Cyp1a1-mRen2)). And even within the strain, phenotypic differences can occur as shown by Schroen et $\mathrm{al}^{33}$, where she showed that TSP-2 was selectively overexpressed in TGR(mRen2)27 prone to progress to heart failure. In the present study, we did not see a difference in TSP-1 and -2 mRNA expression whereas the hypertrophic markers, ANF and $\beta$-MHC mRNA transcripts, were upregulated during malignant hypertension and returned to baseline levels in the regression phase, reflecting the hypertrophic response of the heart to the induction of the malignant hypertension. We used 30-week-old TGR(Cypla1-mRen2) rats because we presumed that old animals treated with $\mathrm{I} 3 \mathrm{C}$ were more prone to develop heart failure than young rats. However, l'Huiller showed that young 6-10 week old TGR(Cyp1a1-mRen2) rats treated with $0.3 \% \mathrm{I} 3 \mathrm{C}$ exhibited the same cardiac phenotype (personal communication). Surprisingly, no difference in cardiac fibrosis was observed. One could argue that this could be related to the age of the rats since treatment was started when rats were 30 weeks old. However, the same observation was made by l'Huiller (Thesis, personal communication) in young (6 weeks) rats treated with $0.3 \% \mathrm{I} 3 \mathrm{C}$, suggesting that age- 
related differences in the capacity of collagen syntheses can be ruled out. In our study, all groups showed a $10 \%$ of interstitial fibrosis in the heart. Changes in properties of the myocyte (structures of the sarcormere or the cytoskelet) can contribute but it is also possible that there was a greater degradation (possibly also related to the catabolic state).

The mechanisms leading to cardiac hypertrophy have been intensively investigated. In these studies GSK-3 $\beta$ emerged as a negative regulator of cardiac hypertrophy ${ }^{12-15,34}$. In I3C-induced hypertensive TGR(Cyp1A1-mRen2), phosphorylation of the $\mathrm{Ser}^{9}$ residu was significantly upregulated whereas in the regression group, there was a trend towards a significant decrease. This observation suggests the involvement of AngII binding to the AT1receptor in the regulation of GSK-3 $\beta$ activity. This leads to the activation of phosphoinositide 3-kinase and its target Akt, which than inactivates GSK$3 \beta^{35}$. In mice, treatment with losartan, an ATlreceptor antagonist, leads to an attenuation of the inactivation of GSK-3 $3 \beta^{36}$. In contrast to the inhibitory modulation, $\mathrm{Tyr}^{216}$ phosphorylation of GSK-3 $\beta$ increased the enzyme activity. In this study, we observed the dephosphorylation of the $\mathrm{Tyr}^{216}$ residues whereas regression of cardiac remodeling led to a trend of phosphorylation of the $\mathrm{Tyr}^{216}$ residues of GSK-33. Increasing the GSK-3 $\beta$ activity is sufficient to suppress cardiac hypertrophy in vivo ${ }^{12}$. Transgenic mice expressing a cardiac-specific signal-resistant form of GSK-3 $\beta$ (containing a serine-9 to alanine mutation) showed a diminished hypertrophic growth response $^{12}$ after chronic $\beta$-adrenergic stimulation and pressure overload. In the hypertrophic response, stabillization of $\beta$-catenin is sufficient to induce hypertrophic growth $^{23}$, and inactivation of GSK-3 $\beta$ leads to stalibilization of $\beta$-catenin. Supporting the role for $\beta$-catenin in regulating cardiomyocyte growth, a conditional, cardiacspecific deletion of $\beta$-catenin in the adult mouse significantly reduced the hypertrophic response to pressure overload ${ }^{37}$. 
A

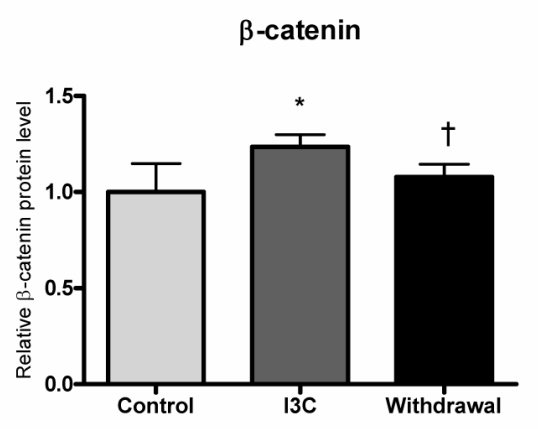

C

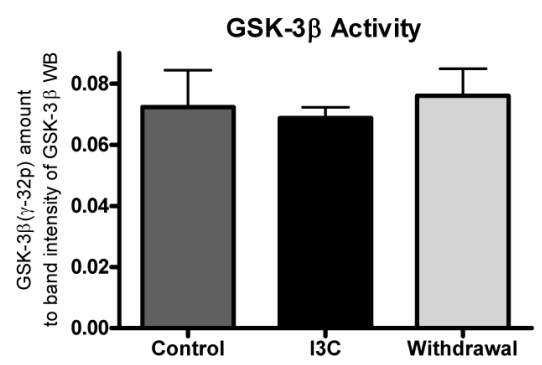

B

$$
\begin{aligned}
& p^{\text {Ser } 9} \text { G S K }-3 \beta \\
& \text { GSK }-3 \beta
\end{aligned}
$$

pSer ${ }^{9}-$ GSK-3 $\beta$

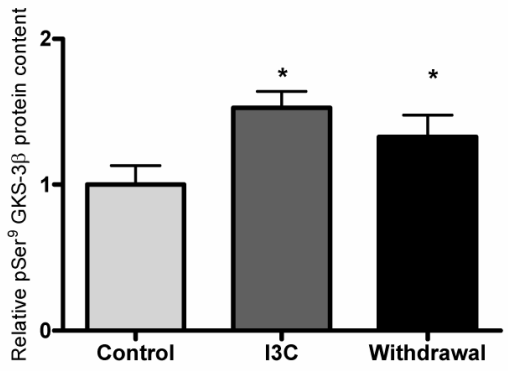

D

$\mathrm{p}^{\mathrm{Ty}} 216 \mathrm{GSK}-3 \beta$

GSK-3 $\beta$

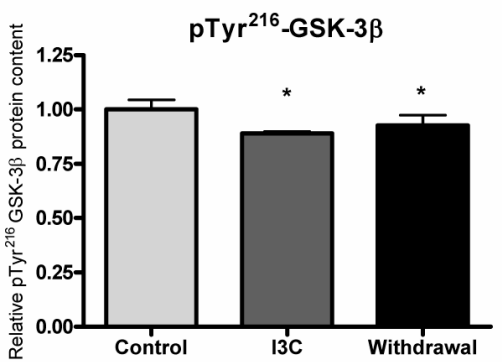

Figure 6. Panel A shows the $\beta$-catenin protein content in TGR(cypla1-Ren2): control (dark grey bars), I3C treated (black bars) and regression (light grey bars) group. Quantification of the Western blot signals, expressed as $\beta$ catenin/ $\alpha$-tubulin ratios. Panel B, C and D: GSK-3 $\beta$ forms determined by Western Blotting and GSK-3 $\beta$ kinase

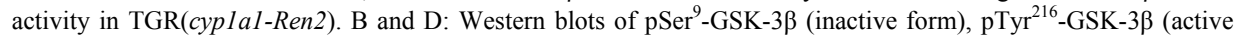
form) and total GSK-3 $\beta$ protein expression. Densitometric analysis of the $\mathrm{pSer}^{9}-\mathrm{GSK}-3 \beta$ (B) and $\mathrm{pTyr}^{216}-\mathrm{GSK}-3 \beta$

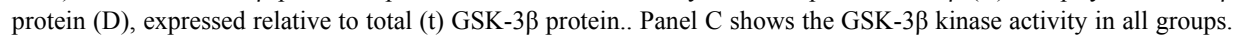
Values are expressed as means \pm S.E.M. and $* \mathrm{P}<0.05$ vs. Controle. All $\mathrm{n}=4-6$

In the present study, we observed a significant upregulation of $\beta$-catenin protein in the I3C-treated group whereas regression has a trend toward a decrease in $\beta$-catenin protein level. Thus, induction of malignant hypertension leads to inhibition of GSK-3 $\beta$ activity and stabilization of $\beta$-catenin protein whereas restoration of the blood pressure leads to enhanced activation of GSK-3 $\beta$ and reduced $\beta$-catenin protein. 
The inducible hypertensive transgenetic rat allows to study the regression of cardiac remodeling after induction of malignant hypertension. This study shows that withdrawal of the $\mathrm{I} \mathrm{C}$ dietary administration markedly restored cardiac functions and molecular markers of cardiac hypertrophy following transient induction of AngIIdependent hypertension, and therefore, indicates the importance of treatment of hypertension. It also allows especially the stepwise assessment of the role of BP and Ang II in the development and/or the regression of hypertension-induced end-organ damage.

In conclusion, our data demonstrate that the concentric remodeling in TGR(Cyp1A1mRen2) is able to regress to near control values. At the molecular level, regression leads to increased GSK3 $\beta$ activity, resulting in a lower $\beta$-catenin content, confirming the potential role as mediators in the process. 


\section{Reference}

1. lemitsu M, Maeda S, Miyauchi T, et al. Gene expression profiling of exercise-induced cardiac hypertrophy in rats. Acta Physiol Scand.2005;185(4):259-270.

2. Liew CC, Dzau VJ. Molecular genetics and genomics of heart failure. Nat Rev Genet.2004;5(11):811-825.

3. Kass DA, Bronzwaer JG, Paulus WJ. What mechanisms underlie diastolic dysfunction in heart failure? Circ Res.2004;94(12):1533-1542.

4. Hunter JJ, Chien KR. Signaling pathways for cardiac hypertrophy and failure. $N$ Engl $J$ Med.1999;341(17):1276-1283.

5. Patterson ME, Mouton $\mathrm{CR}$, Mullins $\mathrm{JJ}$, et al. Interactive effects of superoxide anion and nitric oxide on blood pressure and renal hemodynamics in transgenic rats with inducible malignant hypertension. Am J Physiol Renal Physiol.2005;289(4):F754-759.

6. Mullins JJ, Peters J, Ganten D. Fulminant hypertension in transgenic rats harbouring the mouse Ren-2 gene. Nature.1990;344(6266):541-544.

7. Kantachuvesiri S, Fleming S, Peters $\mathrm{J}$, et al. Controlled hypertension, a transgenic toggle switch reveals differential mechanisms underlying vascular disease. $J$ Biol Chem.2001;276(39):36727-36733.

8. Patterson ME, Mullins JJ, Mitchell KD. Renoprotective effects of neuronal NOS-derived nitric oxide and cyclooxygenase-2 metabolites in transgenic rats with inducible malignant hypertension. Am J Physiol Renal Physiol.2008;294(1):F205-211.

9. Mitchell KD, Mullins JJ. Enhanced tubuloglomerular feedback in Cyp1a1-Ren2 transgenic rats with inducible ANG II-dependent malignant hypertension. Am $J$ Physiol Renal Physiol.2005;289(6):F1210-1216.

10. Howard LL, Patterson ME, Mullins JJ, et al. Salt-sensitive hypertension develops after transient induction of ANG II-dependent hypertension in Cyp1a1-Ren2 transgenic rats. Am J Physiol Renal Physiol.2005;288(4):F810-815.

11. Dorn GW, 2nd, Force T. Protein kinase cascades in the regulation of cardiac hypertrophy. $J$ Clin Invest.2005;115(3):527-537.

12. Antos $\mathrm{CL}$, McKinsey TA, Frey N, et al. Activated glycogen synthase- 3 beta suppresses cardiac hypertrophy in vivo. Proc Natl Acad Sci U S A.2002;99(2):907-912.

13. Badorff $\mathrm{C}$, Ruetten $\mathrm{H}$, Mueller $\mathrm{S}$, et al. Fas receptor signaling inhibits glycogen synthase kinase 3 beta and induces cardiac hypertrophy following pressure overload. $J$ Clin Invest.2002;109(3):373-381.

14. Badorff C, Seeger FH, Zeiher AM, et al. Glycogen synthase kinase 3beta inhibits myocardindependent transcription and hypertrophy induction through site-specific phosphorylation. Circ Res.2005;97(7):645-654.

15. Haq S, Choukroun G, Kang ZB, et al. Glycogen synthase kinase-3beta is a negative regulator of cardiomyocyte hypertrophy. J Cell Biol.2000;151(1):117-130.

16. Morisco $C$, Zebrowski D, Condorelli G, et al. The Akt-glycogen synthase kinase 3beta pathway regulates transcription of atrial natriuretic factor induced by beta-adrenergic receptor stimulation in cardiac myocytes. J Biol Chem.2000;275(19):14466-14475.

17. Hardt SE, Sadoshima J. Negative regulators of cardiac hypertrophy. Cardiovasc Res.2004;63(3):500-509.

18. Kerkela R, Woulfe K, Force T. Glycogen synthase kinase-3beta-actively inhibiting hypertrophy. Trends Cardiovasc Med.2007;17(3):91-96.

19. Huelsken J, Behrens J. The Wnt signalling pathway. J Cell Sci.2002;115(Pt 21):3977-3978.

20. He TC, Sparks AB, Rago $C$, et al. Identification of $\mathrm{c}-\mathrm{MYC}$ as a target of the APC pathway. Science.1998;281(5382):1509-1512.

21. Tetsu O, McCormick F. Beta-catenin regulates expression of cyclin D1 in colon carcinoma cells. Nature.1999;398(6726):422-426. 
22. Anna $\mathrm{CH}$, lida $\mathrm{M}$, Sills RC, et al. Expression of potential beta-catenin targets, cyclin D1, c-Jun, c-Myc, E-cadherin, and EGFR in chemically induced hepatocellular neoplasms from B6C3F1 mice. Toxicol Appl Pharmacol.2003;190(2):135-145.

23. Haq $S$, Michael $\mathrm{A}$, Andreucci $\mathrm{M}$, et al. Stabilization of beta-catenin by a Wnt-independent mechanism regulates cardiomyocyte growth. Proc Natl Acad Sci U S A.2003;100(8):46104615.

24. Przyklenk K, Maynard M, Darling CE, et al. Aging mouse hearts are refractory to infarct size reduction with post-conditioning. J Am Coll Cardiol.2008;51(14):1393-1398.

25. van de Schans VA, van den Borne SW, Strzelecka AE, et al. Interruption of Wnt signaling attenuates the onset of pressure overload-induced cardiac hypertrophy. Hypertension.2007;49(3):473-480.

26. Peters B, Grisk O, Becher B, et al. Dose-dependent titration of prorenin and blood pressure in Cyp1a1ren-2 transgenic rats: absence of prorenin-induced glomerulosclerosis. $J$ Hypertens.2008;26(1):102-109.

27. Mitchell KD, Bagatell SJ, Miller CS, et al. Genetic clamping of renin gene expression induces hypertension and elevation of intrarenal Ang II levels of graded severity in Cyp1a1-Ren2 transgenic rats. J Renin Angiotensin Aldosterone Syst.2006;7(2):74-86.

28. Vanourkova Z, Kramer HJ, Huskova Z, et al. AT1 receptor blockade is superior to conventional triple therapy in protecting against end-organ damage in Cyp1a1-Ren-2 transgenic rats with inducible hypertension. J Hypertens.2006;24(12):2465-2472.

29. Katz AM, Zile MR. New molecular mechanism in diastolic heart failure. Circulation.2006;113(16):1922-1925.

30. Rysa J, Leskinen $H$, llves $M$, et al. Distinct upregulation of extracellular matrix genes in transition from hypertrophy to hypertensive heart failure. Hypertension.2005;45(5):927-933.

31. Wollert $\mathrm{KC}$, Drexler $\mathrm{H}$. The renin-angiotensin system and experimental heart failure. Cardiovasc Res.1999;43(4):838-849.

32. Kahan T, Bergfeldt L. Left ventricular hypertrophy in hypertension: its arrhythmogenic potential. Heart.2005;91(2):250-256.

33. Schroen B, Heymans $S$, Sharma $U$, et al. Thrombospondin- 2 is essential for myocardial matrix integrity: increased expression identifies failure-prone cardiac hypertrophy. Circ Res.2004;95(5):515-522.

34. Morisco C, Seta K, Hardt SE, et al. Glycogen synthase kinase 3beta regulates GATA4 in cardiac myocytes. J Biol Chem.2001;276(30):28586-28597.

35. Force $\mathrm{T}$, Michael $\mathrm{A}$, Kilter $\mathrm{H}$, et al. Stretch-activated pathways and left ventricular remodeling. $J$ Card Fail.2002;8(6 Suppl):S351-358.

36. Gurusamy N, Watanabe K, Ma M, et al. Glycogen synthase kinase 3beta together with 14-3-3 protein regulates diabetic cardiomyopathy: effect of losartan and tempol. FEBS Lett.2006;580(8):1932-1940.

37. Chen X, Shevtsov SP, Hsich E, et al. The beta-catenin/T-cell factor/lymphocyte enhancer factor signaling pathway is required for normal and stress-induced cardiac hypertrophy. Mol Cell Biol.2006;26(12):4462-4473. 
CHAPTER

134 


\section{Chapter 7}

\section{Summary and Conclusions:}

Wnt signaling and cardiac hypertrophy 
Cardiac hypertrophy has recently been recognized as the net result of the activity of proand anti-hypertrophic signaling. Because current pharmacotherapy of hypertrophy primarily focuses on the pro-hypertrophic signaling, it is worthwhile to explore antihypertrophic mechanisms for novel therapeutic targets of cardiac hypertrophy. The aim of the studies described in this thesis was to explore the role of the Wnt signaling pathway in the development of cardiac hypertrophy. To this end, we focused on the levels of the second messenger $\beta$-catenin, a pro-hypertrophic protein, and the activity of the kinase GSK-3 $\beta$, an anti-hypertrophic protein, in the development of cardiac hypertrophy.

During the hypertrophic response, there is a re-expression of a fetal gene expression pattern in the cardiomyocytes ${ }^{1}$. An example of such pathway involved in fetal development is the Wnt signaling pathway ${ }^{2,3}$. Until now, suggestive data for a reexpression of the canonical Wnt signaling in cardiac hypertrophic remodeling was described $^{4,5}$. In Chapter 2 of this thesis, the time course of the expression of components of the Wnt pathway in Wistar rats subjected to aortic banding is described. In the canonical Wnt pathway, only Wnt-3a, but not Wnt-5a, has been shown to be capable of an efficient stabilization of $\beta$-catenin protein level ${ }^{6,7}$, which acts as a signal transduction molecule in this pathway. Most Fz receptors have been reported to signal through the canonical Wnt pathway, whereas some Fz receptors signal independent of the canonical Wnt pathway however, all pathways are thought to use Dvl as a transduction component ${ }^{8}$, 9. A re-expression of components of the canonical Wnt pathway was observed, with a gradual increase in mRNA levels of Fz-2 and Dvl-1 at 10 days after aortic banding. On the other hand, the expression of Wnt-5a was markedly and persistently downregulated at all time points tested. The relative amount of the active form of GSK-3 $\beta$ gradually decreased over time, whereas the amount of the inactive form showed a less consistent pattern. Protein levels of $\beta$-catenin were up-regulated as early as 1 day after aortic banding. These findings are indicative for an upregulation of the 
canonical, $\beta$-catenin-mediated Wnt signaling during the development of pressure overload-induced cardiac hypertrophy in the rat.

Because no pharmacological tools are available to specifically inhibit Wnt signaling at the level of the Wnt/frizzled interaction, we used a genetically modified mouse, a 'conventional knockout mouse', with germline loss of the Dishevelled-1 gene to explore the functional role of Wnt signaling in the hypertrophic response (Chapter 3). To this end, mice lacking the Dishevelled-1 gene were subjected to aortic banding, and the development of cardiac hypertrophy was compared to wildtype littermates. The lack of the Dishevelled-1 gene attenuated the hypertrophic response up to 14 days after aortic banding, as determined by increases in heart weight and expression of ANF and BNP. Interestingly, the activity of GSK-3 $\beta$ was found to be elevated in the hypertrophic $D v l-1^{-}$ ${ }^{-}$mice compared to sham, whereas in wildtypes GSK-3 $\beta$ showed a tendency towards a decrease. This difference in GSK-3 $\beta$ activity was also reflected in considerably lower $\beta$ catenin levels in the $D v l-1^{-/}$mice. This study showed that interruption of Wnt signaling leads to an attenuated hypertrophic response upon pressure overload. This attenuated hypertrophic response may be explained by an elevated activity of the anti-hypertrophic kinase GSK-3 $\beta$ and/or a reduction in the pro-hypertrophic protein $\beta$-catenin. This indicates that the stabilization of $\beta$-catenin occurs not only by a Wnt-independent mechanism ${ }^{10}$ but also by canonical Wnt signaling. In both chapters ( 2 and $\mathbf{3}$ ), we also determined the mRNA levels of $\beta$-catenin together with the protein levels of $\beta$-catenin. The results, however, did not show any correlation between mRNA levels and protein content of $\beta$-catenin, which can be explained by the fact that the cell controls its $\beta$ catenin content by regulating its degradation rather than its production ${ }^{11}$. So, determination of the $\beta$-catenin protein content is the method to examine the role of $\beta$ catenin in the hypertrophic response.

The effect of inactivation of GSK-3 $\beta$ on the development of cardiac hypertrophy, induced by pressure overload, was the subject of the study described in Chapter 4. In this study, we used $\mathrm{LiCl}$, a well-known GSK-3 $\beta$ inhibitor, at two different doses. 
Animals were pre-treated for 4 weeks which did not induce any noticeable effects; then cardiac hypertrophy was induced by aortic banding. The low $\mathrm{LiCl}$ dose $(600 \mathrm{mg} / \mathrm{l})$ induced elevated ANF levels compared to the untreated group, but no significant difference in heart weight or cardiomyocyte cross sectional area were observed. This suggests that the hypertrophic response upon aortic banding is already maximal and can not further be aggravated by $\mathrm{LiCl}$ treatment. But aortic banding turned out to be fatal in animals that received the high $\mathrm{LiCl}$ dose $(800 \mathrm{mg} / \mathrm{l}$ in drinking water). Death occurred within 12 hours after aortic banding in most animals and these animals showed pulmonary edema, a sign of acute heart failure. The mechanism behind this observation requires futher investigation.

The aim of the study described in Chapter 5 was to investigate the effect of treatment of cardiac hypertrophy with Angiotensin receptor type I blockers on the expression of components of the Wnt signaling pathway. Losartan and olmesartan, although administered in equipotent doses, induced different degrees of regression of cardiac hypertrophy regression in spontaneously hypertensive heart failure-prone (SHHF) rats. However, the effect on the re-expression of the components of the Wnt pathway was similar for the two AT1 receptor blockers. This suggests that AT1 receptor blockers do not affect the expression of Wnt components indirectly by reducing cardiac hypertrophy, but that there is a more direct link between AT1 receptor blockers and Wnt component expression. The mechanism behind this direct modulation remains to be elucidated.

In Chapter 6 of this thesis we studied the effect of induction and regression of cardiac hypertrophy in TGR(cypla1-mRen2) rats. In these rats, severe hypertension can be induced by adding indole-3-carbinole to the food, whereas blood pressure normalizes upon withdrawal of this compound. This hypertension caused concentric cardiac hypertrophy without fibrosis, which returned to values observed in non-treated animals at 5 weeks after discontinuation of the treatment. GSK-3 $\beta$ activity was lower and $\beta$ catenin levels were elevated in the hypertrophic phase, but were normalized after 
withdrawal of indole-3-carbinole. The data show that regression of cardiac hypertrophy is accompanied by a return of the activated Wnt signaling towards baseline values.

In conclusion, Wnt signaling is consistently activated during the development of cardiac hypertrophy in our studies. This was characterized by an increase in the expression of

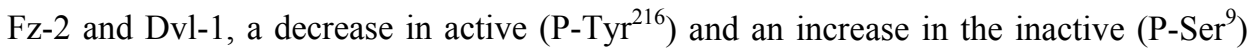
form of GSK-3 $\beta$ and increased levels of $\beta$-catenin protein. Interruption of Wnt signaling attenuates the hypertrophic response upon pressure overload, indicating a functional role for this pathway in cardiac remodeling. On the other hand, additional inhibition of GSK$3 \beta$ did not further aggravate the hypertrophic response but could induce lethal heart failure.

All these experimental results point to GSK-3 $\beta$ as a central regulator of the hypertrophic response. From a therapeutic point of view it seems beneficial to increase the GSK-3 $\beta$ activity $^{12,13}$ in the hypertrophic heart, thereby activating an anti-hypertrophic pathway, but recent data indicate that systemic activation of GSK-3 $\beta$ leads to heart failure ${ }^{14-16}$. From this perspective, the best way to intervene in Wnt signaling is at the level upstream of GSK-3 $\beta$, e.g. by applying antagonists for the binding of Wnt to Frizzled receptors, which therefore could serve as a novel therapeutic approach for cardiac hypertrophy. Also inhibiting the interaction of Dvl with $\mathrm{Fz}$ receptors could be a promising intervention to treat cardiac hypertrophy. The next challenge in this field will be to develop these specific Wnt antagonists and test their effect on cardiac remodeling. 


\section{REFERENCES}

1. McMullen JR, Jennings GL. Differences between pathological and physiological cardiac hypertrophy: novel therapeutic strategies to treat heart failure. Clin Exp Pharmacol Physiol.2007;34(4):255-262.

2. Eisenberg LM, Eisenberg CA. Wnt signal transduction and the formation of the myocardium. Dev Biol.2006;293(2):305-315.

3. Brade $\mathrm{T}$, Manner $\mathrm{J}$, Kuhl M. The role of Wnt signalling in cardiac development and tissue remodelling in the mature heart. Cardiovasc Res.2006;72(2):198-209.

4. Blankesteijn WM, Essers-Janssen YP, Ulrich MM, et al. Increased expression of a homologue of drosophila tissue polarity gene "frizzled" in left ventricular hypertrophy in the rat, as identified by subtractive hybridization. J Mol Cell Cardiol.1996;28(5):1187-1191.

5. Cerutti C, Kurdi M, Bricca G, et al. Transcriptional alterations in the left ventricle of three hypertensive rat models. Physiol Genomics.2006;27(3):295-308.

6. Takada R, Hijikata H, Kondoh $\mathrm{H}$, et al. Analysis of combinatorial effects of Wnts and Frizzleds on beta-catenin/armadillo stabilization and Dishevelled phosphorylation. Genes Cells.2005;10(9):919-928.

7. Topol L, Jiang $X$, Choi H, et al. Wnt-5a inhibits the canonical Wnt pathway by promoting GSK-3independent beta-catenin degradation. J Cell Biol.2003;162(5):899-908.

8. Boutros $\mathrm{M}$, Mihaly $\mathrm{J}$, Bouwmeester $\mathrm{T}$, et al. Signaling specificity by Frizzled receptors in Drosophila. Science.2000;288(5472):1825-1828.

9. Wharton KA, Jr. Runnin' with the Dvl: proteins that associate with Dsh/Dvl and their significance to Wnt signal transduction. Dev Biol.2003;253(1):1-17.

10. Haq $S$, Michael $A$, Andreucci $M$, et al. Stabilization of beta-catenin by a Wnt-independent mechanism regulates cardiomyocyte growth. Proc Natl Acad Sci U S A.2003;100(8):4610-4615.

11. Kimelman $\mathrm{D}, \mathrm{Xu} \mathrm{W}$. beta-catenin destruction complex: insights and questions from a structural perspective. Oncogene.2006;25(57):7482-7491.

12. Hardt SE, Sadoshima J. Negative regulators of cardiac hypertrophy. Cardiovasc Res.2004;63(3):500-509.

13. Kerkela R, Woulfe K, Force $T$. Glycogen synthase kinase-3beta-actively inhibiting hypertrophy. Trends Cardiovasc Med.2007;17(3):91-96.

14. Michael $A$, Haq $S$, Chen $X$, et al. Glycogen synthase kinase-3beta regulates growth, calcium homeostasis, and diastolic function in the heart. J Biol Chem.2004;279(20):21383-21393.

15. Hirotani $\mathrm{S}$, Zhai $\mathrm{P}$, Tomita $\mathrm{H}$, et al. Inhibition of glycogen synthase kinase 3beta during heart failure is protective. Circ Res.2007;101(11):1164-1174.

16. Badorff $\mathrm{C}$, Ruetten $\mathrm{H}$, Mueller $\mathrm{S}$, et al. Fas receptor signaling inhibits glycogen synthase kinase 3 beta and induces cardiac hypertrophy following pressure overload. J Clin Invest.2002;109(3):373-381. 